\title{
The Relationship Between Environmental Justice and Voluntary Environmental Programs: Towards a Conceptualization of Ecological Democracy
}

\author{
by \\ Kris Hornburg B.A. (Hon).
}

A thesis submitted to the Faculty of Graduate and Postdoctoral Affairs in partial fulfillment of the requirements for the degree of

Master of Arts

in

Legal Studies

Carleton University

Ottawa, Ontario

(c) 2012

Kris Hornburg 
Library and Archives

Canada

Published Heritage

Branch

395 Wellington Street

Ottawa ON K1A ON4

Canada
Bibliothèque et

Archives Canada

Direction du

Patrimoine de l'édition

395 , rue Wellington

Ottawa ON K1A ON4

Canada
Your file Votre référence

ISBN: 978-0-494-93563-7

Our file Notre référence

ISBN: 978-0-494-93563-7
NOTICE:

The author has granted a nonexclusive license allowing Library and Archives Canada to reproduce, publish, archive, preserve, conserve, communicate to the public by telecommunication or on the Internet, loan, distrbute and sell theses worldwide, for commercial or noncommercial purposes, in microform, paper, electronic and/or any other formats.

The author retains copyright ownership and moral rights in this thesis. Neither the thesis nor substantial extracts from it may be printed or otherwise reproduced without the author's permission.
AVIS:

L'auteur a accordé une licence non exclusive permettant à la Bibliothèque et Archives Canada de reproduire, publier, archiver, sauvegarder, conserver, transmettre au public par télécommunication ou par l'Internet, prêter, distribuer et vendre des thèses partout dans le monde, à des fins commerciales ou autres, sur support microforme, papier, électronique et/ou autres formats.

L'auteur conserve la propriété du droit d'auteur et des droits moraux qui protege cette thèse. $\mathrm{Ni}$ la thèse ni des extraits substantiels de celle-ci ne doivent être imprimés ou autrement reproduits sans son autorisation.
In compliance with the Canadian Privacy Act some supporting forms may have been removed from this thesis.

While these forms may be included in the document page count, their removal does not represent any loss of content from the thesis.
Conformément à la loi canadienne sur la protection de la vie privée, quelques formulaires secondaires ont été enlevés de cette thèse.

Bien que ces formulaires aient inclus dans la pagination, il n'y aura aucun contenu manquant. 


\section{Abstract}

Both voluntary environmental programs (VEP'S) and environmental justice are key elements that contribute towards the establishment of environmental protection. Unfortunately, examinations of both topics have been largely absent considerations of the other. The purpose of this thesis is to develop a synthetic approach between voluntary environmental programs and environmental justice. In order to accomplish this I examine research on either topic and explain how key principles in each can be better recognized together. I will argue that VEP's can potentially increase environmental protection, and that introducing environmental justice principles, particularly citizen participation, adds to this potential. Additionally, my analysis includes a discussion on how law can be utilized to fill collaborative gaps between environmental justice and VEP's, which further facilitates the establishment of ecological democracy. 


\section{Acknowledgements}

This project would not have been possible without the support of a number of people. In particular I would like to sincerely thank my supervisor Peter Swan, for all his hard work and dedication. Without his guidance, and unwavering patience, my thesis would still only exist as an idea. Additionally, I would like to express my appreciation to Neil Sargent for all his time and effort, and for trying his best to make sense of my work. I would also like to thank the Carleton University Legal Studies Department for providing me the opportunity to complete this project. A special thanks to my girlfriend Stephanie Feldman, who endured this long process and always offered her love and encouragement. Lastly, I would like to sincerely thank my parents, for their continuous love and support throughout my academic career, because without them none of this would have ever been possible. 


\section{Table of Contents}

Title Page

Abstract ii

$\begin{array}{lll}\text { Acknowledgements } & \text { iii }\end{array}$

Chapter 1: Introduction 1

Chapter 2: Examining Voluntary Environmental Programs 9

2.1 The History of Voluntary Environmental Programs $\quad 12$

2.2 Defining Voluntary Environmental Regulation 15

$\begin{array}{ll}2.3 \text { Public Voluntary Programs } & 17\end{array}$

2.4 Negotiated or Bilateral Agreements $\quad 19$

2.5 Unilateral or Industry Sponsored Agreements 21

2.6 Third Party Voluntary Agreements 23

2.7 Citizen Participation and the Contractarian Approach 24

2.8 The 'Formula' for Measuring Success 26

2.9 Industry Participation $\quad 28$

2.10 Environmental Performance and other Program Goals 30

2.11 The Importance of Spillover Effects or Positive Externalities 32

2.12 Tackling the Free-rider Problem 34

2.13 Conclusions 36

Chapter 3: Towards a Theoretical Conceptualization of

Environmental Justice $\quad 39$

3.1 The History of Environmental Justice 40

3.2 Examining the Environmental Justice Frame 45

3.3 Environmental Justice Paradigms $\quad 49$

3.3.1 Distribution 50

3.3.2 Recognition $\quad 52$

3.3.3 Procedure 54

3.4 A More Comprehensive Notion of Justice 57

Chapter 4: The Importance of Citizen Participation $\quad 60$

4.1 Citizen Participation vs. Expert Knowledge 62 
$\begin{array}{ll}\text { 4.2 The Citizen as Local Expert } & 67\end{array}$

4.3 Defining Local Experts and Local Knowledge 69

4.4 The Benefits of Local Expert Knowledge $\quad 70$

4.5 Increased Citizen Participation and Ecological $\begin{array}{ll}\text { Democracy } & 73\end{array}$

4.6 Reconceptualising Nimbyism $\quad 76$

4.7 Forums for Citizen Participation $\quad 80$

$\begin{array}{lr}4.8 \text { Conclusions } & 85\end{array}$

Chapter 5: Developing the Relationship between Voluntary

Environmental Programs and Environmental

$\begin{array}{ll}\text { Justice } & 88\end{array}$

5.1 Critiquing Voluntary Environmental Programs 90

$\begin{array}{ll}5.2 \text { The Deliberative Turn } & 95\end{array}$

5.3 Establishing Environmental Justice in

Voluntary Programs $\quad 98$

5.4 Environmental Policy 'Mixing' in Portugal 103

5.5 Local Expert Knowledge, Citizen Participation $\begin{array}{ll}\text { and Project XL } & 107\end{array}$

5.6 The Importance of Combing VEP's with Formal Laws $\quad 111$

$\begin{array}{ll}5.7 \text { Conclusions } & 116\end{array}$

$\begin{array}{lr}\text { Chapter 6: Conclusions } & 119\end{array}$

$\begin{array}{lr}\text { References } & 124\end{array}$ 


\section{Chapter 1:}

\section{Introduction}

Environmental regulation has experienced an enormous expansion in the last four decades and has become increasingly complex and cumbersome, particularly from a bureaucratic standpoint. It is this complexity, which is currently at the heart of a debate between policy-makers, academics, and citizens alike, who are all arguing for the establishment and inception of alternative modes of regulation. Traditionally, environmental regulations have come in the form of command-and-control systems. In other words, a type of standard is established, which serves as the command, and if said standard is not met, the resulting penalty functions as the control. While, there is no question that these types of regulations have achieved considerable successes, insofar as environmental protection is considered, there is certainly room for improvement. Critics of command-and-control systems argue that they are expensive, inflexible, inhibit innovation, and consistently provide diminishing returns. ${ }^{1}$ Consequently, there has been a push towards establishing and implementing new forms of environmental regulation, which include market-based or economic mechanisms, and voluntary environmental programs, or VEP's.

In this thesis I focus on examining the latter. I analyze voluntary environmental programs within a framework of environmental justice. Environmental justice has often been narrowly defined "on issues relating to discrimination based on race or class in decisions to locate polluting activities or hazardous waste facilities."2 However, as Peter Swan explains, environmental justice issues are not limited to considerations of race or the distribution of

\footnotetext{
' Jonathan C. Borck, \& Cary Coglianese, "Voluntary Environmental Programs: Assessing their Effectiveness," (The Annual Review of Environment and Resources, Vol. 34: 2009) at 306.

${ }^{2}$ Peter Swan, "Democratic Environmental Governance and Environmental Justice" in "Law, Regulation, and Governance." (Oxford University Press, Toronto: 2002) at 134.
} 
environmental risks and hazards. ${ }^{3}$ Thus, it is important to take a broader conception of environmental justice, one that focuses on issues relating to recognition and procedure. Accordingly, this expanded approach seeks to promote "the ability to provide and support the institutional conditions necessary to realize a reflexive self-determination of acceptable levels or risks by individuals and groups in relevant communities. ${ }^{\not 4}$

I utilize this broad definition of environmental justice and describe its possible relationship with voluntary environmental programs. More specifically, I use environmental justice as a means to introduce the concept of real and authentic citizen participation. I believe that citizen participation should be used as a key element in both the establishment and monitoring of voluntary initiatives. In a more macro conceptualization, I am interested in how environmental justice can help establish the use of citizen participation within voluntary programs, thus fostering a greater sense of ecological democracy.

While there certainly exists a large amount of research on both topics, none attempt to critically interpret the relationship between voluntary environmental programs and environmental justice. However, there are a number of articles, which at least at a basic level, try to develop some groundwork for a more inclusive analysis. For example Carmin et al. examine the importance of various stakeholder involvement in the design of U.S. voluntary environmental programs. ${ }^{5}$ However, this article lacks a comprehensive analysis of environmental justice concerns and tends to focus more on the actual design of the programs themselves. While this is certainly an important endeavor, in my opinion it is incomplete when

\footnotetext{
${ }^{3}$ Ibid.

${ }^{4}$ Ibid.

5 JoAnn Carmin, Nicole Darnall, Joao Mil-Homens, "Stakeholder Involvement in the Design of U.S. Voluntary Environmental Programs: Does Sponsorship Matter?' (The Policy Studies Journal, Vol. 31, No. 4: 2003).
} 
attempting to analyze program effectiveness, as it tends to ignore fundamental environmental justice conceptions.

Similarly O'Rourke and Macey have outlined a detailed process whereby citizens are included in the policing or compliance aspect of environmental regulation. ${ }^{6}$ In this article, environmental justice concerns, particularly citizen participation, plays a key role in their arguments, however voluntary environmental programs are not explicitly referred too.

Lastly, Santos et al. and Barbara Scott et al. provide two case studies that evaluate voluntary environmental programs using certain elements of environmental justice. However, both articles fail to adequately establish the relationship between both topics, particularly insofar as the conceptualization of environmental justice is concerned.

This disconnect seems to permeate much of the literature on either topic. The reasons for this demarcation may be attributed to voluntary environmental regulations being a relatively new type of control mechanism, particularly within North America. Additionally, environmental justice itself really only shot into the political and social spotlight in 1987, and perhaps even later in Europe. Thus, there has been a type of geographic divide, where voluntary initiatives and environmental justice have not had the fortune of co-existing with each other insofar as environmental decision-making, or policy development is concerned. Consequently, the goal of my thesis will be to establish a type of relationship between environmental justice and voluntary environmental programs. When attempting to create, or analyze the relationship between these two concepts, there are five important details I would like to highlight at the outset.

First, even though it may seem as though a type of hierarchy exists between environmental justice and VEP's, they should be conceptualized as equals, or as existing within

\footnotetext{
${ }^{6}$ Dara O'Rourke, \& Gregg P. Macey, “Community Environmental Policing: Assessing New Strategies of Public Participation in Environmental Regulation.” (Joumal of Policy Analysis and Management, Vol. 22, No. 3: 2003).
} 
the same parallel. In other words, no concept should be viewed individually as being more important than the other, as their relationship is mutually beneficial, as will be explained throughout my thesis.

Second, it becomes more obvious in the later chapters, that the relationship between environmental justice and VEP's is better explained, or realized, within a framework of law. By this I mean that the relationship itself can be defined more clearly within legal systems. This point will become more obvious in chapter five, as I utilize Kernaghan Webb's arguments relating to the relationship between public and private regulations. Furthermore, this point is also important in understanding how voluntary initiatives and environmental justice can benefit each other, as law provides the link or opportunity for mutual gain.

Third, environmental justice is at its core, a realization of the power imbalances that exist within environmental decision-making. While this interpretation itself is rather basic, it nonetheless captures a key component of environmental justice and is a theme that appears consistently throughout my analysis. Moreover, it is the intricate elements of these power imbalances that I analyze throughout the chapters in order to situate my arguments within an environmental justice frame, particularly as the opportunities for citizen participation are concerned.

Fourth, when referring to the term citizen I mean to do so based on a generic interpretation that is absent legal considerations. In other words, I am not engaging in a discourse which attempts to analyze the participatory opportunities of non-citizens, such as recent immigrants or refugees. While I am not suggesting that this is not an important consideration, it falls beyond the scope of this project.

Lastly, when referring to 'stakeholders' I mean to include citizens within this 
designation. Accordingly, I mean to build on the term stakeholder as defined by the EPA, which delineates three distinct categories, namely direct participants, commentors, and the general public. ${ }^{78}$ Additionally, I also include both industry and government when referring to stakeholders.

This thesis is organized into six chapters. Following this introduction, in chapter two I explain the key elements of voluntary environmental programs. I begin with a brief examination of the history of voluntary environmental programs and explain why their expansion has been so rapid. Thereafter, I list in detail the four archetypes of voluntary programs, beginning with public voluntary programs, followed by negotiated or bi-lateral agreements, unilateral or industry sponsored agreements, and ending with third-party voluntary agreements. In addition, I examine and critique some of the current methods in which program success is measured. I believe that this is extremely important as environmental justice principles may help in removing or remedying some of the inadequacies in measuring program effectiveness or success. Lastly, I engage in a discussion of positive externalities, and free-riding behaviour, and situate these issues within an environmental justice discourse.

In chapter three, I move away from discussions of VEP's and focus specifically on what environmental justice is. Again, I begin with an introduction of the history of environmental justice, and how it evolved from a grassroots movement to a fundamental concept within environmental regulation. Additionally, I examine the environmental justice frame as a means of situating environmental justice itself within a conceptualization of social justice. Furthermore, I

\footnotetext{
${ }^{7}$ Direct participants are defined as "local residents, business people, and environmentalists that work with company sponsors to develop or strongly influence the XL pilot." Commentors are environmental advocacy groups that were interested in the XL projects, but had limited opportunities to participate. The definition of the general public is purposely vague so as to not preclude interested citizens from participating.

${ }^{8}$ Barbara Scott Murdock, \& Carol Wiessner, \& Ken Sexton, "Stakeholder Participation in Voluntary Environmental Agreements: Analysis of 10 Project XL Case Studies." (Science Technology, \& Human Values, Vol. 30, No. 2: 2005) at 226.
} 
emphasize the key components of the environmental justice frame, particularly as it helps in remedying power imbalances that exist within social structures. Consequently, describing this frame also allows me to better conceptualize the environmental justice paradigms, which should not be confused with the frame itself. I name three paradigms of environmental justice, specifically distribution, recognition, and procedure. I rely heavily on Iris Marian Young, and David Schlosberg for this particular part of my thesis, as I believe they both offer more holistic interpretations of environmental justice, especially in regards to citizen participation. ${ }^{9}$ Lastly, I finish with an explanation of why the term justice itself is inherently pluralistic, and why this is an important realization for environmental regulations.

In chapter four, I build upon the environmental justice frame I describe previously, by specifically focusing on citizen participation. This is important as it provides a more practical perspective of how and why environmental justice can affect voluntary environmental programs. I begin by examining citizen participation and expert knowledge. I explain how these two concepts generally compete with each other, insofar as expert knowledge tends to trump lay knowledge. Thereafter, I begin to explain how regular citizens can possess local expert knowledge. In addition, I highlight in a more practical manner the inherent power imbalances that exist within environmental decision-making that I described in a theoretical fashion in the previous chapter. Moreover, I explain how increased citizen participation, and the use of local expert knowledge, can positively benefit environmental decision-making. Furthermore, I use a case study from Swan Hills Alberta, which demonstrates that citizen participation can actually eliminate or, help alleviate, 'nimbyism.' This is extremely important as it illustrates that utilizing citizen participation can have positive impacts on environmental decision-making, from

\footnotetext{
${ }^{9}$ Both Schlosberg and Young place more emphasis on the concepts of recognition and procedure, which are more intimately linked with environmental justice considerations.
} 
both economical and environmental protection standpoints. Lastly, I analyze the forums in which citizen participation can and does occur.

Chapter five serves as my final analysis, where I attempt to conceptualize the relationship between voluntary environmental programs and environmental justice. While I hint at these relationships throughout my thesis, in chapter five I demonstrate more formally how the concepts in the previous chapters work together. I begin by critiquing voluntary environmental programs as a means to illustrate how they may benefit from the inclusion of environmental justice considerations. I utilize a term described by Karin Bäckstrand as the "deliberative turn," which allows me to situate voluntary agreements within a framework of environmental justice. ${ }^{10}$ In addition, I use two case studies to demonstrate the relationship between environmental justice and VEP's. Lastly, I explain how formal laws can reinforce both the practical and theoretical implementations of environmental regulations that utilize a multifaceted or mixed approach.

In my last chapter I summarize my arguments by providing a rationale for the elimination of the strict demarcation between environmental regulation and environmental justice. I encourage the adoption of environmental justice principles within environmental decisionmaking, specifically in regards to voluntary environmental programs. More specifically, I aim to demonstrate that environmental justice and voluntary initiatives can have a collaborative relationship. Accordingly, the effectiveness of voluntary initiatives should not be exclusively measured based on strict and simplified performance criteria, but rather through both performance and environmental justice concerns. These issues, among others, which I identify throughout my thesis, should be examined using a policy mix approach. One which seeks to maximize the positive benefits that each individual system, or approach, can have on the other,

\footnotetext{
${ }^{10}$ Karin Băckstrand, et al. "The promise of new modes of environmental governance." in "Environmental Politics and Deliberative Democracy: Examining the Promise of New Modes of Environmental Governance." (Edward Elgar Publishing Limited, United States: 2010).
} 
thus leading to more comprehensive, inclusive, and effective environmental protection. In addition to increased environmental protection, the inclusion of citizens within the process of establishing environmental regulations is equally important, as both play fundamental roles in the formation of ecological democracy.

The goal of this thesis is to develop a synthetic relationship between the examination of voluntary environmental programs and environmental justice considerations. Accordingly, I will argue that VEP effectiveness should be measured through a conceptualization of environmental justice, which may help increase the environmental performance of these new regulatory approaches, and help establish ecological democracy. 


\section{Chapter 2:}

\section{Examining Voluntary Environmental Programs}

Traditionally, attempts to protect the environment have come in the form of environmental laws and regulations, also referred to as command-and-control systems. While it is true that these topdown approaches have certainly contributed to the overall improvement of the environment, their current effectiveness is up for debate. Critics argue that command-and-control schemes are expensive, static, and generally not able to keep up with the increased demand for environmental protection in response to evolving industrial procedures and operations. ${ }^{1}$ Furthermore, command-and-control mechanisms can be said to create a type of paradox, where not enough laws can be established to protect against all circumstances, and already too many laws exist to effectively measure for compliance. ${ }^{2}$ Thus, industry is outpacing the regulatory institution's ability to effectively establish environmental regulations and subsequently monitor for environmental compliance. Additionally, laws and regulations are reactive in nature and tend to focus almost entirely on end-of-pipe emissions, which do very little to encourage any fundamental changes in manufacturing processes which typically create the most environmental harm.

Not surprisingly, industry and policy experts are also critical of command-and-control approaches, stating that there exists a total lack of flexibility for firms that do comply with current standards, often forcing them unnecessarily to invest large amounts of money into less

\footnotetext{
${ }^{1}$ Jonathan C. Borck, \& Cary Coglianese, "Voluntary Environmental Programs: Assessing their Effectiveness," (The Annual Review of Environment and Resources, Vol. 34: 2009) at 306.

${ }^{2}$ Charles Sabel, Archon Fung, \& Bradley Karkkainen, "Beyond Backyard Environmentalism: How Communities are Quietly Refashioning Environmental Regulation." (Boston Review: 1999) at 118.
} 
efficient environmental protection measures. ${ }^{3}$ In other words, industry is often forced into complying with pollution standards using very specific predetermined methods, potentially reducing environmental protection as a whole. These underlying issues have left many to look for alternatives to expensive and cumbersome command-and-control systems, often in the form of voluntary environmental programs or VEP's.

Voluntary environmental programs differ from command-and-control approaches insofar as they generally rely on a type of negotiation or agreement to occur between industry and regulators. This negotiation allows for more flexibility in terms of meeting program objectives, as the objectives themselves are part of the negotiation process. ${ }^{4}$ Generally, the only stipulation of voluntary programs is that the environmental goals must be stricter than current regulation already demands. In this regard, voluntary programs have more in common with market-based approaches. However, unlike market-based approaches, such as carbon trading strategies, which rely on "the invisible hand of the market place, [voluntary agreements utilize] case-by-case negotiations and agreements between regulators and the regulated."

Unfortunately, voluntary environmental programs are themselves not specifically geared towards formally encouraging citizen participation. In fact, they may even hinder participatory approaches, depending on the type of voluntary program that is established. David Dana defines them as decentralized "contractarian" approaches. ${ }^{6}$ He argues that policy makers must find a balance between voluntary environmental programs potential for increased environmental protection, and the potential limiting of citizen participation. In principle I agree with David

\footnotetext{
${ }^{3}$ JoAnn Carmin, Nicole Darnall, Joao Mil-Homens, "Stakeholder Involvement in the Design of U.S. Voluntary Environmental Programs: Does Sponsorship Matter?’ (The Policy Studies Journal, Vol. 31, No. 4: 2003) at 528.

${ }^{4}$ David A. Dana, "New "Contractarian" Paradigm in Environmental Regulation." (University of Illinois Law ${ }^{5}$ Ibid. Review, Vol. 2000, No. 1:2000) at 37.

${ }^{6}$ Ibid at 35 .
} 
Dana's approach, however I situate my arguments more fundamentally within a conceptualization of environmental justice. I develop a framework that seeks to examine how environmental justice principles, specifically citizen participation, may be implemented within voluntary environmental programs. My strategy is based on the fact that VEP's, although formally defined as deregulatory approaches, inherently contain negotiatory processes, which could support citizen participation.?

The purpose of this chapter is to provide an introduction to voluntary environmental programs and examine the use and effectiveness of these regulatory initiatives to reinforce environmental protection. I will examine and define different types of voluntary programs and discuss their unique characteristics, particularly insofar as citizen participation is concerned. More specifically, I critique voluntary environmental programs through an evaluation of environmental justice. The purpose of critiquing voluntary programs is that it will allow me to impose my own framework of program effectiveness based on environmental justice considerations. This critique will serve as the basis for my next two chapters, which formally conceptualize environmental justice and citizen participation. Subsequently, in chapter five I revisit VEP's and describe how environmental justice may be used to augment the effectiveness of voluntary approaches. Additionally, I will analyze key considerations for measuring program success based on practical considerations, including industry participation and 'spillover' effects. This is important as the individual elements of voluntary programs may lend themselves to further investigation based on environmental justice principles. Lastly I will discuss the opportunity for 'free-riding' that VEP's have created and the potential outcomes of this behaviour. Although I take a critical approach towards voluntary environmental programs, I am

\footnotetext{
${ }^{7}$ I describe these negotiatory processes within the context of specific types of voluntary programs later in the chapter.
} 
doing so from the perspective of ecological democracy. Thus, I am not specifically contesting the potential benefits that VEP's may have in terms of environmental protection, but rather critiquing the fundamental lack of citizen participation within them. ${ }^{8}$ I find this point particularly frustrating seeing that certain categories of voluntary initiatives generally necessitate a type of negotiation process to take place. ${ }^{9}$ Unfortunately, citizens tend to be absent from this process. However, it is certainly encouraging that the structures for their inclusion already exist and this is a point that I will build upon throughout the chapter.

\section{[2.1] The History of Voluntary Environmental Programs}

There has been a dramatic increase in the use of VEP's, throughout the industrialized world since the 1990's. This shift can be largely attributed to a changing public perception of the environment, which forced governments to adopt new environmental policy initiatives. ${ }^{10}{ }^{11}$ In the United States the introduction of the EPA's 33/50 program in 1991 sparked interest in these new modes of environmental regulation. ${ }^{12}$ Consequently, in the U.S. as of 2004, over 50 different voluntary programs had been established at the federal level alone. ${ }^{13}$ VEP's were first established in Japan in the 1960 's, and adopted in France shortly after. They are typically

${ }^{8}$ While the impact VEP's have on environmental protection is certainly important, it is not the main focus of this thesis. Accordingly, when I detail the practical environmental performance considerations of VEP's I generally do so as a means to introduce environmental justice principles, which I believe could increase environmental performance in the first place.

${ }^{9}$ Supra note 4 at 45 .

${ }^{10}$ Richard D. Morgenstern, \& William A. Pizer, "The Challenge of Evaluating Voluntary Programs" in "Reality Check, The Nature and Performance of Voluntary Environmental Programs in the United States, Europe, and Japan." (Resources for the Future, Washington: 2007) at 1.

"Public perception in regards to environmental concerns was increasingly influenced by the scale and destruction of environmental disasters. Additionally, Rachel Carson's novel "Silent Spring" was hugely influential in refocusing the public perception towards the damage of continued environmental degradation. Consequently, citizens became more concerned and involved with environmental concerns, both domestically and abroad.

${ }^{12}$ The 33/50 program was specifically designed to reduce the releases and transfers of 17 predetermined chemicals at certain intervals. By 1992 , there was to be a $33 \%$ reduction of these chemicals, followed by a $50 \%$ reduction in 1995. Additionally, the $33 / 50$ program was meant to be utilized as an experiment into voluntary environmental programs by the EPA in an effort to move beyond command-and-control systems.

${ }^{13}$ Edoardo Croci, “ The Handbook of Environmental Voluntary Agreements: Design, Implementation and Evaluation Issues." (Springer, Netherlands: 2005) at 107. 
categorized as the 'third wave' of environmental regulations after command- and-control structures, which form the first wave, and economic or market-based instruments, which form the second. ${ }^{14}$

In Europe the situation is similar to that of the United States, with voluntary initiatives emerging in the early 1970's and currently undergoing rapid expansion. The EEA (European Environmental Agency) estimated that in 1997, over 300 VEP's existed and that number is growing steadily, particularly, in France, the Netherlands and Germany. Additionally, "within the EU 15, the number of industrial sites subject to eco-management and auditing systems (EMAS) has risen from zero to over 4,000 in just six years." ${ }^{\text {"15 }}$ Fortunately, this expansion has continued and as of July 2012, there are 8, 150 sites registered within Europe. Moreover, the EMAS initiative itself has been expanded, and organizations from outside the EU are now able and encouraged to join. ${ }^{16}$ EMAS is a voluntary program that firms can choose to participate in, with the objective of providing consumers with more information as to how industry operates. Additionally, a core objective of the EMAS program is to examine and better understand the relationship between environmental protection, energy and resource efficiency, and social justice. ${ }^{17}$

Generally speaking there are four predominant explanations as to why there has been a dramatic shift towards the extended and increased use of VEP's. First, there exists a clear dissatisfaction with current regulatory approaches. This dissatisfaction is present with almost all

\footnotetext{
${ }^{14}$ Ibid at ix.

${ }^{15}$ Andrew Jordan, Rüdiger K.W. Wurzel, \& Anthony R. Zito, "New Environmental Policy Instruments: An Evolution or Revolution in Environmental Policy?" in "New Instruments of Environmental Governance? National Experiences and Prospects." (Frank Cass Publishers, London: 2003) at 3.

${ }^{16}$ European Commission, News Stories and Press Releases. <http://ec.europa.eu/environment/emas/news/index ${ }^{17}$ Ibid. en.htm\#279>
} 
stakeholders, including industry, government, and citizens. ${ }^{18}$ As mentioned before these concerns stem from the increased bureaucratic cost of developing new regulations, the cumbersome process of implementation faced by industry, and the general lack of public engagement within policy formation processes. ${ }^{19}$

Second, there is common perception, in both academic and industrial circles, that VEP's are simply 'better' than traditional command-and-control structures. While there is certainly debate on whether or not this is true from an environmental protection standpoint, the overwhelming evidence does suggest they can at least help reduce costs for both industry and government. ${ }^{20}$ Additionally, I will argue later on that voluntary initiatives can certainly facilitate increased environmental protection, particularly if used as originally intended, ie. a supplement to traditional regulatory structures.

Third, predominantly in terms of environmental regulation, there has been a shift from government to governance structures. In other words, voluntary approaches can aid in the facilitation of 'de-regulation,' which is prominent in neo-liberal governance approaches. Thus, de-regulation itself is not inherently compatible with environmental justice and as such I do take a critical approach towards it. However, instead of de-regulation proper, voluntary programs seek to shift the burden of environmental regulation away from predominantly top-down discourses. In other words, they achieve a type of de-regulation, which may actually benefit environmental justice principles insofar as citizen participation and environmental protection is concerned by relying more on negotiatory processes. Furthermore, VEP's do not necessarily

\footnotetext{
${ }^{18}$ Australia, Austria, Finland, France, Germany, Ireland, the Netherlands, and the United Kingdom have all expressed severe dissatisfaction with traditional regulatory frameworks. For more information see note 10. ${ }^{19}$ Supra note 15 at 202.

${ }^{20}$ Ibid at 203.
} 
'suffer' from the same negative publicity of traditional environmental regulations, particularly with regards to economic development. ${ }^{21}$

Lastly, increasingly competitive international markets have forced governments to adopt new modes of regulation. This has led countries to look "for more cost-efficient policy instruments compared to traditional regulation, which is often seen as a competitive disadvantage for industry, especially during a downturn of global economy...,22

\section{[2.2] Defining Voluntary Environmental Regulation}

Interestingly enough, there is no formal definition of what constitutes a voluntary environmental program, and different organizations and countries have adopted different meanings or categorizations. For instance, VEP's are often simply referred to as 'environmental programs.' "Other commonly used terms are 'codes of conduct,' and covenants."23 For example, the scope of what constitutes VEP's is by no means common or universal.

Consequently, the European Environmental Agency (EEA) defines voluntary programs as only those that were established through negotiations with public authorities, stemming from commitments between firms and sector associations. On the other hand, the EU Commission has taken a far broader approach. They define voluntary programs as "agreements between industry and public authorities on the achievement of environmental objectives. ${ }^{24}$ For the purpose of my research, I tend to adopt a broader definitional approach to voluntary environmental programs. ${ }^{25}$

\footnotetext{
21 Ibid.

22 Ibid at 204.

23 Ibid at 10 .

24 Ibid.

25 Adopting a broader approach is extremely important as VEP's can differ quite significantly, and excluding certain initiatives is problematic as they each contain unique characteristics. Thus, for the purpose of my thesis I define VEP's based on four distinct archetypes, namely public voluntary programs, bi-lateral agreements, unilateral agreements, and third party sponsored programs. Each of the four is examined in detail later in the chapter.
} 
Nonetheless, I find it extremely important to be clear on the different types of programs and their constructions, and thus offer four distinct categories of VEP's, which I define below.

Unlike command-and-control methods, these new approaches were to focus on environmental performance, as opposed to simple and inflexible regulatory compliance. ${ }^{26}$ The goal of voluntary programs was to supplement or even replace the traditional mechanisms for environmental control. Thus ironically, instead of defining voluntary approaches as what they are, they can almost be best categorized by what they are not, mandatory regulations. ${ }^{27}$

Voluntary approaches to environmental protection are unique insofar as they can be created by a number of different entities. For instance, VEP's can include "collaborative arrangements between individual businesses, industry associations and regulatory agencies or central governments, with... industry participants committed in either formal or non-formal ways. ${ }^{28}$ In other words, voluntary approaches can be fashioned privately by industry, suggested and created together with government, or collaboratively arranged with citizens and firms working together. ${ }^{29}$ Perhaps the largest difference between voluntary environmental agreements and other forms of environmental regulation, including both regulatory and market-based alternatives, is that voluntary programs have the ability to rely on positive or negative support. Therefore, participation and membership in voluntary programs can be achieved through positive incentives, rather than punishments, generally in the form of fines or supplementary regulation. ${ }^{30}$ Just as the participants in creating voluntary approaches can differ, so too can the overall structure and format of the programs themselves. Accordingly, it is extremely important to

\footnotetext{
${ }^{26}$ Seong-Gin Moon, \& Peter de Leon, “Contexts and Corporate Voluntary Environmental Behaviours, Examining the EPA's Green Lights Voluntary Program." (Organization \& Environment, Vol. 20, No. 4: 2007) at 480.

${ }^{27}$ Supra note 1 at 307.

${ }^{28}$ Donald G. Chittock, \& Kenneth F.D. Hughey, "A review of international practice in the design of voluntary ${ }^{29} \mathrm{lbid}$. Pollution Prevention Programs." (Journal of Cleaner Production, Vol. 19, No. 5: 2011 ) at 542.

${ }^{30}$ Supra note 1 at 307.
} 
categorize different voluntary approaches, in order to illustrate how their creation plays such a critical role. Four distinct categories of voluntary environmental programs exist, each of which I will describe below. ${ }^{31}$ Additionally, I will provide a brief analysis of how citizen participation may be introduced within these approaches, as this will form the basis of my arguments in Chapter five.

\section{[2.3] Public Voluntary Programs}

The first types of voluntary approaches to be examined are public voluntary programs. These are established through an environmental authority, such as the Environmental Protection Agency, or Environment Canada, which effectively invites industry into conforming to certain environmental advances voluntarily. ${ }^{32}$ Public approaches are typically designed with the purpose of creating a type of acknowledgement, or recognition, which is imparted to companies who enter into these programs, thus fostering a better public image. One such example of a current public voluntary program that citizens may be familiar with is the EPA sponsored Energy Star program. ${ }^{33}$ Energy Star is a program that allows makers of electronics and appliances to apply its badge to their products in order to demonstrate their increased efficiency in hopes of winning favour with potential customers. Kathryn Harrison defines these types of programs as "voluntary challenges." 34 She explains that this approach, where a program is established without any significant communications to potential industry participants results in less "armtwisting in the form of explicit threats of regulation or other punitive measures." ${ }^{35}$ The main

\footnotetext{
${ }^{31}$ While some may argue that 'Eco-labels' are also a form of voluntary initiatives, I believe that they can be utilized in combination with the four archetypes I describe. In other words, labeling a product through a certification process based on voluntary participation can, and does, appear in many of the four categories I define.

${ }^{32}$ Supra note 28 at 542 .

33 Supra note 1 at 308.

${ }^{34}$ Kathryn Harrison, "Voluntarism and Environmental Governance," in "Governing the Environment, Persistent Challenges, Uncertain Innovations." (University of Toronto Press, Toronto: 2001) at 211. ${ }^{35}$ Ibid.
} 
difference between public voluntary approaches and negotiated or bilateral agreements described next is that the former is presented as simple take-it or leave-it invitations. Thus, the motivation for joining such programs is suggested to take the form of increased public approval, rather than fear of regulation. ${ }^{36}$

Public voluntary approaches offer a distinctive and tangible entry point for citizen participation within environmental regulation. This results from the motivation of industry participation in the first place, being mainly driven by the objective of a better public image, which in turn may foster increased consumerism. If local citizen groups were consulted during program creation a direct link could be established between their suggestions, program goals, and ultimately, the compliance with said goals. Thus, as Archon Fung et al. explains, citizens would be able to help establish environmental performance targets and participating industry would reap the benefits of compliance, through a better public image. ${ }^{37}$

It is important to remember that increased consumerism is better categorized as a beneficial by-product of citizen participation itself. Accordingly, citizen input or participation should also be defined in regards to environmental justice. For example, citizen participation during the development phases of public voluntary programs would result in a procedural benefit, as citizens would be able to raise environmental concerns and hopefully establish programs which address them. ${ }^{38}$ However, seeing that public voluntary approaches tend to be structured as take-it or leave-it invitations, the process of negotiation inherent within voluntary programs is often absent. Accordingly, governments would need to establish formal procedures that encourage citizen participation in order to establish it as a required element in the design and

\footnotetext{
${ }^{36} \mathrm{Ibid}$ at 212.

${ }^{37}$ Supra note 2 at 117.

${ }^{38}$ For a discussion of environmental justice and its paradigms see chapter three.
} 
planning process itself. This would foster transparency and help establish more credible programs. In addition, it would aid in the establishment of ecological democracy.

\section{[2.4] Negotiated or Bilateral Agreements}

Negotiated or bilateral agreements involve a more collaborative process where industry is asked to participate in the establishment of the programs themselves. Consequently, these programs are generally larger in scope, as leading firms within industrial sectors are asked to provide input, thus encouraging a greater level of industrial participation. ${ }^{39}$ Bilateral agreements, just as public voluntary programs typically attempt to establish one or more environmental target(s), which exceed current regulatory standards. However, they differ significantly in the benefits offered to participating firms. Bilateral agreements, as opposed to public voluntary programs, tend to offer more tax and/or regulatory incentives. An example of this is EPA's Project XL, where rather than create a program and invite industry to join, Project XL programs are negotiated between individual firms and the EPA, based on site specific performance. Firms are allowed to create their own pollution reduction strategies, which may replace or modify regulations so long as they show increased environmental performance. " $\mathrm{XL}$ defines site-specific performance standards that are more stringent than the de facto standards implied by current regulation, and allows facilities some flexibility in meeting them." Kathryn Harrison defines these types of programs as 'voluntary agreements,' and situates them closely to regulation in terms of the overall coercion of membership exacted by government on potential firms. She explains that these types of agreements carry with them expectations that possible members, particularly leadings firms in specific industrial sectors will participate, and

\footnotetext{
${ }^{39}$ Supra note 28 at 542 .

${ }^{40}$ Allen Blackman, \& Janice Mazurek, "The Cost of Developing Site-Specific Environmental Regulations: Evidence from EPA's Project XL." (Environmental Management, Vol. 27, No. 1:2001) at 109.

${ }^{41}$ Ibid.
} 
furthermore comply with the programs. These expectations are reinforced through "explicit threats of traditional or market-based regulation should the voluntary approach fail.,942

There is an increased potential to establish an element of citizen participation within bilateral approaches. This stems from the increased communication that occurs during program development between government and industry. Thus, because these programs are established through a process of negotiation, extensive changes within developmental stages would not be necessary. In other words, citizens would simply need a seat at the negotiation table, as opposed to public voluntary approaches, where the table itself would need to be created. Furthermore, because negotiated agreements tend to be site specific, if citizens were included during the negotiation process they would have an increased opportunity to rely on their local expert knowledge based purely on geographic considerations. ${ }^{43}$ I will demonstrate this potential for citizen participation within Project XL programs in chapter five.

However, there exist difficulties in regards to establishing a more comprehensive participatory approach. First, the private nature of the communication within these approaches could result in industry potentially 'hijacking' the negotiations. ${ }^{44}$ Because industry is already intimately involved in the development phase of negotiated programs, they may advocate for less stringent environmental performance measures and less frequent monitoring thereof as well. ${ }^{45}$ Moreover, they may strongly oppose citizen participation in the first place. Therefore, similar to public voluntary programs, governments may need to step in and demand or legislate the inclusion of citizen participation within the negotiation process itself. ${ }^{46}$

\footnotetext{
${ }^{42}$ Supra note 34 at 211.

${ }^{43}$ For a discussion of local expert knowledge see chapter four.

${ }^{44}$ Supra note 3 at 531 .

45 Ibid.

${ }^{46}$ While community participation is required in Project XL strategies the same is not true of all negotiated or bilateral agreements.
} 


\section{[2.5] Unilateral or Industry Sponsored Agreements}

Unilateral or industry sponsored agreements are solely created by industry, generally within a particular sector completely free of a formal regulatory authority. ${ }^{47}$ Thus, while regulators can certainly support and/or assess these initiatives, they do not participate actively in their design or compliance monitoring. ${ }^{48}$ These types of voluntary programs gained popularity in the late 1980's. Perhaps the two most prominent examples are the "pulp and paper industry developed... Sustainable Forestry Initiative and the American Chemistry Council... Responsible Care Program." 49 Industries have been extremely enthusiastic and active in terms of establishing and implementing their own voluntary approaches. However, voluntary agreements that fit within this category tend to garner the most discussion and debate, particularly in terms of the motivational underpinnings of creation and membership. Critics argue that unilateral programs tend to emerge from the threat of future government regulations. As a result, such critics believe that unilateral programs are established simply in an effort to mitigate these regulations, which potentially leads to decreased environmental standards, or business-as-usual practices. ${ }^{50}$ Furthermore, serious questions arise when it comes to monitoring the compliance of participating members, as these types of approaches are completely self-regulated and enforced.

Proponents, on the other hand, suggest that this type of voluntary behaviour can stem from a type of corporate responsibility. ${ }^{51}$ In addition, advocates suggest that this type of behaviour is

\footnotetext{
${ }^{47}$ Supra note 28 at 542.

48 Anna Alberini, \& Kathleen Segerson, “Assessing Voluntary Programs to Improve Environmental Quality." (Environmental and Resource Economics, Vol. 22, No. 1-2: 2002) at 158.

49 Supra note 3 at 532.

${ }^{50}$ Thomas P. Lyon, \& John W. Maxwell, "Self-regulation, taxation and public voluntary agreements." (Journal of Public Economics, Vol. 87, No. 7-8: 2003) at 1454

${ }^{51}$ Supra note 1 at 307.
} 
proactive in nature, and allows firms to specifically tailor environmental performance targets to individual requirements. ${ }^{52}$

Unilateral agreements tend to have the lowest levels of citizen participation, but could arguably benefit most from its systematic inclusion. As a result, there exists a certain level of cynicism about the credibility of these types of industry initiatives. ${ }^{53}$ It is interesting to note that not just citizens would benefit from increased participation by assuring increased environmental performance, so too would industry by demonstrating increased transparency, thus alleviating concerns of legitimacy. In essence, citizen participation within unilateral agreements could combat feelings of public cynicism and business-as-usual practices simultaneously. Moreover, while industry may feel that restricting environmental compliance standards may benefit their bottom line, new research may help determine that stricter regulations may lead to increased consumerism, leaving profit margins largely unchanged. However, the challenges in establishing citizen participation within unilateral agreements cannot be understated, specifically because the programs themselves are so private in nature. Accordingly, governments cannot demand that citizens be included within the design process as governments themselves are absent as well. As a result the structures that may allow for citizen participation within public or negotiated agreements would require industry support. This support may be achieved by using environmental justice as a mechanism that mobilizes citizens around the idea that unilateral agreements should be subject to deliberative strategies. Accordingly, the failure by industry to support citizen participation could be highlighted through environmental justice interpretations, which may 'force' industry into adopting more democratic processes in order to avoid bad publicity and potentially decreased consumerism.

\footnotetext{
52 Supra note 3 at 532.

53 Ibid.
} 


\section{[2.6] Third Party Voluntary Agreements}

The last forms of voluntary approaches are third party initiated programs. ${ }^{54}$ These programs are created and monitored by "non-industry NGO's, including standard-setting bodies, advisory groups, and environmental advocacy organizations." ${ }^{55}$ Although these are the least prominent of the voluntary programs discussed thus far, they also produced some of the most significant impacts on industry in general, particularly ISO $14001 .^{56}$ ISO 14001 was established in 1996 and was developed by the International Organization for Standardization. It is widely regarded as the most important voluntary program, which has a membership of over 36000 and has enjoyed a $50 \%$ increase in membership annually since $1996 .^{5758}$

ISO 14001 provides compliant members with a certification that is earned through an action-plan based on a firms individual requirements, which is aimed at correcting environmental problems. ISO 14001 does not require third party verification of compliance, however it is highly recommended. ${ }^{59}$ Furthermore, while third party programs are established independently of industry and government, they are often consulted during the development process, generally as a means to ensure legitimacy. ${ }^{60}$

Citizen participation in this category of voluntary approaches, share much in common with negotiated or bi-lateral agreements, insofar as the negotiatory structures are normally inherent within the formation of these programs. Additionally, seeing that environmental advocacy organizations play an instrumental role in many of these types of programs, citizen

54 Ibid.

55 Ibid.

56 Ibid.

${ }^{57}$ Matthew Potoski, \& Aseem Prakash, “Green Clubs and Voluntary Governance: ISO 14001 and Firms' Regulatory Compliance." (American Journal of Political Science, Vol. 49, No. 2: 2005) at 235.

58 As of 2010, over 223149 certificates had been granted in over 150 countries. <http://www.iso.org/iso/news.htm ?refid=Ref1363>

59 Supra note 57 at 237 .

${ }^{60}$ Supra note 3 at 533 . 
participation is often promoted as a key ingredient for success. Furthermore, "third-party VEP's may have greater legitimacy with stakeholders because they are implemented and monitored by organizations that are unaffiliated either with the regulatory system or with program participants. ${ }^{361}$ Thus, third party voluntary initiatives offer perhaps the most comprehensive and meaningful opportunities to establish citizen participation within environmental regulation, as discussion tends to be actively fostered among all participants. However, it would be more beneficial if citizen participation was actively encouraged by the ISO instead of environmental advocacy groups. In other words, a formal acknowledgement by those that establish the programs that citizen participation is beneficial would effectively aid in the establishment of procedural justice, and ecological democracy.

\section{[2.7] Citizen Participation and the Contractarian Approach}

It is important to conceptualize the difficulties of establishing citizen participation within voluntary approaches. In this regard, David Dana explains that "it may... be more difficult for environmentalists... to influence the formation of contractarian environmental regulation than it is for them to influence the formation of command-and-control environmental regulation." ${ }^{.62} \mathrm{He}$ explains that in the context of command-and-control legislation, relatively small environmental organizations can monitor and participate in most legal developments. For instance, Dana explains that the U.S. Natural Resource Defence Council is capable of "commenting on and lobbying for or against virtually every piece of environmental legislation debated in Congress and every EPA rulemaking under development at EPA headquarters. ${ }^{963}$ Conversely, Dana states that in terms of VEP's, which can often be site specific, and which number in the hundreds of

\footnotetext{
${ }^{61}$ Ibid.

${ }^{62}$ Supra note 4 at 52 .

${ }^{63}$ Ibid at 53.
} 
thousands, a significant amount of resources would be necessary to maintain or establish formal participatory mechanisms. ${ }^{64}$

However, Dana does suggest three strategies that may help alleviate these concerns. First, legislation could be created that sets specific criteria in terms of environmental protection, and minimum standards of citizen participation. Second, a formal restructuring of voluntary initiatives could occur that requires a multilateral as opposed to a bi-lateral approach. ${ }^{656}$ Lastly, citizens could sue companies that are not meeting program standards, and alternatively they could sue regulators for not adequately enforcing program objectives.

Unfortunately, I believe that Dana's critiques and subsequent suggestions do not sufficiently address core environmental justice considerations. Thus, while I do agree with the strategies that Dana provides, I find it necessary to include additional tactics that seek to address environmental justice theory. First, particularly in terms of site specific VEP's, utilizing local expert knowledge should not be ignored. The site-specific nature that Dana defines as problematic should be reconceptualised to include the possible benefits from relying on local experts in the first place. Second, industry and government should provide citizens with monetary resources that they can use towards participatory opportunities. This would allow citizens to hire their own experts, which would assist them in making more informed and transparent decisions. ${ }^{67}$ Lastly, drawing on arguments from Thomas Caballero, the EPA and regulatory bodies developing voluntary programs should better define the role and authority of citizens with regards to participation. ${ }^{68}$ This would simultaneously establish formal roles for all

64 Tbid.

${ }^{65}$ lbid at 54.

${ }^{66}$ This point is the same argument that I make earlier in the chapter in regards to the negotiatory processes being expanded in order to formally establish citizen participation during program development.

${ }^{67}$ This point is explained extensively using a case study from Swan Hills Alberta in chapter four.

${ }^{68}$ Thomas E. Caballero, "Project XL: Making it Legal, Making it Work." (Stanford Environmental Law Journal, Vol. 17, No. 2: 1998) at 410. 
stakeholders and ensure the procedural inclusion of citizens within the design and implementation processes of VEP's.

While these criteria are by no means exhaustive, they do provide the practical basis for the framework that I develop in the next two chapters. Furthermore, they demonstrate how using environmental justice principles as a guide may foster increased environmental performance and ecological democracy.

\section{[2.8] The 'Formula' for Measuring Success}

Generally speaking, when attempting to measure the success or effectiveness of any types of the above listed voluntary programs, three main criteria are utilized. These include, the number of participants, the average effect participation has on environmental performance, and any potential spill-over effects. ${ }^{69}$ Alberini and Segerson explain that "the evaluation of any given policy instrument, including a voluntary approach, is inherently a normative analysis, i.e., an analysis of whether a particular instrument is 'good' or 'bad." I0 In terms of voluntary environmental programs, good or bad is measured in the context of whether or not a particular voluntary program achieved a reduction in pollution, and whether or not it did so in a manner that was more economically efficient than traditional methods. ${ }^{71}$

In addition to these criteria the establishment of citizen participation could also be used to gauge success within an environmental justice frame. Thus, while the first three criteria seek to establish technical performance markers, in relation to environmental and economic performance, using citizen participation as an evaluative mechanism can help define success in the grander scheme of environmental and social justice. This would require that citizens are

\footnotetext{
${ }^{69}$ Supra note 1 at 310.

${ }^{70}$ Supra note 48 at 159.

71 Ibid.
} 
intimately involved within the process of program design, implementation, and compliance monitoring. This approach could lead to significant gains in establishing more robust forms of social justice and ecological democracy. In this regard, the cultural theory of environmental justice can be utilized to demonstrate how culture plays a significant role in institutional learning processes, and subsequently, on the effectives of VEP's. ${ }^{72}$ Cultural theory can explain how local populations may be able to learn from science and policy experts. ${ }^{73}$ However, as Peter Swan explains if this learning is relegated solely to the citizen and not subsequently to the experts as well, then the learning itself may transform into a type of passivity and blind acceptance. This in turn may subvert the "political and moral dimension of democratic deliberation... under the presumed neutrality of science and technology."74

Before I analyze the above mentioned criteria it is important to note that in order to establish credible calculations of any type of performance, relevant baseline measurements must be determined first. ${ }^{75}$ This is adequately demonstrated in Böhringer and Frondel's analysis of unilateral voluntary programs in the German cement industry. They determined that, because unilateral agreements do not require participating industry to declare pre-program pollution statistics, an accurate measurement of program effectiveness beyond business-as-usual practices is virtually impossible. ${ }^{76}$ In fact, just as Lyon and Maxwell have argued, they suggest that unilateral agreements tend to be used as a strategy by industry to "delay or even circumvent

\footnotetext{
${ }^{72}$ Dorceta E. Taylor, "The Rise of the Environmental Justice Paradigm, Injustice Framing and the Social Construction of Environmental Discourses." (American Behavioral Scientist, Vol. 43, No. 4: 2000) at 513.

${ }^{73}$ The cultural theory of environmental justice attempts to demonstrate how environmental justice concerns are inherently linked with a culturally constructed representation of nature itself, and how this shapes our understanding of environmental concerns or problems, and their subsequent solutions.

${ }^{74}$ Peter Swan, "Democratic Environmental Governance and Environmental Justice." in "Law, Regulation, and Governance." (Oxford University Press, Ontario: 2002) at 138.

${ }^{75}$ Christoph Böhringer, \& Manuel Frondel, "Assessing Voluntary Commitments in the German Cement Industry, The Importance of Baselines," in "Reality Check, The Nature and Performance of Voluntary Environmental Programs in the United States, Europe, and Japan." (Resources for the Future, Washington: 2007) at 115. ${ }^{76}$ Ibid.
} 
regulatory threats." ${ }^{77}$ Not surprisingly, by confirming pre-program pollution statistics, an added layer of accountability is conferred to participating industry, particularly if citizens are involved in the development process. While Böhringer and Frondel focused their attention on a unilateral voluntary program, relevant baseline measurements would certainly assist researchers in determining ancillary measurements of any voluntary approach.

\section{[2.9] Industry Participation}

Industry participation is certainly a key element in the success of voluntary programs, however, using it as a criterion by itself is largely inadequate. For example, even if participation rates are relatively high, pollution reduction, or measurements of environmental performance in general, could remain comparatively minimal. ${ }^{78}$ Thus, industry participation must be coupled with the above mentioned criteria in order to form a more holistic assessment of voluntary approaches. Furthermore, it is important to examine the motivational underpinnings for industry participation to determine why firms choose to subject themselves to additional environmental commitments. A firm's motivation for joining a voluntary program can differ significantly. However, generally speaking a decision to participate stems from some type of benefit, in the form of either increased revenue, or a potential reduction or delay in future laws and regulations.

Market-based incentives are created through a demand for 'green' alternatives to everyday products. In other words, environmentally concerned consumers can induce companies into joining voluntary programs, in order to differentiate their products from competitors as environmentally friendly, ie. the Energy Star labelling program. Jorge Rivera and Peter de Leon have further observed that environmentally conscious consumers not only prefer to buy products based on certain environmental standards, but also favour stock purchases from companies that

\footnotetext{
${ }^{77}$ Ibid at 114.

${ }^{78}$ Supra note 48 at 159.
} 
act proactively to environmental concerns. Again, this creates a demand and subsequent effort from companies to adopt sound environmental management practices, often in the form of voluntary agreements. ${ }^{79}$ Additionally, market-based incentives need not stem from consumer preference, and can be created by general overhead costs, which may be reduced using environmentally friendly actions. For example, using fewer plastics in containers, and dimming lights in stores can be described as 'win-win' solutions, as they simultaneously reduce costs to private firms and help environmental performance. It is precisely in these areas, that voluntary agreements can serve as educational instruments, whereby companies can identify possible cost savings and as such may be encouraged to join voluntary agreements. ${ }^{80}$ This potential educational factor may be augmented by the inclusion of citizen participation, and more specifically local expert knowledge.

Government based incentives are unique insofar as they can rely on either positive or negative reinforcement for encouraging participation within voluntary programs. Positive encouragement generally takes the form of tax breaks or exemptions, whereas negative encouragement is generally created by the imminent 'threat' of a future law or tax that will be established if goals are not met 'voluntarily. ${ }^{, 81}$ Negative encouragement forces polluters into a scenario where they must choose between a lesser of two 'evils.' While it is true that voluntary agreements may include more stringent environmental goals, often there is greater leniency awarded to participating firms in reaching said goals and subsequently with continuing compliance standards. Regardless of which method is used in acquiring industry participation, academics and researchers tend to agree that voluntary approaches, in general, "are likely to be

\footnotetext{
${ }^{79}$ Jorge Rivera, \& Peter de Leon, “Is Greener Whiter? Voluntary Environmental Performance of Western Ski Areas." (The Policy Studies Journal, Vol. 32, No. 3: 2004) at 422.

80 Supra note 48 at 162 .

${ }^{81}$ Ibid at 163.
} 
more successful when backed by an underlying regulatory framework. ${ }^{82}$ Thus, some type of negative reinforcement is generally seen as favourable inclusion. Furthermore, it demonstrates the importance of situating VEP's within a framework of law.

\section{[2.10] Environmental Performance and other Program Goals}

As mentioned above, baseline measurements certainly play a significant role in establishing program effectiveness. On the other hand, there still exists an inherent difficulty in determining the overall environmental impact of VEP's. Measuring environmental performance is often described as circumstantial at best, as the counterfactual to program implementation can never be measured accurately, seeing that both cannot exist together ${ }^{83}$ For example EPA's 33/50 program was implemented shortly after the establishment of the TRI or Toxic Release Inventory. The TRI mandated that companies had to list emissions of pre-determined toxic substances, which may have had detrimental effects on their public image, perhaps forcing many to reduce emission targets that were also part of the voluntary program. ${ }^{84}$ However, it must be mentioned that the EPA did find that $40 \%$ of the participating companies were able to reduce the release/transfer of the targeted toxic chemicals, in comparison to only $27 \%$ of those that did not volunteer. ${ }^{85}$ Nonetheless, it is still only a guess as to whether or not similar findings and numbers would have presented themselves if the $33 / 50$ program had been replaced with a similar type of command-and-control regulation.

Thus, while considerations of environmental performance are perhaps the most important and easiest to understand within the sphere of effectiveness, they are also the most difficult to

\footnotetext{
82 Ibid.

${ }^{83}$ Ibid at 160 .

84 Ibid.

${ }^{85}$ David R. Karp, \& Clark L. Gaulding, "Motivational Underpinnings of Command-and-Control, Market-Based, and Voluntarist Environmental Policies." (Human Relations, Vol. 48, No. 5: 1995) at 457.
} 
measure. As described above, even if one works from a comprehensive baseline established at the outset of a voluntary program, it could not be assumed that the program itself has led to all or any potential improvements beyond what may have occurred naturally through business-as-usual practices, or in replacement to traditional forms of regulation. This problem boils down to an empirical issue of attempting to measure "what if" type of questions. ${ }^{86}$ In other words, researchers cannot accurately determine the pollution abatement that may have occurred if a voluntary program had not been established, and instead had been replaced with traditional legislation. However, there are two important ways of adding to the overall accuracy of measuring programs effectiveness.

First, in addition to establishing a relevant baseline of environmental harm from the outset, it is of equal importance to attempt to find "a credible control group against which to measure behavior and impacts of the participants in the VEP. ${ }^{187}$ Researchers should attempt to find comparable industries, one of which joined a voluntary program and one that did not. Although finding two exact counterparts is perhaps unreasonable, by controlling the variables statistically, accurate measurements could still be established. ${ }^{88}$

A second method of accurately measuring program goals is to establish this criteria as part of the voluntary program itself. This translates to providing extra funding into the program, perhaps in order to collect real-time statistics at predetermined intervals which researchers could analyze for program success. By including evaluation strategies within the fabric of the design process, researchers may be able to look beyond simply indentifying process variables. Thus, they could switch their attention from questions of industry participation, to what actions "were

\footnotetext{
${ }^{26}$ Vicki Norberg-Bohm, \& Theo de Bruijn, "Industrial Transformation, Environmental Policy Innovation in the United States and Europe." (The MIT Press, Cambridge: 2005) at 381.

${ }^{87}$ Supra note 1 at 311.

${ }^{88}$ Ibid.
} 
taken to reduce environmental impacts as well as the actual reduction of [the] environmental impacts [themselves]."89

\section{[2.11] The Importance of Spillover Effects or Positive Externalities}

Spillover effects are an extremely important consideration when measuring the effectiveness of a voluntary program, however they have received little attention in the academic literature. Spillover effects are the measurement of how VEP's affect non-participants. ${ }^{90}$ Thus, even if a voluntary program does not produce significant environmental changes in participating members, it could potentially influence non-participants to improve their environmental footprint, thus still rendering the program effective as a whole.

In 1999 the EPA explained that voluntary programs have the ability to alter environmental behaviour among participants and non-participants alike. ${ }^{91}$ From this finding, the EPA also introduced the 'performance curve,' which attempts to describe the distribution of environmental performance measurements across all facilities. This performance curve has been carefully implemented in their subsequent voluntary initiatives, and expanded on in an attempt to "create opportunities for more learning and sharing of information and to highlight highly visible leadership companies and encourage others to improve and thereby move the performance curve."92

Generally speaking, there are two ways in which spillover effects can induce better environmental behaviour in non-participating firms. First, as mentioned above, if voluntary programs can be used to educate industries on how to save money through environmentally friendly means, then those firms could also potentially educate others as to the cost saving

\footnotetext{
${ }^{89}$ Supra note 86 at 381 .

${ }^{90}$ Supra note 1 at 316.

${ }^{91}$ Ibid.

${ }^{92}$ Ibid.
} 
methods. Additionally, firms that do participate in VEP's that learn new methods or opportunities to pollute less, or use less energy, beyond what the program has already taught them, would be expected to share such information with non-participants. The motivation for divulging these practices to those who did not participate in the program could be the ability to label themselves as environmental leaders. ${ }^{93}$ While companies may lose a competitive edge by divulging best practices, the beneficial public image gained from being environmental leaders may offset such economic concerns.

Second, external pressures, generally from the consumer market, can potentially drive those that choose not to participate in a voluntary program to reduce environmental harm regardless. In other words, simply because some companies choose to be proactive in their protection of the environment by joining a voluntary program it may force others, if they want to remain competitive, to realize many of the same goals. ${ }^{94}$ For example, if numerous companies within an industrial sector promote the adoption of 'Green Supply Chain Management,' or GSCM, which is advocated for in ISO 14001 , it may force less environmentally conscious supplier's to adopt better environmental practices. ${ }^{95}$ Thus, a spillover effect can be created through the adoption of ISO 14001 practices to non-participating firms. ${ }^{96}$

Spillover effects also provide a unique opportunity for citizens to be incorporated into the evaluative measurements of VEP's. Consider for example that although a VEP, which incorporated citizen participation has the potential to not yield any significant environmental improvements, its spillover, in regards to establishing a more democratic form of governance,

${ }^{93}$ Ibid at 317.

94 Ibid.

${ }^{95}$ By setting environmentally friendly precedents, companies can influence or even force others to meet said standards, based on the assumption that consumers prefer green products or companies that engage in friendly environmental practices over those that do not.

${ }^{96}$ Toshi H. Arimura, \& Nicole Darnall, \& Hajime Katayama, "Is ISO 14001 a Gateway to More Advanced Voluntary Action, A Case for Green Supply Chain Management." (Resources for the Future, Washington: 2009) at 14. 
still may have created increased environmental performance for non-participants through public pressure. This may result in an added pressure to incorporate citizens into the design process, as a type of democratic standard may have been created. While this standard may not have a significant impact on environmental protection per se, it could in the sense of fostering ecological democracy.

\section{[2.12] Tackling the Free-rider Problem}

Free-riding has been observed numerous times within voluntary programs. It is generally made possible because any potential participatory benefits are awarded based on a segment of industry performance as a whole, as opposed to individual assessments. ${ }^{97}$ In other words, because voluntary program goals are generally shared by a collective, there is a possibility that firms who have not participated in a given program would still reap the benefits of those who have. ${ }^{98}$ Furthermore, even if firms do register for membership in a voluntary program, insufficient monitoring can result in the perception of industry participation, without any actual effort by 'committed' members. This tends to result from the almost complete lack of provisions in voluntary approaches dedicated to identifying and subsequently punishing free-rider behaviour. ${ }^{99}$ As a result, free-riding has a high potential for undermining the entire validity of a voluntary program. Consider that for each firm that engages in free-riding activity a share of their burden is passed on to a participating firm, thus requiring a greater effort, on their behalf, in order to comply with group specified targets. Accordingly, if participating firms cannot keep up

\footnotetext{
${ }^{97}$ Toddi A. Steelman, Jorge Rivera, "Voluntary Environmental Programs in the United States, Whose Interests are Served?' (Organization \& Environment, Vol. 19, No. 4: 2006) at 510.

${ }^{98}$ Magali A. Delmas, \& Ann K. Terlaak, "A Framework for Analyzing Environmental Voluntary Agreements." (California Management Review, Vol. 43, No. 3: 2001) at 53.

${ }^{99}$ Magali Delmas, \& Arturo Keller, "Free riding in voluntary environmental programs: The case of the U.S. EPA WasteWise Program." (Policy Sciences, Vol. 38, No. 2-3: 2005) at 91.
} 
with the disproportionate environmental demand, as a result of free-riding activity, the voluntary approach may be considered unsuccessful, which could result in stricter formal regulations. ${ }^{100}$

In addition to affecting program validity, free-riding also has the potential to undermine the credibility of a program. This is largely caused by opportunistic businesses who attempt to find "programs with no performance standards, no sanctions, and no third-party oversight to disguise poor performance and adopt the outward appearance of action while not making efforts to improve environmental performance."101 Not surprisingly, industry sponsored environmental agreements tend to suffer most from free-rider behaviour. These unilateral agreements are the least likely voluntary approaches to include sufficient monitoring and reporting mechanisms or controls, generally resulting in decreased environmental performance. ${ }^{102}$ Consequently, as discussed above, these are also the programs that could benefit most from an inclusion of citizen participation, both in the form of program development, and compliance monitoring; though I suspect citizen inclusion in these programs may be resisted more so than in others.

In order to combat free-rider behaviour, industry needs to take a vested interest in maintaining the credibility of a program through increased monitoring, and the sharing and reporting of accurate information with various stakeholders. Potoski and Prakash have argued that companies need to conceptualize membership as a type of excludable benefit, or as 'club or collective goods. ${ }^{, 103}$ In doing so, they may realize that members who engage in free-rider activity harm the program as a whole, which in turn effects everyone's reputation. Thus, from a collective standpoint, two problems must be combated in order to help reduce the potential for free-riding. First, a voluntary program must convey to potential members that the cost of

\footnotetext{
${ }^{100}$ Supra note 98 at 53.

101 Supra note 97 at 506 .

102 Ibid.

${ }^{103}$ Supra note 57 at 246.
} 
implementing program goals is a worthwhile effort. Second, all stakeholders to a voluntary program, including government, industry, and citizens should ensure that participating members continue to meet program requirements, through increased third party and self-monitoring methods. $^{104} 105$

\section{[2.13] Conclusions}

The purpose of this chapter was to introduce voluntary environmental programs and further determine the effectiveness of these approaches. In order to accomplish this, a thorough analysis of different programs, as well as current evaluative techniques was considered.

Additionally, I have set up the basis, or outline, which will be analyzed using an environmental justice frame in the subsequent chapters. In other words, I have, at very basic level, illustrated how I intend to infuse the research on VEP's with environmental justice considerations, namely establishing citizen participation, and utilizing local expert knowledge.

While any conclusions based on current research regarding voluntary approaches are tentative at best, there is nonetheless a certain level of enthusiasm that as voluntary approaches become more developed, their effectiveness will certainly increase. Thus, I believe that the tentativeness stems less from questions of inefficacy and more from a feeling that the design of voluntary programs has merely scratched the surface of what is possible. There is no denying that voluntary programs have resulted in the reduction of pollution and the general improvement of environmental performance. ${ }^{106}$ However, as I will argue later on, perhaps the most important

\footnotetext{
${ }^{104}$ Ibid.

${ }^{105}$ In chapter five I provide a more thorough analysis of free-riding, particularly in terms of how citizen participation may be used as resource that aids in the facilitation of compliance monitoring.

${ }^{106}$ Al lannuzzi Jr., "Industry Self-Regulation and Voluntary Environmental Compliance." (Lewis Publishers, United States: 2002) at 141.
} 
aspect of VEP's is the increased potentiality for citizen participation within environmental regulation that they provide.

All things considered, I do believe a greater emphasis has to be placed on voluntary approaches as they pertain to ecological democracy at both a practical and academic level. While their technical effectiveness is no doubt important, those systematic considerations fall beyond the scope of this project. Furthermore, it is my opinion that environmental justice theory can play a key role in establishing its own conceptualizations of program effectiveness in the first place. Thus, while researchers have found alternative environmental regulation can result in increased citizen participation, more stringent expectations of participation must be realized. These include authentic and meaningful participatory opportunities, which should be "firmly anchored in the articulation of equal rights of access to the public sphere," and evaluations of voluntary approaches at the procedural level. ${ }^{107}$ These considerations, among other environmental justice concerns will be discussed at length in chapters three and four.

In conclusion, I certainly believe voluntary approaches form a positive supplement to traditional command-and-control mechanisms. Furthermore, as Kernaghan Webb describes, it is important to not ignore this compatibility and rather use it to enhance each system, both individually and together. ${ }^{108}$ Lastly, environmental justice should be implemented, as a theoretical framework, for analyzing individual program components, thus resulting in the greatest possible advancement of democratic realizations in environmental regulation, which I will argue later on, should internally foster better environmental performance.

In the next chapter, I will shift my focus away from VEP's and discuss and establish an environmental justice frame. This is important, as it will form the basis of my critique of

\footnotetext{
${ }^{107}$ Supra note 74 at 138.

${ }^{108}$ Kernaghan Webb, "Government, Private Regulation, and the Role of the Market." In "Law, Regulation, and Governance." (Oxford University Press, Ontario: 2002).
} 
voluntary programs. In other words, I will utilize an environmental justice approach to evaluate how voluntary programs may benefit from its systematic inclusion. 


\section{Chapter 3:}

\section{Towards a Theoretical Conceptualization of Environmental Justice}

Environmental justice can be seen as a social movement that has formed as a response to unfair and disproportionate levels of environmental hazards within identifiable communities. ${ }^{1}$ The basic principle of environmental justice is that all people should be protected from environmental hazards and that they have the right to enjoy a "clean and healthful environment." Furthermore, environmental justice should ensure that all people have the right to participate in a meaningful way, with the "implementation and enforcement of environmental laws, regulations and policies and the equitable distribution of environmental benefits." ${ }^{3}$ In a more theoretical sense, environmental justice is the fundamental expression, which seeks to permeate environmental decision-making processes with more robust and deliberative forms of democracy. Additionally, in regards to this thesis, it forms both the practical and theoretical conceptualizations, which one can use to examine and critique new and emerging forms of environmental regulations, specifically voluntary environmental programs and the move towards ecological democracy. Due to its significance for this project, there must be a thorough analysis of the intricacies of environmental justice, as this examination will provide the necessary mechanisms in which to apply its principles to new modes of environmental regulation.

\footnotetext{
${ }^{1}$ Peter D. Swan, "Environmental Justice and Minority Ecological Rights." in "Do we need Minority Rights? Conceptual Issues." (Martinus Nijhoff Publishers, London: 1996) at 185.

2 Julian, Agyeman, \& Bob, Evans. "Just Sustainability: The Emerging Discourse of Environmental Justice in ${ }^{3}$ lbid. Britain?" (The Geographical Journal, Vol. 170, No. 2: 2004)at 156.
} 


\section{[3.1] The History of Environmental Justice}

The environmental justice movement began to emerge in America in the mid to late 1970's as a response to a perceived inequality in terms of the proximity to environmental hazards certain populations faced. Consequently, environmental justice concerns prompted the creation of groups of citizen activists, predominantly from working-class and minority neighbourhoods, as they were most effected by environmental injustices. As a result, two overarching groups or movements emerged, the largely working-class Caucasian 'Anti-toxics Movement' and the 'People of Colour Environmental Movement,' comprised primarily of identifiable minorities. ${ }^{4}$ Thus, environmental justice effectively owes its foundations to small communities such as Love Canal, New York, and Warren Country, North Carolina. ${ }^{5}$

In terms of environmental justice considerations within the legal sphere, a landmark case took place in Houston in 1979, where a predominantly African-American community attempted to prevent the construction of a sanitary landfill within their suburban middle-income neighbourhood. ${ }^{6}$ In their fight against the proposed construction, the residents formed the Northeast Community Action Group (NECAG) and filed a class action lawsuit; Bean v. Southwestern Waste Management Inc. The plaintiffs requested a preliminary injunction against the construction of the waste facility on two grounds. First, that the approval of the construction by the Texas Department of Health (TDH) was indicative of a systematic pattern of racially motivated siting decisions, insofar as unwanted industries were predominantly constructed in

${ }^{4}$ David N. Pellow, \& Robert J. Brulle, "Power, Justice, and the Environment: Toward Critical Environmental Justice Studies." in "Power, Justice, and the Environment: A Critical Appraisal of the Environmental Justice Movement." (The MIT Press, London: 2005) at 8.

${ }^{5}$ The Love Canal disaster resulted from building a residential community on a former chemical disposal site, exposing residents to dangerous levels of toxic compounds. The disaster in Warren County, North Carolina resulted from PCB contamination, first from illegal dumping by a private company, followed by an EPA approved PCB landfill, which continued to leak hazardous chemicals that affected the surrounding community.

${ }^{6}$ Robert D. Bullard, \& Glen S. Johnson, "Environmental Justice, Grassroots Activism and Its Impact on Public Policy Decision Making." (Journal of Social Sciences, Vol. 56, No. 3: 2000) at 556. 
minority communities. Second, that the approval to build the landfill sufficiently demonstrated a historical bias towards the placement of unwanted facilities in minority communities, and that this constituted discrimination. ${ }^{7}$ The arguments were framed in this manner, because the courts had previously established in, Washington v. Davis, five factors that one should consider when attempting to ascertain discriminatory intent.

(1) the impact of the official action; (2) the historical background of the decision; (3) the specific sequence of events leading up to the challenged decision; (4) any departures from the normal procedural or substantive sequence of decision-making process; and (5) the legislative or administrative history of the challenged action. ${ }^{8}$

This case was the first of its kind where a community attempted to use the U.S.

Constitution, specifically the equal protection clause, and "challenged the siting of a waste facility under civil rights law."9 Furthermore, during the trial residents explained to the court that a similar construction permit to build a potentially hazardous facility in the same location had previously been denied by the Texas Department of Water Resources (TDWR). This was largely in part due to the fact that the facility was to be built only 1700 feet from a high school, within a community that was comprised of approximately $70 \%$ African-Americans. ${ }^{10}$ Unfortunately, the court rejected the plaintiff's claims and explained that they had failed to demonstrate that the issuance of the permit constituted, or was motivated by, racial animus. In terms of providing a history of discriminatory processes, the courts refused to interpret the decision of the (TDWR) as having any bearing on the (TDH) as the proposed facilities were different and thus statistically insignificant. ${ }^{11}$

${ }^{7}$ Gerald Torres, "Environmental Burdens and Democratic Justice." (Fordham Urban Law Journal, Vol. 21, No. 3: 1993) at 440.

8 Ibid at 439.

${ }^{9}$ Supra note 6 at 556.

${ }^{10}$ Supra note 7 at 440 .

"Though there was evidence that $15 \%$ of Houston's solid waste facilities were situated in areas where only $7 \%$ of the total population lived, and of those $7 \%, 70 \%$ were African-American, "the court found no evidence of 
However unfortunate the case may be, the overall importance thereof cannot be understated as it occurred approximately three years before the environmental justice movement shot into the national public spotlight in Warren County, North Carolina. The Warren County protests occurred in response to a siting decision regarding a PCB landfill facility. The protests provided the necessary motivation, which prompted the U.S. General Accounting office to conduct a study entitled "Siting of Hazardous Waste Landfills and Their Correlation With Racial and Economic Status of Surrounding Communities." 12 This study illustrated that approximately three out of four commercial off-site hazardous waste landfills located in eight southern States happened to be sited within predominantly African-American communities, despite the fact that they comprised only $20 \%$ of the total population within those particular States. Arguably, the protests paved the way for the reconceptualization of the term environmental justice, insofar as environmental racism helped facilitate the expansion of environmental justice discourses in general. ${ }^{1314}$ The protests in Warren County also directly led to the ground-breaking study by the Commission for Racial Justice in 1987 entitled "Toxic Wastes and Race in the United States."15 This was the first national study that examined and subsequently determined that there was a statistical correlation between waste facility locations and certain demographic characteristics. The study found that race was the most important variable in predicting where hazardous facilities would be located. Race even proved to be more accurate in terms of predicting waste facility locations than income, land values, and home ownership. ${ }^{16}$

disparate impact." The court even explained that while the siting decision was perhaps illogical and insensitive, there was insufficient evidence to establish any racially motivated intent. For more information see note 7 at 441

${ }^{12}$ Supra note 6 at 556.

${ }^{13}$ Ibid.

${ }^{14}$ Even though these protests were linked to racial issues, they helped establish the awareness of social injustices relating to environmental considerations in general, which helped define environmental justice as a pluralistic discourse.

${ }^{15}$ Supra note 6 at 556.

${ }^{16}$ Ibid. 
The increased attention that was given to environmental injustices in the United States was elegantly presented in Robert Bullard's book "Dumping in Dixie: Race, Class, and Environmental Quality."17 Bullard explained and examined the similarities between social justice and environmental movements, and demonstrated how they could be conceptualized together as the environmental justice movement proper. This book highlighted how local based community environmental struggles often transformed into "multi-issue, multiethnic, and multiregional movement[s]." ${ }^{.18}$ This book helped illustrate the inherent plurality within the environmental justice movement and additionally how it could be used as a mechanism for coherent mobilization.

The environmental justice movement saw enormous growth throughout the 1980's and 1990's. During this time "several thousand groups emerged in the United States to oppose perceived inequalities in the distribution of environmental hazards, based on the assumption of a threat to the public health of nearby communities."19 Perhaps the single most important event in the history of the environmental justice movement was the National People of Color Environmental Leadership Summit held in Washington D.C. in 1991. This summit expanded the focus of environmental justice beyond "its antitoxics focus to include issues of public health, worker safety, land use, transportation, housing resource allocation, and community empowerment." ${ }^{20}$ Additionally, the summit demonstrated that it was entirely possible, and in fact desirable, to build coherent multiracial groups dedicated to the pursuit of environmental justice objectives. Over 650 separate grassroots organizations and their leaders attended the

${ }^{17}$ Robert Bullard, "Dumping in Dixie: Race, Class, and Environmental Quality." (Westview Press Inc., United States: 2000)

${ }^{18}$ Supra note 6 at 556.

${ }^{19}$ William M. Bowen, \& Michael V. Wells, "The Politics and Reality of Environmental Justice: A History and Considerations for Public Administrators and Policy Makers." (Public Administration Review, Vol. 62, No. 6: 2002) at 689.

${ }^{20}$ Supra note 6 at 557. 
four-day summit in order to share their own action strategies, which helped redefine the environmental justice movement. Furthermore, the immense participation in the summit resulted in the creation of a set of standard rules and goals, which communities could use to combat environmental injustices around the world. In fact, summit delegates adopted 17 core principles which served as a guide in terms of fostering communication between individual groups and non-governmental and governmental entities insofar as organization and networking was concerned. ${ }^{21}$ For instance, principle two states that "Environmental Justice demands that public policy be based on mutual respect and justice for all peoples, free from any for of discrimination or bias," and principle five states, "Environmental Justice affirms the fundamental right to political, economic, cultural and environmental self-determination of all peoples."22

As a result of the massive citizen support for environmental justice principles, by the mid 1990 's the movement not only transcended its traditional focus on racial inequalities, but also included examples of gender, socioeconomic, and age related injustices or disparity. ${ }^{23}$ Furthermore, the importance of environmental justice at the institutional level continued to expand as well. Countless State and federal reports were commissioned, a number of academic conferences were established, and new corporate strategies were introduced, all of which reinforced the original 'street-level' citizen engagement. This continued growth eventually influenced the Clinton Administration to enact Executive Order 12898 on February $11^{\text {th }}, 1994$; "Federal Actions to Address Environmental Justice in Minority Populations."24 This had immediate effects on environmental justice concerns as they became relevant, and more importantly, significant at the highest level of government. This order required each federal

\footnotetext{
${ }^{21}$ Ibid.

$22<$ http://www.ejnet.org/ej/principles.html>

${ }^{23}$ Supra note 19 at 689.

${ }^{24}$ Ibid.
} 
agency to establish strategies that would help in the identification of environmental injustices stemming from past and future activities or operations. Furthermore it served as a fortification of the Environmental Protection Agency (EPA) that was established in $1970 .{ }^{25}$

Clearly, the growth and expansion of the environmental justice movement had significant impacts on how the concept thereof was used throughout the world. Its formation as a predominantly monolithic construction has changed, both in practical and academic spheres. Additionally, its emergence within mainstream American media has helped establish it as a critical component insofar as the struggle against environmental injustice is concerned. While this historical analysis is by no means exhaustive it nonetheless illustrates some of the key moments within its evolution, and furthermore how its evolution was largely community and citizen based.

\section{[3.2] Examining the Environmental Justice Frame}

Before engaging in a discussion of the individual aspects of environmental justice, it is important to analyze its meanings and significance within social structures. In this regard, environmental justice must be understood as a conceptual construction that was formed through both, bottom-up and top-down discourses, insofar as it was utilized and established by both local grass-roots and national organizations. ${ }^{26}$ Furthermore, it is important to note the significant impact that academic literature had on the construction of environmental justice. Even though discrepancies existed within academic definitions of environmental justice, with regards to highlighting the importance of race as opposed to socioeconomic status for example, the influence of academic literature as a whole cannot be denied. In other words, as I have explained

\footnotetext{
${ }^{25}$ Ibid at 690.

${ }^{26}$ Stella M. Capek, The “Environmental Justice” Frame: A Conceptual Discussion and an Application. (Social Problems, Vol. 40, No. 5: 1993) at 5.
} 
both above, and in my historical analysis, even though environmental justice was largely formed by local activist groups, academic research has served to fortify and reinforce concerns within the confines and objectivity of the scientific method. ${ }^{27}$

Consequently, environmental justice often functions as a mobilizing phenomenon by creating a mechanism for the establishment of community solidarity. It provides the opportunity for coherent organization around a specific cause, by attributing a meaning to the cause itself. Accordingly, it has often taken the form of a symbolic conceptualization that provides a tangible assessment and rally-point around instances of environmental injustices, by offering those injustices a 'name.' The opportunity for mobilization that environmental justice discourses provide are effectively the mechanisms that allow it to function as a 'counter' against the inherent power imbalances that exist within environmental decision-making processes. This function is an extremely important component in terms of my research, as environmental justice may provide an entry point, or at the very least, a recognition that an entry point is necessary, into the design stages of VEP's. It is important to keep in mind that "every environmental struggle is, at its foundations, a struggle among interests about power. ${ }^{28}$ Correspondingly, environmental justice discourse is often used as a tool that seeks to negate, as much as possible, these inherent power imbalances. In this regard, there has been a lot of focus on the justice aspect of environmental justice, as this is arguably the key term, or conceptualization, which provides the opportunity to combat power imbalances in the name of fairness and equity. ${ }^{29}$

When looking at the environmental justice frame as a micro level construction, there are four key archetypical themes. First, environmental justice seeks to provide a community, or the

${ }^{27}$ Conner Bailey, et al. "Environmental Justice and the Professional." in "Environmental Justice: Issues, Policies, and Solutions." (Island Press, United States: 1995) at 42.

${ }^{28}$ Douglas Weiner, "A Death-Defying Attempt to Articulate a Coherent Definition of Environmental History." In "Canadian Environmental History." (Canadian Scholars' Press Inc., Toronto: 2006) at 76.

${ }^{29}$ The concept of justice within environmental justice will be analyzed later on, as it requires a significant amount of explanation. 
public in general, with accurate and reliable information about a specific situation or environmental concern. Second, environmental justice should provide the opportunity to establish an unbiased forum in which a particular environmental concern can be heard. Third, a real and authentic element of citizen participation should be established within environmentaldecision making processes. Lastly, environmental justice seeks to provide the conceptualization of potential compensation from those that have harmed another group or individual. ${ }^{30}$ While these generalizations certainly do not account for all environmental justice concerns, as it is by definition an evolving and multifaceted concept, they nonetheless provide a manageable categorization to conduct more specific and elaborate analysis.

These specific elements of environmental justice are strongly connected by an overwhelming determination to reinforce "citizenship rights, democratic processes, and respect for grass-roots knowledge." ${ }^{31}$ This last point is particularly important, as it conceptualizes the adversarial relationship between 'expert' knowledge and local or lay knowledge. This divide is a core component within environmental justice concerns, as expert knowledge undermines, or may be used to undermine, more inclusive forms of environmental decision-making. As discussed in Benton \& Short, Samuel Hays suggests that experts have purposely created a system where environmental issues have become institutionalized, which results in the authoritative control of information and influence on environmental issues themselves. ${ }^{32}$ This argument plays a fundamental role in the construction of my argument and will be looked at in detail in chapter four.

\footnotetext{
${ }^{30}$ Supra note 26 at 8.

${ }^{31}$ Ibid.

${ }^{32}$ Lisa, M., Benton, \& John, R., Short, "Environmental Discourse and Practice." (Blackwell Publishers Inc., Massachusetts: 2000 ) at 156.
} 
Although environmental justice is often used as a device to create solidarity, this is certainly not an automatic or inevitable outcome. While the principles of environmental justice certainly transcend jurisdictional, geographic, economic, and racial boundaries, they cannot be assumed to apply evenly within all communities. Consequently, while community specific goals may help create a more formidable and organized group to combat instances of environmental injustices, each individual's understanding and experience of harm is inherently unique. As a result, it is extremely difficult to satisfy the needs and wants of all community members. This difficulty has sometimes led to infighting within communities between different identifiable victim groups. ${ }^{33}$ Thus, as Čapek explains, framing environmental concerns around the collective principle of environmental justice is sometimes problematic as a unified interpretation of issues is not always possible, or in fact appropriate. Consider that protests against industry pollution or practices may negatively affect the distribution of jobs within a particular community. Additionally, homeowners within contaminated or affected communities may wish to maintain the status quo, insofar as denying allegations of contamination enables them to cling to the ideal of the 'American Dream. ${ }^{34}$ Thus, citizens who are not opposed to specific instances of environmental injustices in their community, for whatever reason, may come into conflict with those who do express opposition. ${ }^{35}$

Exploring the environmental justice frame is particularly important when examining the individual elements thereof. Thus, while the majority of this chapter takes a more practical approach to conceptualizations of environmental justice, the frame itself cannot be forgotten or ignored. Furthermore, within the broader frame of environmental justice, there are several

\footnotetext{
${ }^{33}$ Supra note 26 at 8.

34 Ibid at 9.

${ }^{35}$ This is particularly important as it demonstrates that environmental justice cannot be defined as a monolithic discourse, as individuals necessarily interpret its core objectives and potential outcomes differently.
} 
different approaches to the paradigms of justice that exist within the frame itself, which I will describe below.

\section{[3.3] Environmental Justice Paradigms}

As previously mentioned the goals of environmental justice are inherently linked to a conceptualization of justice itself. Thus, one must ask, what is justice? As David Schlosberg points out, traditional liberal attempts to define justice within the environmental context were almost exclusively associated with the theories of John Rawls. Rawls defined justice as a conceptualization of fairness with two basic principles. First, that everyone would share an equal political right, and second that society as a whole should benefit from the distribution of social and economic inequality. ${ }^{36}$ As a result, the discourse on environmental justice was consistently situated in the distributional paradigm. Justice was defined as "the distribution of goods in a society, and the best principles by which to distribute those goods." ${ }^{, 37}$ It is important to note that Rawl's model of distribution itself did not foster a utilitarian calculus. However, focusing mainly on distributional considerations may ultimately result in utilitarian approaches, which have tended to dominate the environmental policy landscape. Thus, just distribution inherently requires a type of normative analysis, and principles of utilitarianism potentially help in making the 'most beneficial' decisions. In this regard, utilitarian approaches seemed desirable insofar as environmental decision-making was concerned, as their logic would attempt to bring the greatest benefit to the greatest number of people. ${ }^{38}$ Authors, like David Schlosberg, Iris Young, Axel Honneth, and Nancy Fraser do not disagree that distributional considerations are important,

${ }^{36}$ David Schlosberg, "Defining Environmental Justice. Theories, Movements, and Nature." (Oxford University Press Inc., New York: 2007) at 13.

${ }^{37}$ Ibid at 3.

${ }^{38}$ Iris M. Young, "Justice and Harzardous Waste." (Bowling Green Studies in Applied Philosophy, Vol. 5: 1983) at 171. 
however they emphasize that justice cannot be defined as a simple monolithic construction. Fraser in particular emphasizes that the paradigms themselves are not in competition with each other and that a holistic definition of justice should seek to frame all paradigms together. ${ }^{39}$ Nonetheless, I believe that it is still important to analyze each paradigm individually in order to understand their separate complexities. In doing so, it is possible to form a more comprehensive and multidimensional definition of environmental justice, which helps me establish the relationship between it and voluntary environmental programs.

\section{[3.3.1] Distribution}

As mentioned above, the conception of justice within political theory has been almost exclusively defined as it pertains to questions of distributional equity. Furthermore, Schlosberg explains that traditionally conceptualizations of just distribution themselves have been problematic as they tend to take on universal constructions. In other words, justice was seen as distribution, and distribution was defined through static, or monolithic terms. ${ }^{40}$ Additionally, in order to define justice according to Rawls, one must assume that all citizens "are situated behind a veil of ignorance. ${ }^{, 11} \mathrm{He}$ argued that this cloak would preclude men from attempting to exploit or gain an advantage over each other, as a person's true place in society would be unknown. Accordingly, individual citizens would not be able to draw comparisons between their own fortunes of distribution with the fortunes of others. Rawls argued that this would result in a particularly fair construction of justice, as everyone would have the same standing, whether perceived or real, as everyone else.

\footnotetext{
${ }^{39}$ Nancy Fraser, "Social Justice in the Age of Identity Politics: Redistribution, Recognition, and Participation." (The Tanner Lectures on Human Values, Stanford University: 1996) at 5.

${ }^{40}$ David Schlosberg, "The Justice of Environmental Justice: Reconciling Equity, Recognition, and Participation in a Political Movement." In "Moral and Political Reasoning in Environmental Practice." (The MIT Press, Cambridge: 2003) at 80.

${ }^{41}$ John Rawls, "A Theory of Justice. Revised Edition." (Harvard University Press, America: 1971) at 118.
} 
This approach to justice has been highly criticized by a number of academics, most notably Iris Young, Nancy Fraser, Alex Honneth, and David Schlosberg. I do agree with their approach, insofar as distributional considerations are significant elements of justice as a whole, and that by examining distributional theories of justice, distribution can be improved. However, generally speaking, distributional theories do not "thoroughly examine the social, cultural, symbolic, and institutional conditions underlying poor distributions in the first place., ${ }^{, 42} 43$

Michael Walzer, while still forming his arguments in accordance with distributive thought, began to move away from distribution as a universal application of justice and argued that distribution itself must be understood as pluralistic, through an understanding of "historical and cultural particularism. ${ }^{.44} \mathrm{He}$ explained that citizens will value and desire individual items differently, according to temporal and cultural principles. Consequently, Walzer illustrated how one-dimensional definitions of distribution were problematic and created a type of paradox. As an example, traditional distributional formations of justice ignored individual experiences of the environment, by attempting to form a universal collective. However, since the distribution of goods themselves is inherently based on a type of normative analysis, generally applied through utilitarian calculus, it is arguably not collectively applicable. ${ }^{45}$

Although Walzer begins to expand on the notion of justice, by developing its foundation in distributional thought to entertain more pluralistic conceptions, I believe it is still limited insofar as it does not consider other important factors. For example, Young points out that for distributional considerations to work in the first place, society must assume the neutrality in

${ }^{42}$ David Schlosberg, "Reconceiving Environmental Justice: Global Movements and Political Theories." (Environmental Politics, Vol. 13, No. 3: 2004) at 518.

${ }^{43}$ These conditions are extremely important for a theory of justice as they illustrate that justice itself must be defined as pluralistic, as different culture's and social structures will have different definitions of justice. Consequently, justice cannot be completely defined through purely distributional interpretations.

${ }^{44}$ Michael Walzer, "Spheres of Justice. A Defense of Pluralism and Equality." (Basic Books Inc., America: 1983) at 6.

${ }^{45} \mathrm{Ibid}$ at 7 . 
which governments come to certain decisions. "The assumption that the state can and should transcend all particular interests and carry the force of the general will is so strong in our society that calling into question the state's right to make policy decisions generally lacks legitimacy.,46 Unfortunately, the state often has a vested economic interest in attracting industry, which it accomplishes by establishing favourable siting conditions. As a result of the desire to establish and expand industry, the state also has an inherent bias in terms of how and why it may make certain siting decisions. ${ }^{47}$ This argument is critical in understanding why distributional conceptions of justice themselves are inadequate; as they require an entity capable of making neutral decisions, yet inherent biases always exist. Thus, more often than not, industrial facilities are located in marginalized communities, which perpetuates environmental injustices in the first place. Accordingly, a multidimensional approach to justice is required and in this regard, Schlosberg has developed a more comprehensive way in which one can attempt to define justice, particularly within an environmental justice framework. Schlosberg breaks the definition of justice down so as to include three distinct and interconnected paradigms: distribution, recognition, and procedure. While I ultimately agree that Schlosberg's categorization of justice within three separate paradigms helps create a more comprehensive definition of justice itself, his analysis, in my opinion, lacks a more theoretical reflection. As such, I tend to take a more theoretical approach towards key issues associated with recognition and procedure as this helps define the potential relationship that I propose between these paradigms and VEP's.

\section{[3.3.2] Recognition}

Schlosberg argues that the idea or concept of recognition is fundamental in the understanding of justice as a whole. Both, Schlosberg and Young explain that there has been a

\footnotetext{
${ }^{46}$ Supra note 38 at 178 .

${ }^{47}$ Ibid at 179.
} 
complete lack of recognition of both individual identity and different interests or values among citizens. This lack of recognition ultimately leads to unjust distributional practices by ignoring intricate and unique group differences. ${ }^{48}$ Additionally, lacking recognition cannot simply be understood as lacking a mechanism for being heard. The realities are far more complex and are demonstrated through insults, not acknowledging or engaging with citizen concerns, and devaluation at individual, community, and cultural levels. Charles Taylor argues that this lack of recognition results in communities and individuals feeling harmed, but more importantly, these injustices devalue a person's own conceptualization of self. ${ }^{49}$ In other words, misrecognition results in a distorted perception of self worth, which can be categorized as another means of oppression. ${ }^{50}$ This point will become more obvious in the next chapter when I discuss the affect and the emergence of the 'expert' within environmental decision-making processes.

Fraser however, contends that it is more appropriate to view misrecognition as a systematic pattern of oppression through institutional mechanisms. She argues that this conceptualization provides more opportunity for individuals themselves to form their own ideas of what they believe is "the good life, and to devise... an approach [for] pursuing it." She believes that Taylor's conceptualization of recognition is too easily hijacked by the idea that self worth is inherently universal; which by definition it cannot be as every individual will equate worth to mean different things. Thus, as is the case with distribution, relying solely on self worth is problematic as it may lead to pre-constructed philosophies of what worth is to a collective and thus 'should' mean to the individual. ${ }^{52}$

\footnotetext{
${ }^{48}$ Supra note 40 at 81 .

${ }^{49}$ Ibid at 82.

${ }^{50}$ Charles Taylor, "The Politics of Recognition." in "New Contexts of Canadian Criticism." (Broadview Press, Ontario: 1997) at 98.

${ }^{31}$ Supra note 39 at 25.

52 Ibid.
} 
In my view both Fraser and Taylor's arguments cannot be ignored, and together they form a more comprehensive definition of justice. While I understand that relying solely on self worth as a categorization of recognition is problematic, in conjunction with Fraser's more pragmatic approach, it nonetheless illustrates the importance of the recognitionary paradigm. However, I certainly agree with Fraser that recognition, by its definition, requires an examination of power imbalances within environmental-decision making processes. In other words "where social and group differences exist and some groups are privileged while others are oppressed, social justice requires explicitly acknowledging and attending to those group differences in order to undermine oppression." ${ }^{\text {33 }}$ Thus, while distributional theories of justice tend to ignore the inherent power imbalances that exist in the formation of distributional-based policy, recognition can be used as a means to combat or remedy this problem. Accordingly, recognition may be best defined using a multifaceted approach, which is categorized by feelings of self worth and an awareness of the presence of systematic institutional oppression. In my opinion, this forms the most comprehensive definition of recognition, by being 'sensitive' to critiques that it cannot be interpreted as a monolithic element and incorporating perceptions of self worth.

\section{[3.3.3] Procedure}

The last paradigm, and perhaps also the most significant, is the procedural paradigm. While some academics have tended to incorporate procedure within the paradigm of recognition, I believe doing so precludes more exhaustive examinations of the participatory elements of environmental justice. Furthermore, Schlosberg has elegantly explained that establishing more robust forms of authentic and meaningful citizen participation can positively influence both distribution and recognition. While there is a certain degree of overlap among the principles of

\footnotetext{
${ }^{53}$ Iris Marion Young, “Justice and the Politics of Difference." (Princeton University Press, New Jersey: 1990) at 3.
} 
recognition and procedure, this last paradigm directly demonstrates that citizens are "structurally excluded from the possession of certain rights within a given society." ${ }^{54}$ Thus, procedural concerns tend to focus more on the particular ways and forums in which citizen rights are ignored, while the paradigm of recognition focuses more on the practical and theoretical implications thereof. Thus, analyzing procedural concerns is extremely important as they demonstrate the oppression that citizens face in traditional forums for participation, or the complete lack of the forums themselves.

Alice Kaswan frames the concept of procedural justice differently, and defines it as political justice. She explains that political injustice is caused through the disproportionate application of government policy, unjust or biased siting decisions, and a lack of enforcement after particular siting decisions have been reached. ${ }^{55}$ Although Kaswan uses different terminology in her conceptualization of procedural injustices, her arguments tend to mirror those of Schlosberg and Young. However, her practical approach to the subject engenders the most obvious examples of the inherent power imbalances that exist during environmental decisionmaking processes. For instance, Kaswan explains that increased citizen participation may 'force' government and industry to "consider all interests equally." have already been reached, which were absent any type of formal citizen engagement, can and should be challenged, both through litigation and political organization. Thus, when a community believes that a particular decision-making process was unjust, insofar as the decision affected them and they were not consulted, the process itself should become the mechanism for

\footnotetext{
${ }^{54}$ Axel Honneth, "Integrity and Disrespect" Principles of a Conception of Morality Based on a Theory of Recognition." (Political Theory, Vol. 20, No. 2: 1992) at 190.

${ }^{55}$ Alice Kaswan, "Environmental Justice: Bridging the Gap Between Environmental Laws and Justice." (The American University Law Review, Vol. 47, No. 221: 1997) at 236.

${ }^{56}$ Ibid at 251.
} 
challenging the injustice. ${ }^{57}$ She argues that this type of retroactive engagement became possible through President Clinton's Executive Order 12 898. This order pursued mechanisms intended to improve distributional outcomes, and include environmental justice principles within decisionmaking processes. Environmental justice advocates do believe that the two pronged approach adopted in in Executive Order 12898 "(1) the compilation and consideration of demographic information, and (2) the improvement of public participation mechanisms - will result in fairer decision-making." 58

One example of this retroactive engagement occurred in a largely Latino community in Kettleman City, California, after the company Chemical Waste Management attempted to construct a hazardous waste incinerator. ${ }^{59}$ Luke Cole, the attorney for the community, and outspoken environmental justice advocate, argued that while the company provided the community with necessary documents, they failed to translate them into Spanish, the only language for over $40 \%$ of the residents. The courts agreed with Cole, and explained that the failure to translate documents precluded many citizens from "their statutory right to participate. ${ }^{160}$ Kaswan presents this example as a way of demonstrating how she feels procedural justice, or process in general, is inherently linked with political justice. Thus, while Kaswan's use of the term political justice refers to both recognition, and procedure, I believe that grouping them together may prohibit more exclusive theoretical inquires into each paradigm.

The procedural aspect of environmental justice attempts to rectify the almost complete lack of opportunity for citizen participation within decision-making processes. The rules that govern citizen participation in the first place are designed to limit democratic principles.

\footnotetext{
${ }^{57}$ Ibid at 252.

58 Ibid.

${ }^{59}$ Luke W. Cole, \& Sheila R. Foster "From the Ground Up: Environmental Racism and the Rise of the Environmental Justice Movement.” (New York University Press, New York: 2001) at 94.

${ }^{60}$ Supra note 55 at 253.
} 
Consider that those who are most affected by a particular environmental decision, are the least likely to have any contribution in the making of the decision itself. In other words, citizens who will undergo a type of environmental change, as a result of a particular siting decision, are generally excluded from the processes that inform those decisions in the first place.

Additionally, identifiable minorities and communities of lower socio-economic status are disproportionately affected by these types of injustices.

The participatory aspects of justice are perhaps the only universally acceptable conceptualizations of justice. In other words, while distributional and recognitionary considerations cannot be defined in collective terms, participation itself is inherently compatible with varied and multidimensional notions of justice. Establishing opportunities for real and authentic citizen participation can limit or rectify the power imbalances in which environmental decisions are made by forcing institutions to consider individual concerns. Furthermore, as mentioned above, participation itself has the ability to "address issues of distribution and cultural misrecognition." ${ }^{161}$ Thus, for the purpose of my research I place a greater emphasis on the establishment of environmental justice principles through procedural aspects thereof.

\section{[3.4] A More Comprehensive Notion of Justice}

The purpose of examining the environmental justice frame and its paradigms was to illustrate the importance of establishing a pluralistic conception of justice. Furthermore, it is critical to understand that a multifaceted approach to justice is in fact desirable and that there is a certain amount of interconnectivity among different aspects of justice. In other words, distribution and recognition should not be seen as competing choices, rather they should be

${ }^{61}$ Supra note 40 at 85. 
formulated and considered together to establish the most holistic conception of justice possible. ${ }^{62}$ Thus, those in favour of distributional considerations cannot ignore procedural elements and vice versa. Accordingly, as Schlosberg explains "the relationship between justice as equity and justice as recognition is played out in the procedural realm, because barriers in both areas can hinder the ability of individuals and communities to participate. ${ }^{.63}$ In other words, when one examines justice as more than a simple lack of equitable distribution and includes elements of recognition, ultimately a connection must be made to the democratic processes that engender these circumstances. Thus, in my opinion, the only authentic definition of justice is one that includes all the elements detailed above.

The argument I am making here will be critical in understanding the connections that I make between deliberative democracy and voluntary environmental programs later in my thesis. Principally, it is government and corporate institutions that encumber equity and recognition, which results in a lack of participation in political spheres. ${ }^{64}$ This combination of circumstances works together to produce injustice, which is exactly why environmental justice must be defined within the same pluralistic frame.

In the next chapter I will take a closer look at the participatory elements of environmental justice, specifically focusing on recognition and procedure. Furthermore, I will introduce the debate between local lay knowledge, and expert knowledge, and situate it within an environmental justice frame. Additionally, I will build upon the theoretical conceptualizations I have discussed thus far, by demonstrating how they work in practical contexts. I will examine two case studies intended to illustrate the potential benefits associated with adopting environmental justice principles. Additionally, using these examples will allow me to engage

${ }^{62}$ Supra note 36 at 5 .

${ }^{63}$ Supra note 40 at 86.

${ }^{64}$ Ibid. 
with the nimbyism argument, often proposed by critics to increased citizen participation. Lastly, I will discuss in greater detail the forums in which citizen participation takes place, in order to demonstrate the need for increased recognitionary and procedural elements. 


\section{Chapter 4:}

\section{The Importance of Citizen Participation}

The purpose of this chapter is to take a closer look at the participatory elements of environmental justice. Doing so will provide a more practical perspective from which I can begin to illustrate the potential benefits that citizen participation may have on voluntary environmental programs.

In order to accomplish this, I will begin by examining the discourse surrounding expert vs. lay knowledge. This analysis will play a crucial role in determining the importance of citizen participation, and will additionally illustrate the inherent power imbalances within environmental decision-making processes. Furthermore, I will explain the importance of local expert knowledge and the positive impact it can have on individuals, communities, and environmental policy in general. In order to illustrate the importance of this last point, I use a case study from Swan Hills Alberta that demonstrates how citizens can play fundamental roles in policy development and implementation. Lastly, I will include an analysis of current and possible future forums for citizen participation and how they may affect the move towards ecological democracy as a whole. Consequently, this analysis allows me to situate, in a practical manner, citizen participation within formal legal structures. These considerations will help explain why citizen participation within environmental decision-making processes has been fundamentally avoided and furthermore what a reversal thereof could mean for alternative modes of regulation, namely voluntary environmental programs.

There exists an obvious tension and divide between scientific knowledge, or so-called professional expertise and democratic governance and decision-making, specifically within 
environmental discourses. ${ }^{1}$ The 'rationality' of the scientific community has traditionally trumped citizen's rights to participation in environmental decision-making processes. The right to access to information, access to meaningful and authentic recognition and participation, and the consistent efforts to ignore local expert knowledge are generally rooted in dialogues that put the economy first. Consequently, a citizen's capability to engage within environmental decisionmaking is restricted by limiting relevant criteria within potential forums to "the market and state administrative agencies."2 Governments and corporations, who generally control the expert knowledge and the resources to employ it, assert a 'neutrality' in which those experts reach their decisions. However, even if one were to believe the decisions were based on purely objective criteria, this is not the only element necessary to foster ecological democracy. Citizens need the ability and opportunities to dispute decisions and call into question the methods in which environmental decisions are reached.

My framework for analyzing citizen participation is broken up into five sections. First, I begin by establishing the relationship that currently exists between citizens and experts within environmental decision-making processes. This analysis is extremely important as it allows me to examine the inherent and obvious power imbalances that exist during these dialogues. Consequently, in section two, I redefine citizens as local experts. I describe the important and unique knowledge they posses as local expert knowledge, and explain the potential benefits of relying on this information during environmental decision-making. Third, I situate citizen participation within an analysis of ecological democracy. In other words, I utilize my arguments from the previous chapter to describe, in a more practical manner, how citizen participation

\footnotetext{
${ }^{1}$ Frank Fischer, "Citizens, Experts, and the Environment." (Duke University Press, London: 2000) at ix.

${ }^{2}$ Robert J., Brulle, \& Jonathan Essoka, "Whose Environmental Justice? An Analysis of the Governance Structure Environmental Justice Organizations in the United States." in "Power Justice and the Environment A Critical Appraisal of the Environmental Justice Movement." (The MIT Press, London: 2005) at 207.
} 
affects ecological democracy as a whole. In section four, I build upon this practical conceptualization by using a case study, which elegantly demonstrates the importance of encouraging and maintaining citizen participation throughout environmental decision-making processes, insofar as nimbyism is concerned. I have chosen this particular case study as it illustrates the potential benefits of utilizing citizen participation in terms of economic considerations, environmental protection, and the establishment of ecological democracy. Lastly, I examine the forums in which citizen participation occurs, and how it may be improved. Additionally, this last section allows me to ground my analysis within a framework of law, which is extremely important, as it is a necessary step towards the formulation of a policy mix approach, which I argue in favour of in chapter five.

\section{[4.1] Citizen Participation vs. Expert Knowledge}

Expert knowledge and citizen participation have not enjoyed a relationship of trust and mutual gain. In fact the two are almost always identified as separate and competing discourses that create a divide between those who are deemed to be experts and those who are not. Thus, the question which must be addressed is, "can democracy thrive in a complex technological society?"3 The answer to this question is not an obvious one, and requires a complex analysis of participatory elements and their effects on ecological democracy.

Fischer asserts, that even though democracy remains the undisputed political philosophy in Western societies, "the prospects of meaningful citizen participation... are neither clear nor obvious." Accordingly, in a society that places so much emphasis on democracy, it is odd that citizen participation and deliberation, arguably democracies core components, are so highly

\footnotetext{
${ }^{3}$ Ibid at 1 .
} 
inaccessible in the environmental sphere. ${ }^{4}$

A possible reason for this may be that in our technocratic society, science can be symbolically defined as a type of weapon, particularly within an environmental justice frame. It is something that can be strategically utilized by those with the necessary resources to administer it, in order to restrain or limit the controversies surrounding decisions, which affect the environment, and in turn certain populations. ${ }^{5}$ In essence, scientific knowledge can be used to de-politicize issues, which tends to remove them from the public sphere in the first place. ${ }^{6}$ It is my intention to argue the opposite. I believe that expert knowledge, which informs environmental policy decisions should not remove itself from the public sphere, but rather from the partisan political one. ${ }^{7}$ This would limit the opportunity for political biases to be injected within environmental-decision making processes. Accordingly, it is this relationship between experts and policy makers that should be called into question through the widening of procedures intended to foster citizen participation in order to critically examine environmental policy decisions and reduce environmental injustices. ${ }^{8}$

To this end, there has recently been a growing concern within Western societies to question the authority of the professional expert and his/her alleged mastery in a specific field,

${ }^{4}$ Ibid.

${ }^{5}$ Barbara L., Allen, "Environmental Justice and Expert Knowledge in the Wake of a Disaster." (Social Studies of Science, Vol. 37, No. 10: 2007) at 103

${ }^{6}$ Ibid.

${ }^{7}$ While I understand that environmental justice and considerations of local expert knowledge are inherently linked within a political framework, I believe the focus of environmental discourses should be discussed within the public sphere, absent of partisan interference. I use Habermas' definition of the public sphere which he states is the "realm of our social life" where public opinion can be formed, and access to this process is granted to all citizens. Furthermore, "citizens act as a public body when they confer in an unrestricted fashion-that is, with the guarantee of freedom of assembly and association and the freedom to express and publish their opinions-about matters of general interest." Thus, the public sphere is dependent on the process of participation, and expert knowledge should seek to aid and promote public sphere autonomy. For more information see Jargen Habermas, "The Public Sphere: An Encyclopedia article (1964)." (The New German Critique No. 3, 1974) at 49.

${ }^{8}$ Sheila Jasanoff, "Technologies of Humility: Citizen Participation in Governing Science." (Humanities, Social Sciences and Law, Vol. 41, No. 3: 2003) at 225. 
particularly within environmental discourses. ${ }^{9}$ Critics of the increased technocratization of the state maintain that experts "misappropriated their social status and specialized knowledge to serve both their own interests and those of elites intent on maintaining their dominance over the rest of society."10 In order to examine this statement, it is important to situate and explain the 'battle' between experts and citizens within practical situations.

When experts are called into an environmental decision-making process they are required to quantify the potential risks to a specific target and/or specific sectors of the population. This is known as risk assessment, which has been the prevailing mechanism that governments and corporations utilize in order to measure environmental health effects. ${ }^{11}$ Because of the inherent structure of risk assessments they inevitably result in a cost-benefit analysis originating from the source of the proposal, extending to those who will be affected by it. Ideally, throughout this process and quantification of risk, there will exist a dialogue between policy makers and the affected community. However, the public is often absent from this quantification and subsequent decision-making process. ${ }^{12}$ Furthermore, Frank Fischer argues that risk assessment, in general, only "heighten[s] the conflict between citizens and experts." ${ }^{.13}$ He explains that communities and individuals are often unconvinced by risk assessments, as they are inevitably formed through processes, which seek to advance the objectivity of the technocratic method, thus effectively eliminating participatory opportunities. In addition, the scientific terminology used in expert judgements may exclude certain populations from understanding why certain

\footnotetext{
${ }^{9}$ Supra note 1 at 29.

${ }^{10}$ Ibid at 31.

" Jason Corburn, "Street Science, Community Knowledge and Environmental Health Justice." (The MIT Press, London: 2005) at 25.

${ }^{12}$ Ibid at 26.

${ }^{13}$ Frank Fischer, "Citizen participation and democratization of policy expertise: From theoretical Inquiry to practical cases." (Policy Sciences, Vol. 26, No. 3: 1993) at 175.
} 
conclusions have been reached. This serves to potentially render citizen concerns obsolete in forums that require a firm adherence to scientific principles. ${ }^{14}$

In essence, the forums and their organizational manner, which inform environmental decision-making processes, are some of the very structures that perpetuate environmental injustices. These forums and organizations attempt to portray the average citizen as receiving an authentic opportunity to convey personal or community values and beliefs or opinions on environmental practices. However, in my opinion, this is an unrealistic interpretation at best. The dialogue at these hearings "takes place against the backdrop of large asymmetries of social, institutional and economic power." ${ }^{\text {"15 }}$ Consequently, the forums for open discussion themselves foster the almost adversarial divide between citizen and expert. They expose differing capacities and confidence levels, which make obvious not only the divide between experts and layperson, but also the gap of representation across class, gender, and ethnicity. ${ }^{16}$ Thus, even in settings where there is supposedly a level of authentic citizen participation, systematic differences still create division, and perpetuate the superiority of experts and the elite. ${ }^{17}$ It is precisely in these settings that I believe a firm adherence to the principles of environmental justice is necessary. More specifically, by using procedural elements one can begin to systematically combat the power imbalances by ensuring a more level playing field for citizens and experts.

Nevertheless, there are still those that question the potential beneficial role that citizen participation may have within environmental decision-making processes. These critics, while still adamant about Westerns societies unwavering democracy, question the role of the 'lay'

\footnotetext{
${ }^{14}$ Supra note 11 at 26.

15 John, O'Neill, "Deliberative Democracy and Environmental Policy," in "Democracy and the Claims of Nature," (Rowman \& Littlefield Publishers Inc., Oxford: 2002) at 258.

${ }^{16}$ Ibid.

${ }^{17}$ The term elites is referring to individuals, or groups, who are economically advantaged and consequently have resources that may not be available to everyone, thus creating power imbalances insofar as environmental decision-making is concerned.
} 
citizen to contribute to better environmental decision-making. Their arguments, as mentioned above, revolve around the assumption that given the neutrality or objectivity in which expert discourse is found, why is it not favourable to simply trust in their decisions? Fischer disagrees with these criticisms, and identifies three overarching principles that demonstrate the inherent value that citizen participation establishes. First, Fischer explains that "citizen participation gives meaning to democracy."18 In other words, democracy as a whole cannot exist without citizen participation, as they are dependent upon each other. Second, he asserts that citizen participation legitimizes the development and implementation of policies by allowing for authentic and individual input. Lastly, he believes that citizen participation does in fact contribute to the development of expert knowledge, as lay knowledge possess intricacies not necessarily available to experts unfamiliar with a specific area. ${ }^{19}$ This last point is of key importance and will be explained at length below.

Additionally, critics of increased citizen participation are sceptical insofar as they question the willingness of communities to accept certain, perhaps unwanted facilities, stemming from increased 'nimbyism. ${ }^{20} 21$ In other words, they believe that given the opportunity most citizens will resist the siting of certain unwanted factories or industries within their own communities in favour of locating them elsewhere. As a result of this resistance, critics tend to believe that a neutral third party would be generally required regardless, in order to help determine contested siting decisions. Accordingly, I will situate nimbyism within a conceptualization of environmental justice later in the chapter.

${ }^{18}$ Supra note 1 at 2 .

${ }^{19}$ Ibid.

${ }^{20}$ Supra note 13 at 173 .

${ }^{21}$ The term nimbyism refers to 'not in my backyard.' It is in reference to citizens accepting that certain programs, policies, or facilities may provide benefits to society, so long as they are not situated within their own community, and rather established or implemented elsewhere. For more information see Patrick Devine-Wright "Beyond NIMBY ism: Towards an Integrated Framework for Understanding Public Perceptions of Wind Energy." (Wind Energy, Vol. 8, No. 2: 2005) at 126. 
In conclusion, the divide between citizen participation and expert knowledge is fundamentally governed by those that occupy positions of power. Even if the public is given a forum to address their concerns, the power imbalances within these forums could not be more obvious. ${ }^{22}$ These public hearings are often tightly controlled, by the geographic location of the hearings themselves and by limiting discussions to certain topics. Furthermore, there also exists an obvious partiality towards expert knowledge and opinions within these venues. Thus, the separation between expert and layperson further exacerbates environmental injustices by systematically denying authentic participation to citizens and attempting to replace them with a type of 'show' hearing. Unfortunately, when citizens that have participated in these hearings realize that real and authentic participation may have been denied, it can result in feelings of anger, inadequacy, and self-doubt.

\section{[4.2] The Citizen as a Local Expert}

This section of the chapter elaborates on the previous one, insofar as it discusses in more detail the influence the separation between expert and layperson has had within environmental justice discourses. The distinction between expert knowledge and lay knowledge has been prevalent in both the Canadian, and to a lesser extent, the American contexts in regards to Native populations. Linda Robyn argues that "American courts have many times in the past criminalized, whether consciously or not, traditional knowledge" held by Native peoples. ${ }^{23}$ She explains that it is not uncommon for native people to be arrested and subsequently silenced, when they protest against environmental degradation at the hands of government or corporations. Additionally, Robyn argues that purposely deciding to ignore local knowledge, not just of Native

\footnotetext{
${ }^{22}$ Mary Richardson, \& Joan Sherman, \& Michael Gismondi, "Winning back the Words, Confronting Experts in an Environmental Public Hearing." (Garmond Press, Toronto: 1993) at 9.

${ }^{23}$ Linda Robyn, "Indigenous Knowledge and Technology: Creating Environmental Justice in the Twenty-First Century." (The American Indian Quarterly, Vol. 26, No. 2: 2002) at 198.
} 
peoples, but also local communities in general, is a grave environmental injustice, as it is detrimental to both everyone and everything. ${ }^{24}$ John Borrows also notes the systematic delegitimation of Indigenous knowledge through the consistent concealment of its valuable insights from the public sphere. He argues that "democratic institutions repress Indigenous participation, degrade their environments, and thereby hinder the extension of knowledge about how to coexist with the environment."25 Additionally, local expert knowledge is not confined to Aboriginal people, and additionally not to only that which is natural. Communities and individuals in metropolitan settings also possess local expert knowledge, often through "their experience of living with multiple environmental hazards and chronic diseases."26

Not only do laypersons have the possibility to be considered as local experts, due to their local knowledge offering unique insights into local environmental issues. Additionally, Fischer explains that citizens are "much more able to deal with complicated social and technical questions than the conventional wisdom generally assumes. ${ }^{27} \mathrm{He}$ argues that there is no reason to doubt citizen's capability of dealing with scientific issues and points out, that traditionally, when groups are confronted with significant problems they tend to demonstrate a great deal of rational and informed behaviour if given the opportunity. This is a significant finding, as local communities, particularly the most marginalized populations, increasingly find themselves in situations where they both intend and need to speak for themselves and for their rights to environmental justice. In these types of situations communities often rely on "their firsthand

\footnotetext{
24 Ibid.

${ }^{25}$ John Borrows, "Living Between Water and Rocks. First Nations, Environmental Planning and Democracy." (University of Toronto Law Journal, Vol. 47, No. 4: 1997) at 423.

${ }^{26}$ Jason Corburn, "Combining Community-Based Research and Local Knowledge to Confront Asthma and Subsistence-Fishing Hazards in Greenpoint/Williamsburg, Brooklyn, New York." (Environmental Health Perspectives, Vol. 110, No. 2: 2002) at 241.

${ }^{27}$ Supra note 1 at 148.
} 
experience-here called local knowledge—-to address the environmental risks they face."28

While I am not suggesting that relying on local knowledge will solve all, or even most, environmental problems, utilizing its insights will certainly help inform environmental policy and thus play a significant role in environmental justice discourses related to the inception of voluntary environmental programs.

\section{[4.3] Defining Local Experts and Local Knowledge}

In order to understand the significance of local knowledge as expertise, it is necessary to first define and situate local knowledge within an environmental justice framework. Just as the divide between citizen and expert exists within environmental justice, so too does a divide exist between the knowledge either entity produces. Not surprisingly, this is problematic in many of the same ways that citizens are defined as separate from experts, as the categories themselves seek to limit lay knowledge to the realm of unscientific irrational logic. ${ }^{29}$ However, I intend to avoid this distinction and not treat both the 'professional' and 'local' as monolithic components, apart from examining the existing distinctions and definitions themselves. ${ }^{30}$

Local knowledge can be defined as "knowledge that does not owe its origin, testing, degree of verification, truth, status, or currency to distinctive . . professional techniques, but rather to common sense, casual empiricism, or thoughtful speculation and analysis."31 Thus, local knowledge is information which can only be gained by the relationship one has with certain geographical contexts, and the meanings or understandings inherent to those interpreting a proposed change. Therefore, local knowledge is held by individuals and communities alike, who

\footnotetext{
${ }^{28}$ Jason Corburn, "Bringing Local Knowledge into Environmental Decision Making. Improving Urban Planning for Communities at Risk." (Environmental Management, Vol. 29, No. 4: 2002) at 451.

${ }^{29}$ Frank Fischer, "Citizens and Experts in Risk Assessment: Technical Knowledge in Practical Deliberation." (Technikfolgenabschätzung Vol. 13, No. 2: 2004).

${ }^{30}$ Ibid at 452.

${ }^{31}$ Ibid.
} 
generally share culture, religion, norms, and values. ${ }^{32}$ Linda Robyn notes that local knowledge within the Native context is generally maintained within the individual and community memories, and expressed or retold to future generations in the form of stories, songs, and dances. Thus, Native knowledge is generally a type of oral narrative, often containing very intricate and specific details about environmental considerations within their lands. ${ }^{33}$

Local knowledge does not consist of simple assumptions or speculations from community members, but rather it is formulated through a set of first hand experiences acquired over years or even generations. ${ }^{34} 35$ Thus, it is incorrect to assume that simply because local knowledge does not conform to the scientific method, that it does not contain valuable insight and information within the contexts it is applied. As previously mentioned, many of the intricacies contained within local knowledge are unique to those people and important factors regarding environmental planning and decision-making can be overlooked if those local experts are ignored and not consulted.

\section{[4.4] The Benefits of Local Expert Knowledge}

The potential benefits of increased reliance on local expert knowledge are perhaps most obvious within the relationships between Native communities and the environment. The following example demonstrates that citizens can effectively be used as a resource, in terms of their expert local knowledge, which can greatly affect the procedural realm of environmental decision-making. ${ }^{36}$

\footnotetext{
32 Ibid.

${ }^{33}$ Supra note 23 at 200.

34 Ibid.

${ }^{35}$ This is particularly true of native knowledge, but does apply to other sectors of the population as well.

${ }^{36}$ Supra note 25 at 437.
} 
John Borrows example regards a local Native population and "the Hay Island proposal," which was the proposed and eventual development of a housing project within their traditional lands. Borrows explains that the local expert knowledge possessed by the Anishinabe could have contributed "concrete and valuable information to examine... sustainability, such as water quality, fish habitat, deer migration, mainland connections, burial grounds and the social and cultural effects of siting new villages." ${ }^{37}$

For example the diversity of plant life in the region was not taken into consideration when proposing the site on which to build. Unfortunately for the Anishinabe, this would have had serious detrimental effects on the health and culture of the tribe. The Anishinabe "have very specific knowledge about plants and animals because of their long dependence on these resources. ${ }^{38}$ In addition, almost all Anishinabe villages have a Medicine Society in their communities, known as the Midewewin. This central institution collects information in regards to the different uses of plants in certain areas, and considering its prevalence throughout the Anishinabe lands, it enjoys a "valuable collection of formulas to produce healing medicines from the many plants found around Neyaashinigmiing."39

However, when deciding on a development site, the Anishinabe were not consulted. In addition, "the developer's proposal contained no inventory of plants on Hay Island."40 Had the Anishinabe been consulted they could have "identified significant plants and thereby strengthened the environment around the proposal by retaining important fauna and flora., $\$ 1$ Thus, as Deborah McGregor points out, the relationship the Anishinabe share with nature makes them capable of informed decision-making within processes that effect the environment,

\footnotetext{
${ }^{37}$ Ibid.

38 Ibid at 439.

${ }^{39}$ Ibid at $\mathbf{4 4 0}$.

${ }^{40} \mathrm{Ibid}$ at 441 .

${ }^{41}$ Ibid.
} 
regardless of their characterization as experts or not. She asserts that learning does not need to originate from books, nor does that type of knowledge trump that of local expert knowledge. ${ }^{42}$ Interestingly, Frank Fischer asserts that the knowledge citizen's possess differs from that of scientific experts and may actually be more "attuned to the normative realities of the social world. ${ }^{, 43}$ This point is extremely important as it seemingly reverses the hierarchy of knowledge that 'should' be relied upon in terms of environmental decision-making. Regardless of hierarchies, I believe a mixed approach where scientific experts work with, or for a community, and help them in the way they process and understand complex environmental issues would produce the most advantageous outcomes. It is precisely this mixed approach that I will explain later in the chapter using an example from Swan Hills Alberta.

Local knowledge provides a type of information that is uninhibited by technocratic preconceptions that tend to permeate risk assessments and subsequent decision-making processes. It is informed by people living in an environment that will experience a type of change and as such, is critical in the promotion of environmental justice. Judith Petts explains that "expertise is inextricably linked to its source." the only element considered in environmental siting decisions through the manipulation of expert discourse. This occurrence epitomizes the inherent power imbalance that exists during environmental decision-making processes, as expert knowledge tends to trump lay knowledge, and furthermore its recommendations can be distorted to fit certain pre-determined intentions.

Fischer explains that local knowledge can be used as a mechanism to combat these power imbalances insofar as it can potentially shift predominant discourses away from the unrestricted

\footnotetext{
${ }^{42}$ Deborah McGregor, "Honouring Our Relations: An Anishinabe Perspective on Environmental Justice." in "Speaking for Ourselves Environmental Justice in Canada." (UBC Press, Vancouver: 2009) at 33.

${ }^{43}$ Supra note 29 at 90.

44 Judith Petts, "The public-expert interface in local waste management decisions: expertise, credibility and process." (Public Understanding of Science, Vol. 6, No. 4: 1997) at 359.
} 
reliance on formal scientific knowledge, and its definitional superiority. ${ }^{45}$ In addition, he explains that local knowledge cannot be depicted or defined as simplistic, or primitive. Rather, he asserts that it may provide contexts for mobilization, and more importantly contribute inherently valuable information to environmental decision-making processes. ${ }^{46}$ Thus, citizen participation, and the promotion and recognition that local expert knowledge contributes valuable insights and information, are fundamental concepts to the facilitation of environmental justice and ecological democracy.

However, I am not suggesting that increased reliance on local knowledge alone will solve environmental injustices. Rather, I am arguing that a holistic approach, one that seeks to incorporate both expert knowledge and local knowledge, will aid in the facilitation of environmental justice and in turn environmentally sustainable decision-making. This point is also illustrated in the case study from Alberta below.

\section{[4.5] Increased Citizen Participation and Ecological Democracy}

The previous sections of this chapter detailed and examined the discourses surrounding citizen participation and expert analysis. In this section I expand and elaborate on how increased citizen participation may foster greater ecological democracy and in turn environmental justice.

As suggested in the previous chapter, discussions about environmental justice have often been confined to the distributional realm; which is simply defined as the unequal distribution of environmental risks and burdens. However, communities themselves have concerns that transcend this distributional paradigm. ${ }^{47}$ For instance, as Iris Marion Young explains "the primary question of justice... concerns not the fairness of the distribution of burdens, but rather

\footnotetext{
45 Supra note 1 at 195.

${ }^{46}$ Ibid at 196.

${ }^{47}$ Peter D. Swan, "Environmental Justice and Minority Ecological Rights." In “Do we need Minority Rights? Conceptual Issues." (Martinus Nijhoff Publishers, London: 1996) at 187.
} 
the justice of the decision-making structures. ${ }^{, 48}$ Thus, environmental justice concerns are particularly prevalent at the procedural realm, and arguably, this is where discussions of ecological democracy should be situated. In this regard, research on participation seeks to establish the role of expert as a facilitator of citizen empowerment. In other words, rather than abuse hierarchical status to form decisions independently, an expert should use his knowledge to help citizens "learn, clarify, and decide for themselves." experts could potentially contribute to the opportunity for citizens to participate meaningfully in environmental decision-making processes.

As previously explained, Schlosberg situates his arguments across three archetypes, namely equity, recognition, and procedure or participation. He argues that each component is necessary when discussing environmental justice, and that each has the potential to be integrated comprehensively into definitions thereof. ${ }^{50}$ For the purpose of this thesis, Schlosberg's arguments regarding recognition and procedure are particularly valuable as I can use them to position citizen participation within an ecological democracy framework, which can be used to examine and assess new modes of environmental regulations. Establishing authentic and meaningful citizen participation can be used as a mechanism, which affects all the archetypes, insofar as one can begin to move away from discourses or arenas that tend to systematically deny, or devalue, local knowledge and self-empowerment.

This devaluation plays a significant role in the individual and community struggles for environmental justice as the concept of recognition is generally linked with identity.

\footnotetext{
${ }^{48}$ Iris M. Young, "Justice and Hazardous Waste" in "The Applied Turn in Contemporary Philosophy." (Bowling Green University, Bowling Green: 1983) at 175.

${ }^{49}$ Supra note 13 at 176.

${ }^{50}$ David Schlosberg, "The Justice of Environmental Justice: Reconciling Equity, Recognition, and Participation in a Political Movement." in "Moral and Political Reasoning in Environmental Practice." (The MIT Press, London: 2003) at 92.
} 
Consequently, devaluing recognition simultaneously devalues a citizen's perception of self identity. ${ }^{51}$ More specifically, when an individual is systematically denied participatory rights there exists an implication that said individual "is not being accorded the same degree of moral responsibility as other members of society." ${ }^{\text {,52 }}$ Thus, having one's rights denied could result in a self-stigmatization of being incapable of forming autonomous decisions. Accordingly, battles for recognition have been mirrored, or can be conceptualized, in terms of their affect on projections or interpretations of self-empowerment and self-respect. ${ }^{53}$ It is this selfempowerment that is essentially the core objective of citizen participation, and that which forms the conduit to increased ecological democracy.

The procedural model in Schlosberg's environmental justice concept is generally linked to the participatory role of citizens within the realm of environmental decision-making. He argues that "broader and more authentic public participation is often seen as the tool to achieve both distributional equity and political recognition." 54 Thus, when authentic participation is denied, there can be a loss of self-respect and coupled with a lack of recognition, there can be a corresponding drop in the willingness to participate in the first place. ${ }^{55}$ Therefore, environmental justice and ecological democracy need to be approached in a way that incorporates "democratic decision-making procedures as an element and condition of social justice."\$6

To sum up, citizen participation is the core component necessary to influence ecological democracy. In other words, "communities of people suffering ecological injustices must be

\footnotetext{
${ }^{51}$ Ibid at 83.

32 Axel Honneth "The Struggle for Recognition: The Moral Grammar of Social Conflicts." (Polity Press, Great Britain: 1995) at 133.

53 Ibid at 134.

${ }^{54}$ Ibid at 84.

55 Ibid.

56 Ibid.
} 
afforded greater participation in... decision-making processes." ${ }^{57}$ Thus, the discussion earlier in the chapter about citizen vs. expert dichotomies and the systematic undermining of local expert knowledge provides a context and example of how democracy tends to be hidden, or subdued, in the environmental sphere. Ecological democracy is primarily concerned with the incorporation of citizens and their knowledge into environmental decision-making processes. ${ }^{58}$ Furthermore, it attempts to combine environmental values with those of participatory forms of democracy in a collaborative framework. In this regard, environmental justice serves as a type of channel that endeavours to form connections between ecological democracy and participation through the invigoration of community activism..$^{59}$

\section{[4.6] Reconceptualising Nimbyism}

As previously mentioned, the concept of nimbyism has hampered the inclusion of citizen engagement within decision-making processes. In other words, critics to citizen participation argue that utilitarian approaches are 'necessary' as individual communities will tend to reject proposed industrial operations within their own geographic areas. This has led critics to believe that including citizens will result in a policy or development 'gridlock,' where communities will simply try to push unwanted programs or facilities beyond their own boarders. Accordingly, the threat of nimbyism effectively predetermines the existence of a competitive discourse between citizens and experts.

While nimbyism is not confined to any particular area of public concern, it is perhaps most common or widespread in cases with a potential for severe environmental degradation. This

\footnotetext{
${ }^{57}$ Daniel Faber, “The Struggle for Ecological Democracy and Environmental Justice. Environmental Justice Movements in the United States." (The Guilford Press, New York: 1998) at 1.

${ }^{58}$ Ross E. Mitchell "Green Politics or Environmental Blues? Analyzing Ecological Democracy." (Public Understanding of Science, Vol. 15, No. 4: 2006) at 459.

${ }^{59}$ Ibid at $\mathbf{4 6 2}$.
} 
widespread fear most likely stems from the massive scale of environmental disasters witnessed in the last four decades, including oil spills, nuclear meltdowns, chemical contamination of food and water sources, and the increased understanding of the link between pollution and human health. ${ }^{60}$ Consequently, the establishment of unwanted facilities in individual communities has been an increasingly difficult and adversarial task. However, Frank Fisher and Barry Rabe have elegantly described a situation in Swan Hills Alberta, where they demonstrate that nimbyism is perhaps best negated, paradoxically, through increased citizen participation rather than the denial thereof. ${ }^{61}$

This example concerns the proposed siting of a hazardous waste incinerator in Swan Hills Alberta in 1987, and the attempts by the Canadian government to deal with nimbyism directly in the public sphere. At that time, as was similar to many other jurisdictions, including British Columbia, Michigan, North Carolina, Quebec and Saskatchewan, Alberta approached the siting and construction of a hazardous waste incinerator through a market-based strategy.

Unsurprisingly, "that approach met a familiar political response as Alberta's market-driven efforts resulted in a pair of private site proposals that were spurned in short order by fierce local opposition. ${ }^{, 62}$ This failure resulted in the establishment of a Hazardous Waste Management Committee that was tasked with devising a novel approach to hazardous waste siting decisions. Ultimately the committee provided a framework for a system that was built around the idea that only communities who volunteered to host a site would be considered. Additionally, measures were put in place, which assured a continued relationship between industry, government and

\footnotetext{
${ }^{60}$ Supra note 13 at 174

${ }^{61}$ Ibid at 176.

${ }^{62}$ Barry G. Rabe, "Beyond the NIMBY Syndrome in Hazardous Waste Facility Siting: The Albertan Breakthrough and the Prospects for Cooperation in Canada and the United States." (Governance: An International Journal of Policy and Administration, Vol 4, No. 2: 1991) at 190.
} 
citizens in regards to this particular siting process. ${ }^{63}$ Thus, by working collaboratively, government, industry, and citizens were able to establish a comprehensive and informed participatory process, which reduced conflict over siting decisions and alternatively fostered meaningful negotiations. Unexpectedly, both government and industry preferred the idea of negotiations with individual communities, and communities working together, over unilateral decision-making as they began to understand the potential benefits. The end result achieved was impressive as the "provincial government... managed through a collaborative venture to site, build, and operate the only major new waste facility in North America in more than a decade.,64 The success of this particular example is largely dependent on the fact that the Alberta government utilized a siting strategy that incorporated the participatory and procedural elements I examined in the previous chapter. For instance, a common tool when making siting decisions is constraint mapping. This method uses a process of elimination to rule out specific areas of land, based on various economic, environmental, social, and political issues or concerns. However, contrary to other jurisdictions which used this approach, the Albertan government relied heavily on public participation to build its map. ${ }^{65}$ Thus, from an environmental justice standpoint, citizens were recognized for the knowledge that they were able to provide. Furthermore, by aiding in the construction of the map, citizens were actively involved in the procedural realm. Overall, during this siting process, there were approximately 120 meetings that were held, which offered citizens the opportunities to voice concerns and have questions answered. ${ }^{66}$

\footnotetext{
${ }^{63}$ Bid.

${ }^{64}$ Supra note 13 at 176.

${ }^{65}$ Supra note 62 at 191.

${ }^{66}$ Ibid.
} 
Additionally, citizen participation was also fostered and encouraged beyond the initial siting process. Upon request communities were given detailed risk assessments, which they could use as a resource to determine, autonomously, if a waste incinerator would be beneficial to them. Overall, 52 of a possible 70 communities requested further information regarding the risks associated with hosting the development. ${ }^{67}$ Of the original 52 communities, 14 expressed further interest, however based on closer analysis, 9 of those communities were removed from contention due to environmental concerns or public dissent. This left five communities, which were eager and ready to host the waste incinerator. Every community held plebiscites, each with positive outcomes, however in Swan Hills there was a remarkable 79\% approval rate, based on $69 \%$ of the eligible population voting. ${ }^{68} 69$

The success in this example is directly related to the effort of creating and fostering participatory processes that engaged and directly involved the citizenry. Furthermore, the government, instead of simply supplying its own expert analysis to possible affected communities, rather opted to supply the necessary monetary resources so that potentially affected communities could hire their own experts and consultants. For instance, over $\$ 100000$ were given to Swan Hills to "cover expenses incurred... for town meetings, consultation with outside experts, and travel expenses." ${ }^{\text {"70 }}$ This allowed the communities to decide for themselves whether or not the consequences of siting the proposed waste incinerator within their neighbourhood was acceptable. Furthermore, the community of Swan Hills was given additional monetary resources to monitor and remain informed about plant operations. This was done through monthly meetings, which fostered communication between citizens and plant managers. Additionally, the

${ }^{67}$ Ibid.

${ }^{68}$ Ibid.

${ }^{69}$ Remarkably, the town of Ryley, which is located $85 \mathrm{~km}$ south of Edmonton, expressed massive disappointment in not being selected for the waste incinerator.

${ }^{70}$ Supra note 62 at 193. 
community was given consistent environmental monitoring reports that were translated, by their own experts, into less technical formats in order to establish transparency through practical access to information. ${ }^{71}$

This example, while perhaps not indicative of all environmental siting decisions, illustrates that "contrary to technocratic assumptions, citizen participation can... prove to be anything but irrational."72 73 Additionally, it shows the largely theoretical benefits of environmental justice that I have discussed thus far, by demonstrating that engaging the citizenry and reducing or eliminating power imbalances can have positive long-term benefits.

This example also serves as a model, whereby a shift in power occurred, insofar as scientists, rather than stand outside of participatory processes, were actively engaged within them, thus allowing more robust forms of communication to occur, which were more in line with environmental justice principles. However, perhaps most importantly, this example demonstrates the specific advantages of citizen participation within policy formation and implementation, which can ultimately be used to identify the beneficial relationship that can be created in regards to new modes of environmental regulations.

\section{[4.7] Forums for Citizen Participation}

Just as it is important to analyze the theoretical implications of environmental justice, it is equally important to describe and examine the various forums for citizen participation in order to better understand their construction in a practical sense. While a recent expansion in

${ }^{71}$ Supra note 13 at 177 .

72 Ibid.

${ }^{73}$ Minnesota has attempted to emulate the siting process from Swan Hills, however has not followed the same strict adherence to participatory opportunities. For instance, they did not establish a crown corporation, they provided less comprehensive compensation and in general ignored some of the key participatory processes in the Swan Hills example. For more information see note 62 at 203 . Unfortunately, the Albertan government has also become complacent in regards to siting decisions, and has begun to stray away from the participatory mechanisms that led to success and the elimination of nimbyism in Swan Hills. 
participatory arenas has been a welcome change, the correlation to increased environmental justice is arguably lacking. This is largely due to the obvious gaps between certain populations ability to take advantage of institutionalized participatory avenues. ${ }^{74}$ In other words, the socioeconomic barriers to participation, and in turn ecological democracy, are still some of the most prevalent and hardest to overcome.

Likewise, perhaps the most obvious venue in which citizens have the option, though not necessarily the resources to participate, is the courtroom. Joseph Sax explains that the "possibility for citizens to reassert their right to determine the fate of their own environment... can be done by carrying the battle into the courtrooms of the nation and restoring democracy to environmental disputes." ${ }^{, 75}$ He believes that the law already provides options that can be used to combat environmental injustices and concerns. However, he also openly admits that this option is not necessarily available to everyone. ${ }^{76}$

Michael McCann and Helena Silverstein provide a similarly cautious, but more optimistic conceptualization of using the courtroom as a mechanism to "democratize the bureaucratic state." ${ }^{\prime 77}$ They provide a conceptual framework for analyzing law as a mechanism of change that goes beyond whether or not a particular case is won or lost. For instance, they argue that the most fundamental contribution of legal mobilization is shifting perceptions and focus away from judges and politics and moving it towards active citizens. In this conceptualization, the law is itself transformed into a resource utilized by groups or individuals engaged in social struggles. ${ }^{78}$

\footnotetext{
${ }^{74}$ Andrea Cornwall, \& Vera Schattan P. Coelho, "Spaces for Change? The Politics of Participation in New Democratic Arenas." (Zed Books Ltd., New York: 2007) at 3.

${ }^{75}$ Joseph L. Sax, "Defending the Environment. A Strategy for Citizen Action." (Alfred A. Knopf Company, New York: 1971).

${ }^{76}$ Ibid.

${ }^{77}$ Michael McCann, \& Helena Silverstein, "Social Movements and the American State: Legal Mobilization as a Strategy for Democratization." in "A Different Kind of State? Popular Power and Democratic Administration." (Oxford University Press, Toronto: 1993) at 132.

${ }^{78}$ Ibid at 133.
} 
In this regard, it is closely related to the idea, or paradigm of recognition, which I believe is fundamental in achieving environmental justice. McCann and Silverstein do admit that law, as an institutional instrument, places limitations or constraints on what constitutes legitimate action. In other words, "because legal traditions structure many of the very relational hierarchies within which citizens are situated, they limit the tactical options and practical knowledge available to groups seeking to renegotiate the terms of established power relations." ${ }^{.79}$ Nonetheless, even though law may not necessarily remedy power imbalances, it can still provide tools for opposition. For instance, the courts can serve as a type of 'spotlight' for injustices that occur, creating opportunities for mobilization around a specific cause. Additionally, it can be used to gain leverage, either economically or politically, putting pressure on governments or organizations to provide certain concessions. Lastly, it can provide a validation of social struggles that individuals or communities have gone through. ${ }^{80}$

McCann and Silverstein do provide three extremely important points insofar as utilizing law as a mechanism for change. First, not all attempts to utilize formal legal avenues result in long drawn-out and expensive trials. Often the threat of legal action can be enough to deter unjust behaviour. Second, formal legal mechanisms work best when used in conjunction with other tactics that seek to promote social justice. Thus, it is best coupled with bottom-up, grassroots mobilization efforts, as these provide more tangible entry points for citizen participation. This point is also mirrored in my arguments that suggest command-and-control systems provide positive supplemental features when paired with voluntary environmental programs. Lastly, law itself offers "more resources for advancing procedural democracy than

\footnotetext{
${ }^{79}$ Ibid.

${ }^{80}$ Ibid at 134.
} 
substantive democratic reform." ${ }^{\text {81 }}$ In this regard, law differs from environmental justice, insofar as the procedural elements of formal law may not affect recognition or distribution to the same extent that this occurs within a framework of environmental justice. These limitations should be kept in mind, as they may dictate, based on the circumstances of a particular struggle, whether or not formal law is a viable, or effective, resource.

I will now turn my attention to the possibility of promoting participation through the use of the Constitution. The entrenchment of certain rights has the potential to create, both improved environmental protection, and subsequent public discourse if laws are violated. For instance, Graham Smith argues that the entrenchment of "an environmental bill of rights... might declare that citizens have a right to ensure that environmental quality is maintained in accordance with the standards set by current environmental laws (standards which would undergo regular public review) ${ }^{\not 82}$ This type of Constitutional entrenchment would seek to promote environmentally sound practises and create a mechanism for deliberation if certain standards were not maintained. Smith also points out that this type of setup would allow for the analysis of substantive rights through constant communication between values that are both environmental and values that are not. $^{83}$

Additionally, the entrenchment of environmental laws could have profound effects on the procedural realm of environmental justice. For example, laws could be created that include "rights to information, rights of legal redress, and rights of participation."84 In essence, the Constitution could be utilized as a mechanism which promotes ecological democracy through the effective change of the procedural paradigm. However, while certainly promising, Smith does

\footnotetext{
${ }^{31}$ Ibid at 141 .

82 Graham Smith "Deliberative Democracy and the Environment." (Routledge, London: 2003) at 108.

${ }^{83}$ Ibid.

${ }^{84}$ Ibid.
} 
point out that enforcement of these rights may still pose a significant barrier to these types of solutions. Nonetheless, I absolutely believe that this would be a significant step forward in the authentic realization of ecological democracy and in turn environmental justice.

The last forum which needs to be addressed is the public hearing. In this regard, Mary Richardson, Joan Sherman, and Michael Gismondi have provided a rather elegant resource for this type of analysis with their book "Winning Back the Words." 85 Here, they document and examine a public hearing which revolved around the proposed and eventual decision to site a Pulp and Paper Mill in Alberta.

Public hearings give citizens opportunities to provide decision makers with concerns that might not otherwise be considered. Furthermore, they provide a context in which people can be heard, and thus offer a situation which could potentially enhance the quality of the decision in question. ${ }^{86}$ In addition, it gives the public the opportunity to question the scientific discourses used by governments and corporations, which may remedy the power imbalances between experts and lay people discussed earlier in the chapter. However, perhaps most importantly, public hearings seek to hold those accountable for making decisions by allowing citizens to come together and realize a common goal that is not purely based on economic values.

Nevertheless, there are a number of criticisms with public hearing approaches as well. First, public hearings generally occur "after development decisions have been made, relegating public participation to reactions to prior decisions. ${ }^{, 87}$ Furthermore, the decisions and outcomes of hearings must not be adhered to by the government, which obviously limits their overall effectiveness. Lastly, there exists the argument that those who choose to participate in public hearings are essentially catalysts in their own subversion. The basis for this argument is that the

\footnotetext{
${ }^{85}$ Supra note 22 at 1 .

${ }^{86}$ Ibid at 19.

${ }^{87}$ Ibid.
} 
construction of public hearings is so unevenly fashioned, and "controlled to such an extent that dissent will not be registered."

In conclusion, it is evident, just as Schlosberg's assertion that environmental justice needs to be addressed in different paradigms, that there also exists a need to combine and utilize different forums for democratic citizen participation. Each venue possesses its own unique values and obstacles, and only through a combination thereof can ecological democracy exist in its most comprehensive form.

\section{[4.8] Conclusions}

The purpose of this chapter was to examine citizen participation in order to provide an analysis into ecological democracy and its subsequent effect on environmental justice. I attempted to address and analyze why citizen participation in environmental decision-making has been fundamentally avoided. I believe the answers to this question lie predominantly in discourses that seek to persuade the citizenry that economic development cannot coexist within the pluralism of environmental values. In my opinion, this reasoning is deeply flawed, and only perpetuates the subversion of the citizen by suggesting that we are not capable of informed decision-making that incorporates the environment, economy, and public spheres. While I certainly believe that citizens are also capable of making mistakes when it comes to environmental decisions, not including them in the process at all, and focusing primarily on economic considerations is reason enough to warrant a shift in current practices.

The second goal of this chapter was to examine the possible benefits that increased citizen participation might have. In this regard, I believe that the illumination of the inherent power imbalances throughout environmental decision-making processes make obvious the need

\footnotetext{
${ }^{88}$ Ibid at 22.
} 
for increased participatory mechanisms. Citizen participation can, and does, contribute to the authentic recognition of community values, and subsequently could be utilized by corporations and governments as a resource that provides valuable insight into environmental decisionmaking processes that would still allow for strong economic development. This type of a system, in which ecological democracy was encouraged, rather than depressed, would play a key role in the struggle for environmental justice by shifting discourses to the procedural realm and making clear the right for citizens to speak for themselves.

The issues I have raised here are applicable with voluntary environmental programs as well. As discussed in chapter two, utilizing citizen participation throughout the establishment, implementation, and monitoring of voluntary initiatives would serve multiple beneficial purposes. First, it may help ensure that voluntary programs move beyond business-as-usual practices, as it adds a fundamental layer of accountability during development phases. Second, as the case in Swan Hills Alberta illustrated, local expert knowledge may provide important insights that policy makers could rely on, which help create more economically and environmentally efficient voluntary programs in the first place. Additionally, citizens may also be utilized as a resource, insofar as they can act as compliance monitors. This would add another layer of accountability while simultaneously reducing costs associated with compliance monitoring. Finally, bringing citizens into the environmental decision-making process will foster increased environmental justice and in turn substantive ecological democracy.

In the next chapter I provide I detailed conceptualization of how environmental justice principles may beneficially influence voluntary environmental programs. I accomplish this in two steps. First, I critique VEP's in terms of social justice and economic considerations. This allows me to establish an entry point into how I believe environmental justice considerations 
may positively affect VEP's. Additionally, I rely on two case studies, one which demonstrates the advantage of a policy mix approach and the other how citizen participation could be included in voluntary environmental decision-making. Lastly, I situate my arguments within a framework of law, which further demonstrates the necessary and collaborative relationships that exist between environmental justice and voluntary environmental programs. 


\section{Chapter 5:}

\section{Developing the Relationship between Voluntary Environmental Programs and Environmental Justice}

The purpose of the previous chapters was to introduce the reader to voluntary environmental programs, and environmental justice considerations, specifically those related to citizen participation and its relationship with expert discourse. Essentially, my aim was to provide a clear conceptualization of these relationships so that my current analysis can examine these three chapters as a whole, rather than individually. This is important because, while there is certainly a vast amount of research on each topic independently, examinations or critiques of VEP's, using environmental justice principles, are largely or even wholly underdeveloped. While I am not suggesting that deliberative components of VEP's have not been analyzed, I do believe that previous examinations tend to ignore the environmental justice frame, particularly the inclusion of citizen participation within decision-making processes.

This is particularly prevalent during the development phases of voluntary environmental programs as industry and governments tend to view citizens through the eyes of 'difference,' as opposed to 'deliberative,' democrats. ${ }^{12}$ Consequently, industry and government generally assume that the internalization of environmental values, in particular expansive categories, such as "genetically modified foods, or climate change, may indeed harbour such deep-seated value

\footnotetext{
' Karin Backstrand, et al. "The promise of new modes of environmental governance." in "Environmental Politics and Deliberative Democracy: Examining the Promise of New Modes of Environmental Governance." (Edward Elgar Publishing Limited, United States: 2010) at 3.

2 The term 'difference' democrat refers to the notion that the environmental values citizens possess are inherently pluralistic, which raises concerns of conflict during decision-making processes.
} 
conflicts that they simply cannot be resolved through deliberative procedures." ${ }^{33}$ While an individual's unique interpretations of environmental values may indeed clash as a result of ideological, cultural, and economical values, excluding them from decision-making processes does not remedy this potentiality. Rather, as described in the Swan Hills example, it simply creates a circumstance where all citizens are devalued and denied deliberative opportunities, which should be viewed as a right and not a privilege.

In this chapter I will examine the prevailing political and economic assumptions that VEP's offer similar, if not improved, environmental performance. This is important to consider, as not all academics are convinced that voluntary programs, as they currently exist, can comprehensively substitute for traditional regulatory approaches. ${ }^{4}$ I will examine these critiques through the lens of environmental justice, in order to demonstrate that environmental justice principles may be able to help reinforce the positive traits that exist within voluntary initiatives. To accomplish this goal I will use a theoretical approach, more intimately connected with examining social and environmental justice principles and objectives. Additionally, I will provide two case studies. In the first study I detail how a policy 'mix' approach was adopted in order to illustrate the benefits that multifaceted approaches can provide. In the second study, I describe how environmental justice elements, particularly citizen participation can be established in VEP's. While both studies do not interject environmental justice qualities within decisionmaking processes to the extent that I believe is necessary, they nonetheless demonstrate the potential advantages of a mixed regulatory approach that includes the involvement of a variety of stakeholders.

\footnotetext{
${ }^{3}$ Supra note 1 at 3.

${ }^{4}$ Kathleen Segerson, \& Thomas J. Miceli, "Voluntary Environmental Agreements: Good or Bad News for Environmental Protection?" (Journal of Environmental Economics and Management, Vol. 36, No. 2: 1998) at 129.
} 
I will begin by examining critiques of voluntary environmental programs. I will attempt to do this in a chronological fashion, beginning with program development, and implementation, followed by examining compliance monitoring and program effectiveness and lastly analyzing market-based considerations. This chapter will focus to a larger extent on European examples as much of the research there is further developed, particularly from a social justice perspective. However, I believe that the fundamental policy shifts towards more deliberative ideals within the European context are also applicable within North American settings. While comparing policy initiatives within distinct jurisdictions is a complex activity, the normative benefits of more deliberative processes can nonetheless be applied to all citizens. Thus, in my opinion the only logical or reasonable argument in terms of citizen participation is not if it should be included, but rather whether or not its inclusion has had differing effects within environmental decisionmaking processes throughout the world. ${ }^{5}$

Subsequently, I will detail the deliberative turn in European environmental regulations. This analysis will provide both a theoretical and contextual framework for analyzing voluntary initiatives through environmental justice principles. Lastly, I will follow up with a discussion that argues in favour of combining voluntary approaches with formal law. This last point is extremely important as it demonstrates the benefits of a mixed approach towards environmental regulation, as formal legislation may facilitate the establishment of more effective VEP's.

\section{[5.1] Critiquing Voluntary Environmental Programs}

Although some academic commentators fear that VEP's may not be able to directly replace formal environmental regulations, we should remember that this was never the goal of these programs. Voluntary programs were created to supplement regulations and not supersede

\footnotetext{
${ }^{5}$ This question lies beyond the scope of my research, however it would certainly provide an interesting and perhaps more conclusive example of the potential benefits of deliberative procedures.
} 
them. Thus, as I will explain in greater detail later in the chapter, it is extremely important for academics and policy experts to find ways in which regulatory approaches can be combined with voluntary initiatives, in order to establish the most robust forms of environmental protection.

The question I will now attempt to answer is, do voluntary environmental programs work? As explained in chapter two, there are three main criteria for success including, the number of participants, the average effect participation has on environmental performance, and any potential positive externalities. ${ }^{6}$ In chapter two my intention was to analyze these conditions themselves as a formula, which determined program success based on practical considerations. In this chapter I will take a more theoretical and critical approach based on economic, social, and environmental justice principles. With this in mind, when measuring success through social justice conceptualizations, the Bruntland Report presented in 1987, and the United Nations Conference on Environment and Development in Rio in 1992, serve prominently as benchmarks for calculating program benefits. ${ }^{7}$ These presentations served as transformational conduits towards inclusionary and participatory processes in regards to new modes of environmental governance, echoed largely in environmental justice literature. The recommendations in these presentations emphasize bottom-up processes that attempt to include various stakeholders and mitigate power imbalances that exist within environmental decision-making. ${ }^{8}$ Unfortunately, the recommendations have been largely ignored, and governments and industry have remained the key, and often exclusive, stakeholders in developing alternative modes of environmental regulations. While it is certainly a positive indication that government and industry are

\footnotetext{
${ }^{6}$ Jonathan C. Borck, \& Cary Coglianese, "Voluntary Environmental Programs: Assessing their Effectiveness." (The Annual Review of Environment and Resources, Vol. 34: 2009) at 310.

${ }^{7}$ Roger Hildingsson, "The deliberative turn in Swedish sustainability governance: participation from below or governing from above?" in "Environmental Politics and Deliberative Democracy: Examining the Promise of ${ }^{8}$ Ibid. New Modes of Environmental Governance." (Edward Elgar Publishing Limited, United States: 2010) at 145.
} 
attempting to address current regulatory environmental problems through new more sustainable methods, the citizen as potential stakeholder is still vehemently denied participatory opportunities. 9

Beginning with program development, there are a number of criticisms of VEP's insofar as deliberative quality and legitimacy are concerned. Unfortunately, important questions tend to be ignored: "to what extent do new modes of governance capture deliberative democracy ideals? Do new modes of governance use deliberative rationality, such as inclusiveness, unconstrained dialogue, and free and public reason among equal individuals [and] what is the quality of the deliberation...?"10 Ignoring these types of questions can result in voluntary initiatives that lack fundamental democratic processes, which can result in decreased environmental performance. Furthermore, the implications of these questions are situated within a conceptualization of environmental justice. Accordingly, ignoring them effectively undermines the potential benefits of environmental justice and citizen participation that I address in the previous two chapters.

Additionally, the power imbalances of participating stakeholders must also be addressed. Thus, even if deliberative practices are established the relationships between citizens and 'elites,' and their potentially competing discourses should exist within fair and equal forums. "I Consequently, although voluntary environmental programs are designed with the intention of increasing environmental performance, their potential for including citizen participation should not be overlooked. I am of course not suggesting that environmental protection is not important, rather, as I will explain throughout this chapter, including citizen decision-making within VEP's,

\footnotetext{
${ }^{9}$ Ibid at 146.

${ }^{10}$ Annica Kronsell, \& Karin Băckstrand, "Rationalities and forms of governance: A framework for analyzing the legitimacy of new modes of governance." in "Environmental Politics and Deliberative Democracy: Examining the Promise of New Modes of Environmental Governance." (Edward Elgar Publishing Limited, United States: 2010) at 41.

11 Ibid.
} 
may be necessary to foster the potential for greater environmental protection. Thus, the ignorance of the questions described above is a signal towards one major overarching criticism associated with voluntary initiatives; their lack of deliberative processes. This is particularly egregious considering VEP's offer some of the 'best' opportunities for citizen participation within environmental decision-making in the first place.

Another major critique of VEP's is that based on the type of program, certain companies that choose to participate may find themselves at a competitive disadvantage. ${ }^{12}$ For example, industries that operate in more environmentally conscious jurisdictions may adopt, or be 'forced' to adopt, stringent voluntary programs. Consequently, this could decrease profit margins, particularly in comparison to industries in neighbouring countries that operate within less environmentally 'friendly' locations. ${ }^{13}$ For example, unilateral or industry sponsored agreements, such as the American Chemistry Council's Responsible Care Program, may set lower targeted abatement goals than other public voluntary programs, or third party programs such as ISO 14001. Thus, industry within jurisdictions that utilizes more unilateral initiatives may be able to gain market advantages over similar industries located in jurisdictions that promote stricter environmental regulations in the form of public and third party sponsored programs.

In terms of program effectiveness, the perceived improved environmental performance of voluntary programs has been increasingly placed under the microscope. While it is certainly true that certain programs have led to increased environmental performance, academics have argued that some companies take advantage of these benefits. For example, King and Lenox have

\footnotetext{
${ }^{12}$ See chapter two for a discussion of the four different archetypes of voluntary programs.

${ }^{13}$ Andrew Jordan, Radiger K.W. Wurzel, and Anthony R. Zito, "New Environmental Policy Instruments: An Evolution or a Revolution in Environmental Policy." in New Instruments of Environmental Governance? Nation Experiences and Prospects." (Frank Cass Publishers, London: 2003) at 221.
} 
analyzed the Chemical Industry's Responsible Care program. Their alarming findings suggest that the program itself may have had a negative aggregate affect on environmental performance specifically linked to toxic emissions. ${ }^{14}$ They found some participating firms increased their environmental performance through the transferring of best practices, adopting new environmental values, and informal coercion among members to maintain program goals and objectives. $^{15}$ However, they also noted that the adoption of the Responsible Care program in some cases actually had detrimental effects on environmental protection. They hypothesize that the opportunistic participants within the program, or free-riders, actually delegitimize the program to such an extent that it could be deemed unproductive. ${ }^{16,17}$

This last criticism is particularly interesting insofar as environmental justice is concerned as King and Lenox both argue that stricter sanctions and increased compliance monitoring would certainly help combat opportunistic behavior. ${ }^{18}$ In terms of my research insufficient compliance monitoring is also unique insofar as the potential for citizen participation is concerned. Accordingly, as I will show later in the chapter, citizens may be able to take on this type of responsibility, thus reducing environmental harms associated with non-compliance, and perhaps reducing non-compliance itself.

Lastly, in terms of market-based issues, VEP's have also been criticized based on a company's ability to sufficiently "signal improvements in their environmental performance to consumers and to successfully and credibly differentiate its products." ${ }^{19}$ Problems arise here, as consumers are less familiar with the quality of a product than those who sell or manufacture it.

\footnotetext{
${ }^{14}$ Andrew A. King, \& Michael J. Lenox, "Industry Self-Regulation Without Sanctions: The Chemical Industry's Responsible Care Program." (Academy of Management Journal, Vol. 43, No. 4: 2000) at 712.

${ }^{15}$ Ibid at 703.

${ }^{16}$ For a more detailed discussion of free riders see chapter two.

${ }^{17}$ Supra note 14 at 713 .

${ }^{18}$ Mbid.

${ }^{19}$ Madhu Khanna, "Non-Mandatory Approaches to Environmental Protection." (Journal of Economic Surveys, Vol. 15, No. 3: 2001) at 306.
} 
When consumers are unaware of the quality of a given product, lower quality products tend to dominate the market. Thus, if companies are not able to effectively identify their products as being superior, superior products cannot justify higher price tags. ${ }^{20}$ This is naturally true of products that attempt to persuade green consumerism, as consumers may not realize the potential environmental benefits of these items. Accordingly, companies may be forced to spend considerable amounts of money to 'educate' consumers as to the environmental benefits of their products, while still relying on the assumption that said knowledge will lead to increased sales. ${ }^{21}$

There are a number of critiques associated with voluntary initiatives, in terms of both social justice and economic paradigms. I will now shift my focus towards addressing these critiques through deliberative processes intended to foster increased citizen participation. In order to effectively address these concerns, I will first detail a major paradigm shift that has occurred in Europe, particularly in Sweden. This purpose of this analysis is to demonstrate that environmental justice considerations are compatible with new modes of environmental governance.

\section{[5.2] The Deliberative Turn}

Sweden perhaps more so than any other developed country has been at the forefront of establishing deliberative processes in conjunction with new modes of environmental governance. In Europe this shift has been labeled "the deliberative turn" and it shot into the spotlight after a conference hosted by the European Commission in 2008, which attempted "to engage public and private actors in a debate over European Climate policy."22 However, deliberative governance strategies have been prominent considerations within Swedish politics

\footnotetext{
${ }^{20}$ The term superior is specifically referring to products that are manufactured using more environmentally friendly means, or products that perform certain tasks with less of an environmental impact.

${ }^{21}$ Supra note 19 at 307.

${ }^{22}$ Supra note 1 at 3.
} 
over the last 20 years. The deliberative turn is associated with establishing new mechanisms of environmental protection, and implementing strategies that contribute towards ecological democracy. "This strive towards more effective forms of governance can be understood as a response to both market failures in internalizing environmental externalities, and politicoadministrative failures in governing environmental problems in effective and legitimate ways. ${ }^{, 23}$

I will use examples from Europe as both a means to discuss the opportunities for citizen participation, and as a critique of environmental strategies that ignore this vital effort. I am not suggesting that European governance models be used as comparative mechanisms for North American systems. My aim is simply to identify the impact of these deliberative strategies on VEP's in order to illustrate that environmental justice strategies could result in similar benefits.

As I have suggested in chapters three and four, there exists a fundamental lack of representation within environmental decision-making structures, which is linked to environmental policy establishment and implementation. Roger Hildigsson explains that these shortfalls can be seen through an understanding of both output and input legitimacy. Output legitimacy is the overall performance and effectiveness of environmental policy, whereas input legitimacy attempts to address questions of who is, and should, be included within decisionmaking processes and identifying mechanisms which may foster greater transparency. ${ }^{24}$

Hildigsson also explains that deliberative processes, which impact input legitimacy, would have wide-ranging benefits in terms of their effect on output legitimacy as well. ${ }^{25}$

However, when analyzed from an individual standpoint ensuring the existence of input legitimacy is linked with the need for formal legislative mechanisms that require deliberative

\footnotetext{
${ }^{23}$ Supra note 7 at 146.

24 Ibid at 148.

${ }^{25}$ Hildigson's argument here is similar to the approach I adopt throughout my thesis, which is that establishing substantive deliberative processes within environmental decision-making can increase the effectiveness of environmental policy and in turn environmental protection.
} 
elements. ${ }^{26}$ Robyn Eckersley defines this type of approach as green constitutionalism. ${ }^{27}$ Her approach includes environmental justice principles, however she tends to frame her arguments through advanced legal descriptions. For example, she argues that there should exist "third-party litigation rights to enable NGO's and concerned citizens to ensure that public environmental laws, including minimum environmental standards, are being upheld." ${ }^{28}$ Furthermore, she believes that states should establish a constitutionally entrenched independent public authority with the objective of representing public environmental interests in both legal and political spheres. $^{29}$ Eckersley's recommendations for an overall green constitution also align, or mirror, suggestions by academics such as Kernaghan Webb, that voluntary initiatives should include formal legal elements. ${ }^{30}$

Output legitimacy, on the other hand, is related to the establishment of new modes of environmental policy, or policy innovations. For the most part, academic studies regarding environmental concerns have predominantly focused on input legitimacy. Even when output legitimacy is said to be the key component for examination, studies often rely mainly on conceptualizing policy from market-based standpoints or institutional effectiveness. ${ }^{31}$ The goal of this thesis is to take an expended view of output legitimacy by including discussions of environmental performance. In other words, "an alternative approach is to study effectiveness in terms of the environmental outcome. To what extent do particular sets of rules, norms or institutions lead to an actual improvement in the state of the environment?"32 While these

\footnotetext{
${ }^{26}$ As discussed in chapter two, it may be necessary for governments to formally legislate the inclusion of citizen participation within voluntary environmental programs, particularly within industry sponsored agreements.

${ }^{27}$ Robyn Eckersley, "The Green State: Rethinking Democracy and Sovereignty." (The MIT Press, Cambridge: 2004) at 243.

${ }^{28}$ Ibid.

${ }^{29}$ Ibid at 244.

${ }^{30} \mathrm{I}$ will discuss this point later in the chapter.

${ }^{31}$ Supra note 10 at 42.

32 Ibid.
} 
innovations can come from both industry and government they should not attempt to deny deliberative opportunities. ${ }^{33}$ As such, voluntary environmental strategies can fall under the definition of endeavoring to improve output legitimacy.

As I have demonstrated the deliberative turn is inherently connected with environmental justice principles, yet more fundamentally grounded within policy frameworks. Thus, this discussion illustrates that environmental justice considerations are not intrinsically incompatible with environmental policy, and additionally provides a discourse in which the two can be analyzed together.

\section{[5.3] Establishing Environmental Justice in Voluntary Programs}

In chapter two my aim was to categorize and illuminate the technical structures of voluntary approaches. I am now going to shift my examination and analyze VEP's within an environmental justice frame. In doing so, one realizes that increased citizen participation within decision-making processes is a key element of establishing better voluntary approaches, and perhaps more importantly fostering ecological democracy. Unfortunately, when analyzing voluntary programs the same democratic deficiencies that exist in traditional command-andcontrol legislation, where the decision-making process is almost exclusive to industry and government, exist as well. ${ }^{34}$ As such, it is true that many of the same arguments pertaining to the inclusion of a greater element of citizen deliberation, or input legitimacy, in decision-making processes can also be applied to voluntary approaches. In other words, the relationship between expert and layperson can be reconceptualised using environmental justice theory, insofar as using laypersons to identify key aspects of voluntary approaches, which are exclusive to their

\footnotetext{
${ }^{33}$ Supra note 7 at 148.

${ }^{34}$ Peter Swan, "Democratic Environmental Governance and Environmental Justice." in "Law, Regulation, and Governance." (Oxford University Press, Ontario: 2002) at 138.
} 
local expert knowledge. ${ }^{35}$ Using this type of an approach can help foster the understanding that voluntary programs must be analyzed for their contribution towards social justice as well as environmental performance, or an expanded interpretation of both output and input legitimacy.

As is generally the case, those that are most affected by a certain type of policy change, including the establishment of voluntary approaches, are the least likely to be consulted. ${ }^{36}$ However, because industry participation is often encouraged through the benefit of a better public image, VEP's are uniquely situated to serve multiple interests. ${ }^{37}$ For example, the inclusion of an element of citizen participation would seek to further the amount of positive public image gained, while simultaneously adding program credibility through increased accountability. Voluntary approaches have the ability to appeal to a common interest, by allowing participation from various stakeholders including "industry, government, nonprofit and nongovernmental groups such as environmentalists and third-party certificate organizations, local communities, and firms' employees directly affected by corporate environmental practices." ${ }^{38}$ However, the only way in which voluntary agreements can lead to the establishment of authentic citizen participation is if procedural and substantive qualities become as important and systematically implemented as economic and technical considerations.

Accordingly, a recognition and desire to change the systematic denial of participatory rights within environmental decision-making must be realized within a broad conceptualization of environmental rights. ${ }^{39}$

\footnotetext{
${ }^{35}$ Ibid at 123.

${ }^{36}$ Lawrence E. Susskind, \& Ravi K. Jain, \& Andrew O. Martyniuk, "Better Environmental Policy Studies, How to Design and Conduct More Effective Analysis." (Island Press, Washington: 2001) at 100.

${ }^{37}$ Toddi A. Steelman, Jorge Rivera, "Voluntary Environmental Programs in the United States, Whose Interests are Served?” (Organization \& Environment, Vol. 19, No. 4: 2006) at 506.

${ }^{38}$ Ibid at 508.

${ }^{39}$ Supra note 34 at 136.
} 
Procedural qualities would include the recognition that authentic participation results in a net benefit to the common interest of the parties discussed above. Furthermore, a voluntary program should strive to encourage active community participation to limit the number of excluded stakeholder opinions. ${ }^{40}$

Substantive qualities recognize that all appropriate concerns, defined as those that are fundamentally compatible with broader community goals, must be considered. In other words, this ensures that authentic participation is established; where citizens can be certain that a sufficient level of engagement will exist to discuss potential concerns. ${ }^{41}$ Consequently, to be considered legitimate, environmental decision-making must address procedural, substantive, distributive and practical considerations. ${ }^{42}$ In addition, the dialogue of participation must occur within a system that allows citizens to challenge the established knowledge and neutrality of expert opinions. ${ }^{43}$ Furthermore, as I demonstrate in the Project XI case study below, there must exist a "political and legal culture that encourages participation."

Carmin et al. have some positive information regarding participation insofar as almost all VEP's contained at a minimum some type of process where various stakeholders, including citizens, or citizen organizations, were consulted during development phases. As a result they believe that citizen participation is routinely becoming an integral factor in voluntary program development. ${ }^{45}$ However, they are also quick to point out that simply opening decision-making processes is insufficient in terms of obtaining genuine and credible citizen input. They suggest that while industry is engaging in more collaborative processes with citizens, they are

\footnotetext{
${ }^{40}$ Supra note 37 at 508.

${ }^{41}$ lbid.

42 Jouni Paavola, "Institutions and Environmental Governance: A reconceptualization." (Ecological Economics, Vol. 63 , No. 1: 2007) at 97.

${ }^{43}$ Supra note 34 at 135.

${ }^{44}$ Ibid.

${ }^{45}$ JoAnn Carmin, Nicole Darnall, Joao Mil-Homens, "Stakeholder Involvement in the Design of U.S. Voluntary Environmental Programs: Does Sponsorship Matter?” (The Policy Studies Journal, Vol. 31, No. 4: 2003) at 538.
} 
simultaneously taking steps to ensure their own protection and interests. ${ }^{46}$ In other words, they differentiate between the number of different stakeholders involved in the development processes, and the actual intensity of the involvement itself. This difference is also articulated within environmental justice discourses as the difference between simple participation and participation that is both meaningful and authentic. Thus, while Carmin et al. did indicate that participation existed at some level within most VEP's, they were careful not to qualify it as necessarily anything beyond a "symbolic gesture used to demonstrate inclusion." it is encouraging that VEP's have begun, at least at a basic level, to reconceptualise the importance of promoting collaboration by recognizing the plurality of various stakeholders and social actors. ${ }^{48}$ However, in order to adequately address environmental justice concerns, this recognition must exist within the institutions that create VEP's as well.

As mentioned earlier in chapter two, a paradox exists with command-and-control schemes, insofar as insufficient monitoring is commonplace, yet the opposite is required for the success of control mechanisms to work properly. Consequently, academics have argued that monitoring could include some type of civic engagement, which would seek to increase citizen participation. $^{49}$ By utilizing citizens in the monitoring efforts of command-and-control structures, one could increase their engagement and concurrently increase compliance monitoring. ${ }^{50}$ Many types of citizen compliance groups have already been established in the United States, with a particular emphasis on air, water, and soil monitoring. Examples include, "river-watch networks, stream teams, watershed councils, citizen air-monitoring teams, and lead-

\footnotetext{
46 Ibid.

${ }^{47}$ Ibid at 539.

${ }^{48}$ Supra note 34 at 129.

${ }^{49}$ Dara O'Rourke, \& Gregg P. Macey, "Community Environmental Policing: Assessing New Strategies of Public Participation in Environmental Regulation." (Journal of Policy Analysis and Management, Vol. 22, No. 3: 2003) at 384.

so Ibid.
} 
monitoring programs."51 Additionally, citizens have proved that they possess the ability to quickly mobilize when their communities are faced with environmental harms, and subsequently monitor for any ongoing potential dangers. For example a community in Brooklyn, New York, displayed this type of behaviour when it mobilized to fight sand-blasting operations. In this particular instance many community members gathered soil samples from their backyards in order to establish lead contamination levels, which they subsequently used to take legal action against the sand-blasting operation. ${ }^{52}$

The purpose of the discussion of community environmental policing is to illustrate how citizens could be actively engaged in another level of environmental regulation. More importantly, this idea is one that I believe could be better established within voluntary programs. Just as the inclusion of citizen participation within the VEP development process should be used in the determination of program success or effectiveness, a similar consideration should be given to citizens to act as compliance monitors. This could simultaneously promote collaboration among various stakeholders, promote program credibility, and reduce the overall costs of monitoring by distributing the burden thereof to all of those actively involved within the program. In other words, this may serve as a mechanism that combats free-riding, which is discussed in both chapter two and above, as a major criticism facing voluntary initiatives. Additionally, establishing citizen compliance monitoring would address substantive concerns of participation, as it may help develop partnerships between citizens, industry, and experts through collaborative processes. In other words, compliance monitoring may foster a continued educational dialogue between industry and citizens, which is a key component of environmental justice.

\footnotetext{
51 Ibid at 385 .

52 Jason Corbum, "Street Science, Community Knowledge and Environmental Health Justice." (The MIT Press, London: 2005) at 25.
} 


\section{[5.4] Environmental Policy 'Mixing' in Portugal}

My aim has been to show that by using environmental justice principles, more environmentally thorough, cost effective, and democratic solutions can be achieved. I have argued in favour of these objectives in the context of voluntary environmental programs. In order to demonstrate the applicability of my arguments, drawing on the work of Santos et al., I will use a case study of pig farming in a municipality in Portugal. ${ }^{53}$ While this study does not explicitly show the benefits that local expert knowledge may provide it does demonstrate the importance of utilizing environmental justice principles within a mixed policy approach. In other words, more efforts could have been made to include local citizens as stakeholders, however the decisions reached were still based on a collaborative process that fostered transparency and open access to information.

Agricultural activities, as well as other resource-based actions, are characteristically very taxing on the environment and often lead to environmental problems and conflicts. ${ }^{54}$ These issues are not just related to environmental degradation, but also include aspects pertaining to land-use conflicts, the location of facilities in populous areas and its subsequent impact on human activities, and problems generally arising from various stakeholder values and interests. ${ }^{55}$ As such, more complex regulatory approaches that go beyond simple command-and-control structures are required to maintain more environmentally friendly solutions. These new approaches are beginning to combine alternative modes of environmental regulation, often in the form of voluntary initiatives, formal legislation, and increasingly citizen participation,

\footnotetext{
${ }^{53}$ Rui Santos, et al. "Stakeholder Participation in the Design of Environmental Policy Mixes." (Ecological Economics, Vol. 60, No. 1: 2006).

${ }^{54}$ Ibid at 100.

${ }^{55}$ These problems commonly include environmental, social, and economic issues.
} 
particularly local community knowledge. ${ }^{56}$ This particular case study is an excellent demonstration of more modern forms of environmental protection, and indicative of how VEP's can be improved using participatory mechanisms.

Montemor-o-Novo is a rather small municipality in south-central Portugal with a population of approximately 19000 . It is located in the Alentejo region, and suffers from high rates of unemployment, and a low variety of economic activities. ${ }^{57}$ The pig farming industry began to grow in the mid 1980's and has become the most important sector in the regional and local economy. Traditionally, the pig farms were largely limited to family operations, however, recently there has been a push towards the establishment of large-scale facilities. As discussed on the previous page, these agricultural activities "cause serious environmental problems in the region, accounting for an organic pollution load which is 12 times the load generated by the population, contributing to water, soil and air pollution." ${ }^{, 58}$ An environmental audit was conducted in 2001, which found that most facilities' wastewater treatment systems were malfunctioning, and existing environmental standards were consistently being breached. Regrettably, many of these facilities were also located within highly sensitive environmental areas, and situated near impoverished communities. Soon after the environmental audits were completed a survey was conducted which sought to better understand the knowledge and attitudes that pig farmers had towards the operational, and economic characteristics of the farms, and more generally how they felt about issues pertaining to the environment and sustainability. ${ }^{59}$ While the findings of the survey itself are largely irrelevant for my research, it is interesting to note that the farmers, through their local expert knowledge, were able to pinpoint that the most

\footnotetext{
${ }^{56}$ Supra note 53 at 102 .

${ }^{57}$ Ibid at 103.

${ }^{58}$ Ibid.

${ }^{59}$ Ibid.
} 
significant environmental problem was related to the treatment of effluent. ${ }^{60}$ They were also extremely aware that if anything was to change a new approach needed to be adopted in order to address the many concerns they had. ${ }^{61}$

As a result of the survey and the environmental audit, it was concluded, by the municipality, that a change was necessary. The objective of this new approach was to improve the social dynamics, environmental protection, and productivity of the region, in order to maintain or establish a sustainable future. ${ }^{62}$ These objectives were to be achieved through a policy 'mix' approach permeated with participatory opportunities. In other words, new command-and-control structures would be established along with economic instruments, marketbased approaches, and a voluntary initiative in the form of an eco-labeling scheme. Although the market-based approaches fall outside the focus of my research, it is important to briefly explain how these approaches utilized extensive participatory opportunities.

Two different economic instruments were used in this case; a sustainability fund, in the form of government subsidies, and tradable pig raising permits, similar to established carbontrading programs, or market-based approaches. ${ }^{63} 64$ The sustainability fund was mainly generated from penalties from violations to environmental standards, and environmental taxes in general. It also included "a strong participation of the local community involved stakeholders,

${ }^{60}$ The farmers not only pinpointed the source of the most significant environmental concern, they also were able to discuss that the design of wastewater treatment facilities contributed to this problem. Essentially, the farmers displayed an extremely high awareness of scientific environmental considerations.

${ }^{61}$ When referring to the pig farmers, I am including both individuals who maintained smaller scale operations and those that consulted or worked exclusively for larger, generally foreign, industrial scale companies. Thus, the pig-farmers can be defined as local experts, however it is important to note that non-farmers should also have had participatory opportunities. Although community members were consulted during the development and implementation phases, more emphasis should have been placed on the knowledge they may provide as well. I will elaborate on this point in the Project XL case study below.

${ }^{62}$ Supra note 53 at 103.

${ }^{63}$ Robert N. Stavins "Experience with Market-Based Environmental Policy Instruments." (Economic Theory and Applications, No. 52: 2002) at 3.

64 When referring to economic instruments, I do not mean to categorize the sustainability fund as a market-based approach. I am simply using the same terms as Santos et al, and presume that he is using the term economic instrument insofar as the generation of revenue is concerned. 
namely in the evaluation of funding proposals and in the allocation of subsidies, through a Community Evaluation Commission. ${ }^{.65}$

The voluntary approach, which was defined as a sustainable production label, functioned as a means to signal greater environmental performance to potential consumers. It did this in two ways; first by providing consumers with knowledge of the effects of their consumption on the environment, and second, by encouraging industry and governments to increase environmental standards. The presumption is that, continued education of consumer consumption, will result in the increased demand for stricter environmental standards. ${ }^{66}$ Thus as mentioned above, the success of these programs is largely dependent on the ability of industry and government to clearly identify the superior 'green' status of a given product. Despite the criticisms mentioned above, eco-labeling programs have become quite popular, particularly in terms of developing sustainability strategies. ${ }^{67}$ Moreover, when coupled with participatory mechanisms, they can also be quite successful. For instance, the requirements for receiving certification in Montemor-o-Novo were developed through participatory processes that involved various stakeholders, including "the Motemor-o-Novo municipality,... pig farmers, acting either as active partners or in a consultative role, the Portuguese Federation of Pig Farmers Associations, the Regional Environment Directorate, the Regional Agriculture Directorate, and the Montemor-o-Novo Health Centre. ${ }^{~}{ }^{68}$ Consequently, the standards established for certification were quite rigorous. They were based on information given by current farmers insofar as environmental management practices and best available techniques were concerned, in addition to pre-existing formal legal requirements. Furthermore, managing the eco-label would

\footnotetext{
${ }^{65}$ Supra note 53 at 105.

${ }^{66}$ Ibid at 106.

${ }^{67}$ Ibid at 107.

${ }^{68}$ Ibid.
} 
be left up to the Pig Farmers Association of Montemor-o-Novo. Lastly, the program itself was grounded in formal regulations, thus legal penalties could be given based on non-performance or compliance. $^{69}$

Throughout the process of establishing this new policy mix, various meetings took place that focused on three of the four mentioned approaches ${ }^{70}$. These meetings fostered transparency, and attempted to both educate and learn from the community. 35 major criteria were voted on by the pig farmers, and because of the collaborative tactics involved, 28 of them were agreed upon consensually. In addition, the remaining criteria were openly discussed at various points, until which a consensus regarding their outcome and implementation was reached as well. ${ }^{71}$

The significance of this case in terms of my research is three fold. First it demonstrates that citizen participation within environmental policy decisions can, and is, a desirable goal. Second, it illustrates that this goal is also applicable in terms of fostering better voluntary initiatives, or at the very least, addressing possible criticisms. Lastly, this example shows first hand, that a policy 'mix' approach is more desirable than any one mechanism on its own. In other words, market-based approaches and VEP's work best when coupled with formal regulations. Additionally, these three mechanisms, work best when intertwined with environmental justice principles that seek to promote active citizen participation.

\section{[5.5] Local Expert Knowledge, Citizen Participation and Project XL}

This case study focuses on ten pilot projects using the EPA established Project XL strategy and demonstrates how local experts can be included in the design

\footnotetext{
69 Ibid.

${ }^{70}$ The three approaches were the sustainability fund, the tradable pig raising permits and the eco-labeling strategy.

${ }^{71}$ Supra note 53 at 108.
} 
and development of voluntary environmental programs. ${ }^{72}$ In 1995 the Clinton-Gore

administration began a regulatory reform initiative, by establishing Project $\mathrm{XL}$, which allowed

"the EPA to enter into partnerships with business, environmentalists, states, and communities."73

The purpose of this reform was to have local citizens help review, and alter, the Final Project

Agreements (FPA's) of Project XL programs. ${ }^{74}$ Thus, the government's objective was to create

a more inclusive environmental risk management system as opposed to an expert-driven one. ${ }^{75} 76$

Initially, Project XL pilot programs included five mandatory criteria. However, for the

purpose of this thesis I will focus on clause five which stated that there must exist "support from

parties with a stake in the project's environmental effect - that is, affected communities,

business, and public interest groups." 7778 This clause made it necessary for companies interested

in establishing XL programs to acquire all stakeholders to accept both the FPA and the

subsequent permit.

Unfortunately, stakeholder participation initially turned out to be extremely cumbersome and unorganized. This occurred because the EPA did not provide any guidance or formal stipulations insofar as citizen participation was concerned. Furthermore, the authority of the citizens was not defined, which created friction between the "differing expectations among

\footnotetext{
${ }^{72}$ The main difference between the local experts in this example, and the case study on pig farming, is that the local experts here did not necessarily work for the industry they were trying to regulate. Thus, this example is more intimately connected with the environmental justice principles I have described in the previous two chapters.

${ }^{73}$ Barbara Scott Murdock, \& Carol Wiessner, \& Ken Sexton, "Stakeholder Participation in Voluntary Environmental Agreements: Analysis of 10 Project XI. Case Studies." (Science Technology, \& Human Values, Vol 30. No. 2: 2005) at 224.

${ }^{74}$ The FPA's served as the basis for the Project XL permits that were eventually handed out by the regional EPA offices.

${ }^{75}$ Supra note 73 at 224.

${ }^{76}$ The government recognized two key points when developing this reform initiative. First, it was recognized that local expert knowledge can complement the knowledge held by scientists, industry, and government. Second, the inclusion of citizens within the decision-making process contributes to the promotion of social justice. For more information see note 69 at 225 .

${ }^{77}$ Supra note 73 at 225 .

${ }^{78}$ For a list of the other for requirements see note 72 at 225.
} 
regulators, business people, environmentalists, and community members."79 80 Additionally, an evaluation of the pilot programs also found that citizen participation was most efficient when communities were given adequate resources. Resources included monetary compensation, access to independent experts, and formal avenues of open dialogue. ${ }^{81}$

In order to address these issues, in 1997 the EPA took a massive step forward with regards to citizen participation. First, the EPA clearly defined the term stakeholder by delineating three distinct groups, namely 'direct participants, commentors, and the general public. ${ }^{, 82}$ Direct participants were defined as "local residents, business people, and environmentalists that work with company sponsors to develop or strongly influence the XL pilot."83 Commentors were environmental advocacy groups that were interested in the XI projects, but had limited opportunities to participate. Lastly, the definition of the general public was left purposely vague so as to not preclude interested citizens from participating. Second, the EPA encouraged potential project XL companies and the aforementioned stakeholders to clearly prescribe participatory rules, and the authority of various stakeholders. Lastly, the EPA recommended that "each sponsor train direct participants and relevant company staff in collaborative processes, recommended giving community representatives technical training on key issues, and offered up to $\$ 25,000$ per project for technical assistance."\$4 85

\footnotetext{
79 Supra note 73 at 226.

${ }^{80}$ Establishing formal rules for participation is one of the key components I identify in chapter two, with regards to addressing procedural concerns and ecological democracy.

${ }^{81}$ Supra note 73 at 226.

82 Ibid.

83 Ibid.

4 Ibid.

${ }^{85}$ The EPA also removed the requirement to have unanimous stakeholder consent. This demonstrates that the EPA was beginning to understand that, as I describe in chapter three, environmental and social justice considerations are inherently pluralistic, thus unanimous consent is problematic.
} 
Unfortunately the results of the ten pilot programs were not as positive as regulators, or citizens had hoped for ${ }^{86}$ Ultimately, two factors contributed to this result. First, in nine of the ten projects the regional EPA offices accepted FPA's and established permits based on these FPA's that the EPA headquarters later rejected. Consequently, "community stakeholders often found themselves embroiled in or listening to wearisome discussion of highly specific technical details of a permit." advantages of expert knowledge," and relegate citizen participation within a technocratic system. $^{88}$ As a result, there were no real opportunities to participate or make clear local community values during these meetings.

Second, although the EPA required stakeholder involvement, they only encouraged the stipulations which governed multi-stakeholder participation. In other words, allowing industry to define the authority of citizens within the participation process was extremely problematic. Consequently, local residents were often defined by the companies as advisors, which effectively limited opportunities for real and authentic citizen participation. Additionally, none of the companies in the pilot projects appointed independent technical experts, as was encouraged by the EPA. ${ }^{89}$

While Project XL programs are a step in the right direction, in terms of effectively establishing citizen participation within VEP's, they lack most of the recommendations I described in chapter two. For instance, although citizen participation itself was required, the role of the citizen was not clearly identified. This led companies to ignore the potential local expert

\footnotetext{
${ }^{86}$ To see a review of each of the ten pilot programs based on process and outcome goals see note 72 .

${ }^{87}$ Supra note 73 at 243.

38 Supra note 34 at 135 .

${ }^{89}$ Supra note 73 at 245 .
} 
knowledge that citizens possessed. In addition, the EPA again only encouraged resources to be given to affected communities, which resulted in the absence of independent technical experts. ${ }^{90}$

The problems associated with these Project XL programs are directly related to the power imbalances during environmental decision-making processes that I describe throughout this thesis. Thus, although these pilot projects were allegedly 'required' to establish multistakeholder acceptance the reality thereof was much different. "Several XL pilots dealt with stakeholders only as an afterthought or on a pro forma basis." ${ }^{\text {91 }}$ Additionally, the EPA was reluctant to move away from a stricter reliance on technical data and command-and-control regulations. Accordingly, local residents had few opportunities to contribute, and participatory processes were "mostly an attempt to inform stakeholders about decisions already made."92

\section{[5.6] The Importance of Combining VEP's with Formal Laws}

The purpose of this chapter thus far has been to analyze voluntary agreements within an environmental justice frame, and further discuss their potential benefits and drawbacks.

However, in order to more accurately gauge their inclusion into mainstream environmental regulation, they must also be measured as originally intended; a supplement to command-andcontrol systems. In this regard Kernaghan Webb argues "private regulatory approaches can and do usefully supplement public regulation. ${ }^{.93}$ It is important to note that the term private regulation includes a number of different approaches; however for the purpose of this chapter, private regulations will refer to VEP's, particularly those that are independent of government

\footnotetext{
${ }^{90}$ Some of the recommendations that I describe in chapter two were followed. For instance, the EPA did attempt to create a multi-lateral approach that encouraged the involvement of various stakeholders. Furthermore, the EPA did recognize the potential benefits of utilizing local expert knowledge within site specific VEP's. However, the EPA needed to mandate rather than simply encourage this behaviour.

${ }^{91}$ Supra note 73 at 247.

92 Ibid.

${ }^{93}$ Kernaghan Webb, "Government, Private Regulation, and the Role of the Market." In "Law, Regulation, and Governance." (Oxford University Press, Ontario: 2002) at 240.
} 
sponsorship. In general, Webb explains that private and public regulations are designed to work together, and as such, foster a type of mutually beneficial and supportive relationship. ${ }^{94}$ Accordingly, although there are no direct legislative requirements to join a particular voluntary agreement, VEP's are nonetheless situated within framework of law, and thus may carry legal repercussions. This relationship between voluntary approaches and its legal framework is extremely important as it may provide more explicit opportunities for creating more efficient voluntary agreements. Consequently, by reemphasizing the supplementary qualities of voluntary programs, more comprehensive policy 'mix' approaches can be established, providing benefits from both public and private strategies. In addition, it may make it easier to identify and avoid any potential negative consequences of establishing VEP's. Lastly, it may shed light on which types of programs should be used, or implemented in a given circumstance or context. ${ }^{9596}$ Additionally, Webb explains that as opposed to command-and-control systems, private regulations attempt to encourage participation and action by a plurality of stakeholders. ${ }^{97}$ This is important to understand, because a major criticism of traditional public regulation has been the complete lack of plurality in terms of actively involved participants. Thus even within an environmental justice frame, as discussed in chapter three, voluntary approaches have the potential to foster a greater element of ecological democracy. In addition, voluntary agreements do not suffer from the same rigid jurisdictional limitations of command-and-control systems, further demonstrating their potential and applicability in increasingly globalized economies and

\footnotetext{
${ }^{94}$ Ibid at 242.

${ }^{95}$ Ibid at 243.

${ }^{96}$ Certain types of voluntary programs may work better in different jurisdictions or contexts. For example, a site specific VEP, such as Project XL programs, may work better in regards to addressing environmental concerns of an individual company, as local expert knowledge may be more readily available and easier to include.

${ }^{97}$ This was shown in the pig farming case described above, and Patrick ten Brink explains that "all relevant stakeholders should participate... in the development of a VEA, and during its whole life-cycle." Additionally, Carmin et al. have stated that VEP's attempt to incorporate at least some form of participatory opportunity. For more information see Patrick ten Brink, "Voluntary Environmental Agreements, Process Practice, and Future Use." (Greenleaf Publishing Ltd., United Kingdom: 2002) at 26. and note 45 at 538.
} 
environmental systems. ${ }^{98}$ Interestingly, even though jurisdictional qualities were identified as a potential criticism earlier, the jurisdictional limitations of formal legislation pale in comparison. Additionally, the criticisms above tend to adopt the view that voluntary agreements will act as the sole mechanism for environmental protection, which I have argued should not be the case. Thus, the jurisdictional limitations of VEP's, in my opinion, do not take a sufficiently comprehensive approach and lack the understanding that VEP's are applicable in a globalized economy.

Webb relies on the Canadian Responsible Care Program to analyze how voluntary approaches can be combined with law to make them more effective. The Responsible Care Program was created by the Canadian Chemical Producers Association (CCPA) in response to wavering public confidence as a result of a series of environmental disasters, including Love Canal, Seveso, and Bhopal. ${ }^{99}$ The mandates of the Responsible Care Program are to "improve environmental performance, improve government-industry relations, and increase public trust." 100 Additionally, a new caveat of membership includes the public reporting of emissions, which again, fits in well with establishing a more democratic environmental governance structure. ${ }^{101}$ Though Webb goes into a detailed explanation of the intricacies of the program and its subsequent development, I am more interested in how he explains the combination between the program and the law, particularly in terms of combating free-riders.

Webb explains that formal regulations can help address the free-rider problem insofar as industry can welcome new regulations if they feel that VEP's they are currently involved with are ineffectual. For example, he quotes the vice-president of the CCPA who stated that "we

\footnotetext{
98 Supra note 93 at 243.

${ }^{99}$ Ibid at 245.

${ }^{100}$ Ibid.

${ }^{101}$ Supra note 34 at 128 .
} 
don't have any problem with having regulations when voluntary programs don't work... When they don't work they have to be backed up by a government willing to actually regulate." ${ }^{102}$ In this regard, Webb explains how the CCPA itself used the threat of potential regulation to foster additional industry participation and compliance. In addition, Webb describes how courts can use voluntary programs to establish accepted industry standards in terms of making a decision about purported negligent behaviour. For example, Webb explains how the Canadian Environmental Protection Act has been amended so as to ensure courts take into consideration whether or not a firm is a member of environmental management system. ${ }^{103}$ Thus, if a company is a compliant member of a popular voluntary agreement, then courts may use this information in order to come to the determination that an injury was not a result of negligent behaviour.

Conversely, those that are not members, or simply non-compliant ones, could find the courts use the same information to come to a determination that negligent behaviour did exist. Again, this is an example of how law may discourage free-rider behaviour and furthermore how law is inherently connected to voluntary agreements. ${ }^{104}$

It is interesting that Webb also hints at a link between voluntary approaches and formal regulations within an environmental justice frame. He argues that law itself creates incentives for citizen participation within the development of voluntary programs insofar as nonparticipation can result in decreased environmental performance standards. These decreased standards can additionally create a ripple effect which many then potentially lower the "industry standard in negligence or regulatory legal action." ${ }^{105}$ Consequently, increased citizen participation can create more meticulous program standards, through increased accountability,

\footnotetext{
${ }^{102}$ Supra note 93 at 247.

${ }^{103} \mathrm{Ibid}$ at 249.

${ }^{104}$ Ibid at 248.

${ }^{105}$ Ibid.
} 
while fostering a more democratic version of environmental governance. This is particularly true if citizens are included in both the development stages of voluntary environmental programs and compliance monitoring structures.

Another major criticism of voluntary approaches has been their lack of deterrent factors when attempting to combat free-riders, and more generally not having any institutional mechanisms in order to produce sanctions based on non-performance. ${ }^{106}$ In other words, voluntary programs themselves have no effective forms of penalties. In this regard researchers believe that government, or law, can play a fundamental role in establishing a regulatory framework which surrounds voluntary approaches in order to achieve greater levels of compliance. ${ }^{107}$ For example, Webb explains how voluntary agreements provide an identifiable service to members, which creates a contractual relationship between participants and program standards. "In all cases, failure to meet the terms of the contract can result in sanctions such as fines, negative publicity, withdrawal of benefits, or termination of relations, all ultimately backed up by legal actions if necessary." 108

Lastly, as described in chapter two, citizens could use legal mechanisms to sue companies who do not meet program standards, and sue regulators who fail to adequately enforce program objectives. ${ }^{109}$

The relationship between voluntary agreements and law is one of mutual benefit. Both together have the potential to mitigate each other's individual weaknesses and build upon each

\footnotetext{
${ }^{106}$ Jorge Rivera, \& Peter de Leon, "Is Greener Whiter? Voluntary Environmental Performance of Western Ski Areas." (The Policy Studies Journal, Vol. 32, No. 3: 2004) at 434.

${ }^{107}$ Donald G. Chittock, \& Kenneth F.D. Hughey, "A review of international practice in the design of voluntary Pollution Prevention Programs." (Journal of Cleaner Production, Vol. 19, No. 5: 2011) at 550.

${ }^{108}$ Supra note 93 at 249.

${ }^{109}$ David A. Dana, "New “Contractarian" Paradigm in Environmental Regulation." (University of lllinois Law Review, Vol. 2000, No. 1:2007) at 54.
} 
other's strengths. ${ }^{110}$ For example, voluntary programs can help alleviate the jurisdictional constrictions of command-and-control structures and conversely formal regulations can combat the non-deterrent characteristics of voluntary approaches; together forming more cohesive and beneficial environmental performance standards.

\section{[5.7] Conclusions}

The purpose of this chapter was to attempt to determine the effectiveness of voluntary approaches and subsequently establish how their effectiveness could be enhanced. By illustrating that voluntary approaches should be implemented within an environmental justice frame, a more comprehensive relationship could be established between the key paradigms, i.e. law, voluntary programs, and environmental justice.

While any conclusions based on current research regarding voluntary approaches are tentative at best, there is nonetheless a certain level of enthusiasm that as voluntary approaches become more developed, their effectiveness will certainly increase. Thus, I believe that the tentativeness stems less from questions of inefficacy and more from a feeling that the design of voluntary programs has merely scratched the surface of what is possible. Furthermore, when VEP's do not exist in a vacuum that lacks participatory opportunities, or connections with formal law, their overall effectiveness can be more readily appreciated and realized. There is no denying that in some circumstances voluntary programs have resulted in the reduction of pollution, the general improvement of environmental performance, and perhaps most importantly the increased potentiality for citizen participation. ${ }^{111}$

\footnotetext{
${ }^{110}$ Supra note 93 at 253.

III Al lannuzzi Jr., "Industry Self-Regulation and Voluntary Environmental Compliance." (Lewis Publishers, United States: 2002) at 141.
} 
However, I do believe a greater emphasis has to be placed on voluntary approaches as they pertain to ecological democracy at both a practical and academic level. While their technical effectiveness, as discussed in chapter two, is no doubt important, any advances in establishing ecological democracy cannot be overlooked. In this regard environmental justice theory can, and should, play a key role in establishing its own conceptualizations of program effectiveness. In other words, while researchers have found alternative environmental regulation can result in increased citizen participation, more stringent expectations of participation must be realized. These include authentic and meaningful participatory opportunities, which should be "firmly anchored in the articulation of equal rights of access to the public sphere," evaluations of voluntary approaches at the procedural level.

In conclusion, I certainly believe voluntary approaches form a positive supplement to traditional command-and-control mechanisms. Furthermore, it is important to not ignore this compatibility and rather use it to enhance each system, both individually and together. In addition, more emphasis must be placed on understanding which types of programs yield the most positive results in particular circumstances. This mode of discovery can be achieved by establishing better evaluative practices, which include utilizing environmental justice approaches.

Lastly, environmental justice should be implemented as a theoretical framework for analyzing individual program components, thus resulting in the greatest possible advancement of democratic realizations in environmental regulation, which should internally foster better environmental performance. Just as the so-called 'competition' between environmental performance and economic success must be re-evaluated, so too must the notions that citizen participation will simply 'interfere' with policy implementation. It is my opinion that combining

${ }^{112}$ Supra note 34 at 138 . 
these three paradigms, namely alternative environmental regulation, formal law, and citizen participation, will not only improve environmental performance, but also productivity, profit margins, and most importantly democracy as a whole. 


\section{Chapter 6:}

\section{Conclusions}

The purpose of this thesis was to develop a synthetic relationship between voluntary

environmental programs and environmental justice. Accordingly, in chapter two I began with an analysis of VEP's and defined four distinct types of voluntary programs. This was important because the programs served as the instrument that I intended to analyze and critique using an environmental justice frame. In chapter three, I developed this frame, with a particular emphasis placed on the participatory processes of environmental justice. Furthermore, I began to describe how inherent power imbalances within environmental decision-making generally reduce the possibility for citizen participation. I expanded on these elements in chapter four and examined the discourse between expert knowledge, and local expert knowledge. Additionally, I discussed how situating citizen participation within the same technocratic and systematic structures that expert knowledge is placed in undermines and ignores the valuable contributions of laypersons. Lastly, in chapter five, I attempted to formally develop the relationship between voluntary programs and environmental justice. I used two case studies, which although not completely indicative of the benefits of citizen participation, nonetheless provided examples of the possible interplay between VEP's and environmental justice. Accordingly, I do not mean to use these case studies as exemplars, but rather as a means to demonstrate that the relationship between voluntary programs and environmental justice can be collaborative. However, I do believe that a greater emphasis has to be placed on formally establishing citizen participation and ensuring its existence throughout a program's life-cycle. This in turn would help facilitate the establishment of ecological democracy, which simultaneously provides mechanisms for increasing 
environmental performance, and fosters more deliberative processes. Thus, the institutionalization of ecological democracy must be understood as a fundamental shift in how decisions are made. According to Archon Fung, "decisions resulting from deliberation will be more informed and rational, they will reflect a more equal consideration of interests, they will be less likely to infringe on individual rights, and such decisions will be more legitimate."1

However, I do not mean to suggest that the road towards ecological democracy will be an easy one. Currently, although citizen participation has become increasingly common, real and authentic participation is still generally absent. In other words, not only do citizens need to fight for their participatory rights, they must also ensure that participation itself is meaningful. For instance, citizens need to be able to participate within environmental decision-making processes that occur before decisions have already been reached. Thus, instead of participating in processes where citizens may play a role in their own subversion, the values, and beliefs of citizens need to have significant impacts on environmental decisions. Additionally, citizens need to transform "their traditionally antagonistic relationships with experts into partnerships for environmental protection." ${ }^{2}$ Furthermore, they must ensure that established experts are willing to undergo a similar transformation, whereby they recognize the valuable insight local knowledge may provide. ${ }^{3}$ If this does not occur then "the political and moral dimension of democratic deliberation will continue to be hidden under the presumed neutrality of science and technology. ${ }^{, 4}$ Thus, in order to begin to establish ecological democracy the existence of power imbalances within environmental decision-making must be recognized. Consequently, steps

\footnotetext{
${ }^{1}$ Archon Fung, "Deliberation Before the Revolution: Towards an Ethics of Deliberative Democracy in an Unjust World." (Political Theory, Vol. 33, No. 2: 2005) at 401.

${ }^{2}$ Charles Sabel, Archon Fung, \& Bradley Karkkainen, "Beyond Backyard Environmentalism: How Communities are Quietly Refashioning Environmental Regulation." (Boston Review: 1999).

${ }^{3}$ Peter Swan, "Democratic Environmental Governance and Environmental Justice." in "Law, Regulation, and Governance." (Oxford University Press, Ontario: 2002) at 138. ${ }^{4}$ Ibid.
} 
need to be taken which address these power imbalances by mandating that citizens be included within participatory processes, and that they share an equal role in environmental decisionmaking.

In this regard, I provided examples throughout my thesis of how I believe formal law may be able, and necessary, to achieve a more democratic environmental decision-making process. Additionally, I explain how law can help fill the collaborative gaps between voluntary programs and environmental justice. In other words, command-and-control systems may help remedy the deficiencies of VEP's and the participatory processes within them. Thus, as is evident in the Project XL pilot programs case study that I examined in chapter five, a relationship between voluntary programs and environmental justice must be grounded in law. I believe that this would strengthen, or 'give teeth' to VEP's, a trait which is often said to be lacking, and help establish formal rules for including citizen participation, and prescribing roles to citizens within environmental decision-making processes. More importantly, it may ensure that the decentralization inherent within voluntary initiatives preserves the procedural gains that citizens have achieved within the legal realm. It is of equal importance to apply a framework of environmental justice towards formal legislative mechanisms that seek to negate the collaborative gaps I identified. In other words, although the EPA mandated that citizens be included during the development phases of pilot Project XL programs, they did little to ensure that this inclusion would provide real and authentic opportunities to actively participate. Consequently, as I discussed in chapter five, the result was less than positive. Nonetheless it did demonstrate the potential to mandate, or require, citizen participation, however more robust participatory opportunities and mechanisms need to be considered. Accordingly, this is what I 
mean when I state that environmental justice considerations must be attributed towards the law as well.

In conclusion, the relationship that I developed throughout this thesis was created in a way that emphasized the potential benefits of citizen participation. Thus, governments should help citizens who do wish to participate communicate the knowledge that they possess, as a means to combat the systematic power imbalances within decision-making processes. ${ }^{5}$

However, following Frank Fischer, I am not suggesting a move towards establishing mass citizen participation. Rather, my position is to create more "deliberative possibilities for those eager to participate." In other words, as I describe in chapter four, it is important not to forget that environmental justice and the benefits it provides are inherently pluralistic. Thus, not everybody in a community may agree with a particular protest, or cause, even if it may potentially result in an environmental benefit. ${ }^{7}$

Throughout this thesis I generally took a critical approach towards voluntary programs, because they have generally failed to capitalize on their opportunities to establish participatory processes. Consequently, the ability to create programs that produce better environmental protection may be lost by denying prospects that "promote mutual learning and encourage reflexivity on the part of both experts and laypersons." ${ }^{\text {"8 }}$ Nonetheless, I do not mean to suggest that VEP's themselves do not contribute towards environmental performance, rather I simply believe that they have the ability to create substantive democratic reform by instituting ecological democracy. This ability to establish democratic deliberation is the fundamental

\footnotetext{
${ }^{5}$ Frank Fischer, "Professional Expertise in a Deliberative Democracy." (The Good Society, Vol. 13, No. 1: 2004) at 24.

${ }^{6}$ lbid at 22.

${ }^{7}$ Stella M. Čapek, The "Environmental Justice" Frame: A Conceptual Discussion and an Application. (Social Problems, Vol. 40, No. 5: 1993) at 5.

${ }^{8}$ Supra note 3 at 138.
} 
element that may produce increased environmental protection. Accordingly, more efforts need to be made that seek to promote participatory processes within VEP's and ensure that these processes adhere to the objectives of environmental justice. Additionally, I believe that it is important to remember the intended supplementary characteristics of voluntary programs. Relying solely on VEP's for environmental protection carries with it a risk of industry complacency, or free-riding, which could result in decreased environmental performance. Thus, the consequences that law provides are necessary to ensure that the objectives of a voluntary program are being followed.

For my thesis I was less interested in the objectives of voluntary programs themselves, than I was with examining how citizens may be able to affect them. In my opinion this is best achieved by utilizing environmental justice principles that seek to promote the systematic inclusion of participatory opportunities. In this regard, as mentioned throughout my thesis, voluntary programs possess certain characteristics that may make the inclusion of citizen participation particularly valuable. However, it is important to remember that in order for citizen participation to positively impact environmental decision-making, the power imbalances within these processes must be addressed. This is a necessary step towards the realization of more deliberative processes, and in turn ecological democracy. 


\section{References}

Agyeman, Julian, \& Evans, Bob, "Just Sustainability: The Emerging Discourse of Environmental Justice in Britain?" The Geographical Journal, 170 (2004) 155-164.

Alberini, Anna, \& Segerson, Kathleen, "Assessing Voluntary Programs to Improve Environmental Quality." Environmental and Resource Economics, 22 (2002) 157-184.

Allen, L. Barbara, "Environmental Justice and Expert Knowledge in the Wake of a Disaster." Social Studies of Science, 37 (2007) 103-110.

Arimura, H. Toshi, \& Darnall, Nicole, \& Katayama, Hajime, "Is ISO 14001 a Gateway to More Advanced Voluntary Action, A Case for Green Supply Chain Management." Washington: Resources for the Future, 2009.

Bäckstrand, Karin, \& Khan, Jamil, \& Kronsell, Annica, \& Lövbrand, Eva, "The promise of new modes of environmental governance." in "Environmental Politics and Deliberative Democracy: Examining the Promise of New Modes of Environmental Governance." United States: Edward Elgar Publishing Limited, 2010.

Bailey, Conner, \& Alley, Kelly, \& Faupel, E. Chalres, \& Solheim, Cathy, "Environmental Justice and the Professional." in "Environmental Justice: Issues, Policies, and Solutions." United States: Island Press, 1995.

Benton, M. Lisa, \& Short, R. John, “Environmental Discourse and Practice.” Massachusetts: Blackwell Publishers Inc., 2000.

Blackman, Allen, \& Mazurek, Janice, "The Cost of Developing Site-Specific Environmental Regulations: Evidence from EPA's Project XL." Environmental Management, 27 (2001) 109-121.

Böhringer, Christoph, \& Frondel, Manuel, “Assessing Voluntary Commitments in the German Cement Industy, The Importance of Baselines." in "Reality Check, The Nature and Performance of Voluntary Environmental Programs in the United States, Europe, and Japan." Washington: Resources for the Future, 2007.

Borck C. Jonathan, \& Coglianese, Cary, "Voluntary Environmental Programs: Assessing their Effectiveness." Annual Review of Environment and Resources, 34 (2009) 305324.

Borrows, John, "Living Between Water and Rocks. First Nations, Environmental Planning and Democracy." University of Toronto Law Journal, 47 (1997) 417-468. 
Bowen, m. William, \& Wells, V. Michael, "The Politics and Reality of Environmental Justice: A History and Considerations for Public Administrators and Policy Makers." Public Administration Review, 62 (2002) 688-698.

Brink, ten. Patrick, "Voluntary Environmental Agreements, Process Practice, and Future Use." United Kingdom: Greenleaf Publishing Ltd., 2002.

Brulle, J. Robert, \& Essoka, Jonathan, "Whose Environmental Justice? An Analysis of the Governance Structure Environmental Justice Organizations in the United States." in "Power Justice and the Environment A Critical Appraisal of the Environmental Justice Movement." London: The MIT Press, 2005.

Bullard, D. Robert, \& Johnson, S. Glen, "Environmental Justice, Grassroots Activism and Its Impact on Public Policy Decision Making." Journal of Social Sciences, 56 (2000) 555-578.

Bullard, Robert, "Dumping in Dixie: Race, Class, and Environmental Quality." United States: Westview Press Inc., 2000.

Caballero, E. Thomas, "Project XL: Making it Legal, Making it Work." Stanford Environmental Law Journal, 17 (1998) 399-474.

Čapek, M. Stella, "The "Environmental Justice" Frame: A Conceptual Discussion and an Application." Social Problems, 40 (1993) 5-24.

Carmin, JoAnn, \& Darnall, Nicole, \& Mil-Homens, Joao, "Stakeholder Involvement in the Design of U.S. Voluntary Environmental Programs: Does Sponsorship Matter?" The Policy Studies Journal, 31 (2003) 527-543.

Chittok, G. Donald, \& Hughey F.D. Kenneth, "A Review of International Practice in the Design of Voluntary Pollution Prevention Programs." Journal of Cleaner Production, 19 (2011) 542-551.

Cole, W. Luke, \& Foster, R. Sheila, "From the Ground Up: Environmental Racism and the Rise of the Environmental Justice Movement." New York: New York University Press, 2001.

Corburn, Jason, "Bringing Local Knowledge into Environmental Decision Making. Improving Urban Planning for Communities at Risk." Environmental Management, 29 (2002) 420-433.

Corburn, Jason, "Combining Community-Based Research and Local Knowledge to Confront Asthma and Subsistence-Fishing Hazards in Greenpoint/Williamsburg, Brooklyn, New York." Environmental Health Perspectives, 110 (2002) 241-248. 
Corburn, Jason, "Street Science, Community Knowledge and Environmental Health Justice." London: The MIT Press, 2005.

Cornwall, Andrea, \& Coelho, Schattan P. Vera, "Spaces for Change? The Politics of Participation in New Democratic Arenas." New York: Zed Books Ltd., 2007.

Croci, Edoardo, “The Handbook of Environmental Voluntary Agreements: Design, Implementation and Evaluation Issues." Netherlands: Springer, 2005.

Dana, A. David, "New 'Contractarian' Paradigm in Environmental Regulation." University of Illinois Law Review, 2000 (2000) 35-60.

Delmas, Magali, \& Keller, Arturo, "Free riding in voluntary environmental programs: The case of the U.S. EPA WasteWise Program." Policy Sciences, 38 (2005) 91-106.

Delmas, A. Magali, \& Terlaak, K. Ann, "A Framework for Analyzing Environmental Voluntary Agreements.” California Management Review, 43 (2001) 44-64.

Devine-Wright, Patrick, "Beyond Nimbyism: Towards an Integrated Framework for Understanding Public Perceptions of Wind Energy." Wind Energy, 8 (2005) 125-139.

Eckersley, Robyn, "The Green State: Rethinking Democracy and Sovereignty." Cambridge: The MIT Press, 2004.

Faber, Daniel, "The Struggle for Ecological Democracy and Environmental Justice. Environmental Justice Movements in the United States." New York: The Guilford Press, 1998.

Fischer, Frank, "Citizen participation and democratization of policy expertise: From theoretical Inquiry to practical cases.” Policy Sciences, 26 (1993) 165-187.

Fischer, Frank, “Citizens and Experts in Risk Assessment: Technical Knowledge in Practical Deliberation.” Technikfolgenabschätzung, 13 (2004) 90-98.

Fischer, Frank, “Citizens, Experts, and the Environment." London: Duke University Press, 2000.

Fischer, Frank, "Professional Expertise in a Deliberative Democracy." The Good Society, 13 (2004) 21-27.

Fraser, Nancy, "Social Justice in the Age of Identity Politics: Redistribution, Recognition, and Participation." Stanford University: The Tanner Lectures on Human Values (1996).

Fung, Archon, "Deliberation Before the Revolution: Towards an Ethics of Deliberative Democracy in an Unjust World." Political Theory, 33 (2005) 397-419. 
Harrison, Kathryn, "Voluntarism and Environmental Governance." in "Governing the Environment, Persistent Challenges, Uncertain Innovations." Toronto: University of Toronto Press, 2001.

Hildingsson, Roger, "The deliberative turn in Swedish sustainability governance: participation from below or governing from above?" in "Environmental Politics and Deliberative Democracy: Examining the Promise of New Modes of Environmental Governance." United States: Edward Elgar Publishing Limited, 2010.

Honneth, Axel, "Integrity and Disrespect" Principles of a Conception of Morality Based on a Theory of Recognition." Political Theory, 20 (1992) 187-201.

Honneth, Axel, "The Struggle for Recognition: The Moral Grammar of Social Conflicts." Great Britain: Polity Press, 1995.

Iannuzzi, Jr. Al, "Industry Self-Regulation and Voluntary Environmental Compliance." United States: Lewis Publishers, 2002.

Jasanoff, Sheila, "Technologies of Humility: Citizen Participation in Governing Science." Humanities, Social Sciences and Law, 41 (2003) 223- 244.

Jordan, Andrew, \& Wurzel, K.W. Rüdiger, \& Zito, R. Anthony, “New Environmental Policy Instruments: An Evolution or Revolution in Environmental Policy? in "New Instruments of Environmental Governance? National Experiences and Prospects." London: Frank Cass Publishers, 2003).

Karp, R. David, \& Golding, L. Clark, "Motivational Underpinnings of Command-andControl, Market-Based, and Voluntarist Environmental Policies." Human Relations, 48 (1995) 439-465.

Kaswan, Alice, "Environmental Justice: Bridging the Gap Between Environmental Laws and Justice." The American University Law Review, 47 (1997) 221-300.

Khanna, Madhu, "Non-Mandatory Approaches to Environmental Protection." Journal of Economic Surveys, 15 (2001) 291-324.

King, A. Andrew, \& Lenox, J. Michael, "Industry Self-Regulation Without Sanctions: The Chemical Industry's Responsible Care Program." Academy of Management Journal, 43 (2000) 698-716.

Kronsell, Annica, \& Bäckstrand, Karin, "Rationalities and forms of governance: A framework for analysing the legitimacy of new modes of governance." in "Environmental Politics and Deliberative Democracy: Examining the Promise of New Modes of Environmental Governance." United States: Edward Elgar Publishing Limited, 2010. 
Lyon, P. Thomas, \& Maxwell, W. John, "Self-regulation, taxation and public voluntary programs.” Journal of Public Economics, 87 (2003) 1453-1486.

McCann, Michael, \& Silverstein, Helena, "Social Movements and the American State: Legal Mobilization as a Strategy for Democratization." in "A Different Kind of State? Popular Power and Democratic Administration." Toronto: Oxford University Press, 1993.

McGregor, Deborah, "Honouring Our Relations: An Anishinabe Perspective on Environmental Justice." in "Speaking for Ourselves Environmental Justice in Canada." Vancouver: UBC Press, 2009.

Mitchell, E. Ross, "Green Politics or Environmental Blues? Analyzing Ecological Democracy." Public Understanding of Science, 15 (2006) 459-480.

Moon, Seong-Gin, \& De Leon, Peter, "Contexts and Corporate Voluntary Environmental Behaviours, Examining the EPA's Green Lights Voluntary Program." Organization \& Environment, 20 (2007) 480-496.

Morgenstern, D. Richard, \& Pizer, A. William, "The Challenge of Evaluating Voluntary Programs." in "Reality Check: The Nature and Performance of Voluntary Environmental Programs in the United States, Europe, and Japan." Washington: Resources for the Future, 2007.

Murdock, Scott. Barbara, \& Wiessner, Carol, \& Sexton, Ken, "Stakeholder Participation in Voluntary Environmental Agreements: Analysis of 10 Project XL Case Studies." Science Technology, \& Human Values, 30 (2005) 223-250.

Norberg-Bohm, Vicki, \& De Bruijn, Theo, "Industrial Transformation, Environmental Policy Innovation in the United States and Europe." Cambridge: The MIT Press, 2005.

O'Neill, John, "Deliberative Democracy and Environmental Policy," in "Democracy and the Claims of Nature," Oxford: Rowman \& Littlefield Publishers Inc., 2002.

O'Rourke, Dara, \& Macey, P. Gregg, "Community Environmental Policing: Assessing New Strategies of Public Participation in Environmental Regulation.” Journal of Policy Analysis and Management, 22 (2003) 383-414

Paavola, Jouni, "Institutions and Environmental Governance: A reconceptualization." Ecological Economics, 63 (2007) 93-103.

Pellow, N. David, \& Brulle, J. Robert, "Power, Justice, and the Environment: Toward Critical Environmental Justice Studies." in "Power, Justice, and the Environment: A Critical Appraisal of the Environmental Justice Movement." London: The MIT Press, 2005. 
Petts, Judith, "The public-expert interface in local waste management decisions: expertise, credibility and process." Public Understanding of Science, 6 (1997) 359381.

Potoski, Matthew, \& Prakash, Aseem, "Green Clubs and Voluntary Governance: ISO 14001 and Firms' Regulatory Compliance." American Journal of Political Science, 49 (2005) 235-248.

Rabe, G. Barry, "Beyond the NIMBY Syndrome in Hazardous Waste Facility Siting: The Albertan Breakthrough and the Prospects for Cooperation in Canada and the United States." Governance: An International Journal of Policy and Administration, 4 (1991) 184-206.

Rawls, John, “A Theory of Justice. Revised Edition.” America: Harvard University Press, 1971.

Richardson, Mary, \& Sherman, Joan, \& Gismondi, Michael, "Winning back the Words, Confronting Experts in an Environmental Public Hearing." Toronto: Garmond Press, 1993.

Rivera, Jorge, \& De Leon, Peter, "Is Greener Whiter? Voluntary Environmental Performance of Western Ski Areas." The Policy Studies Journal, 32 (2004) 417-437.

Robyn, Linda, "Indigenous Knowledge and Technology: Creating Environmental Justice in the Twenty-First Century." The American Indian Quarterly, 26 (2002) 198-220.

Sabel, Charles, \& Fung, Archon, \& Karkkainen, Bradley, "Beyond Backyard Environmentalism: How Communities are Quietly Refreshing Environmental Regulation." Boston Review (1999).

Santos, Rui, \& Antunes, Paula, \& Baptista, Gualter, \& Madeus, Pedro, \& Madruga, Louísa, "Stakeholder Participation in the Design of Environmental Policy Mixes." Ecological Economics, 60 (2006) 100-110.

Sax, L. Joseph, "Defending the Environment. A Strategy for Citizen Action." New York: Alfred A. Knopf Company, 1971.

Schlosberg, David, "Defining Environmental Justice. Theories, Movements, and Nature." New York: Oxford University Press Inc., 2007.

Schlosberg, David, "Reconceiving Environmental Justice: Global Movements and Political Theories." Environmental Politics, 13 (2004) 517-540.

Schlosberg, David, “The Justice of Environmental Justice: Reconciling Equity, Recognition, and Participation in a Political Movement." in "Moral and Political Reasoning in Environmental Practice." Cambridge: The MIT Press, 2003. 
Segerson, Kathleen, \& Miceli, J. Thomas, "Voluntary Environmental Agreements: Good or Bad News for Environmental Protection?" Journal of Environmental Economics and Management, 36 (1998) 109-130.

Smith, Graham, "Deliberative Democracy and the Environment." London: Routledge, 2003.

Stavins, N. Robert, "Experience with Market-Based Environmental Policy Instruments." Economic Theory and Applications 52 (2002) 355-435.

Steelman, A. Toddi, \& Rivera, Jorge, "Voluntary Environmental Programs in the United States, Whose Interests are Served?" Organization \& Environment, 19 (2006) 505526.

Susskind, E. Lawrence, \& Jain, K. Ravi, \& Martyniuk, O. Andrew, "Better

Environmental Policy Studies, How to Design and Conduct More Effective Analysis." Washington: Island Press, 2001.

Swan, D. Peter, "Environmental Justice and Minority Ecological Rights." in "Do we need Minority Rights? Conceptual Issues.” London: Martinus Nijhoff Publishers, 1996.

Swan, Peter, "Democratic Environmental Governance and Environmental Justice." in "Law, Regulation, and Governance." Ontario: Oxford University Press, 2002.

Taylor, Charles, "The Politics of Recognition." in "New Contexts of Canadian Criticism." Ontario: Broadview Press, 1997.

Taylor, E. Dorceta, "The Rise of the Environmental Justice Paradigm, Injustice Framing and the Social Construction of Environmental Discourses." American Behavioral Scientist, 43 (2000) 508-580.

Torres, Gerald, "Environmental Burdens and Democratic Justice." Fordham Urban Law Journal, 21 (1993) $431-460$.

Walzer, Michael, "Spheres of Justice. A Defense of Pluralism and Equality." America: Basic Books Inc., 1983.

Webb, Kernaghan, "Government, Private Regulation, and the Role of the Market." in "Law, Regulation, and Governance." Ontario: Oxford University Press, 2002.

Weiner, Douglas, "A Death-Defying Attempt to Articulate a Coherent Definition of Environmental History." In "Canadian Environmental History." Toronto: Canadian Scholars' Press Inc., 2006.

Young, Marion. Iris, "Justice and the Politics of Difference." New Jersey: Princeton University Press, 1990. 
Young, M. Iris, "Justice and Harzardous Waste." Bowling Green Studies in Applied Philosophy, 5 (1983) 171-183.

\section{Websites:}

Principles of Environmental Justice: Preamble (Environmental Justice/ Environmental Racism Homepage) <http://www.ejnet.org/ej/principles.html>

European Commission: News Stories and Press Releases. <http://ec.europa.eu/environment/emas/news/index_en.htm\#279>

ISO Website: News 2010.

<http://www.iso.org/iso/news.htm?refid=Ref1363> 